\title{
State of the Art in Alcohol Sensing with 2D Materials
}

Cite as

Nano-Micro Lett.

(2020) 12:33

Received: 9 October 2019

Accepted: 5 December 2019

Published online: 21 January 2020

(C) The Author(s) 2020

\author{
Ramin Boroujerdi ${ }^{1 凶}$, Amor Abdelkader $^{1,2}{ }^{凶}$, Richard Paul $^{1 凶}$ \\ $\triangle$ Ramin Boroujerdi, rboroujerdi@bournemouth.ac.uk; Amor Abdelkader, \\ aa494@cam.ac.uk; Richard Paul, rpaul@bournemouth.ac.uk \\ 1 Faculty of Science and Technology, Bournemouth University, Talbot Campus, Fern Barrow, \\ Poole BH12 5BB, UK \\ 2 Department of Engineering, University of Cambridge, Cambridge CB3 OFS, UK
}

\section{HIGHLIGHTS}

- A current review on the applications of graphene and other two-dimensional (2D) materials in alcohol detection.

- A thorough discussion on the fundamental principles and the advantages of using 2D materials in sensing alcohol.

- Critical discussion of the current limitations of alcohol sensors and the role of 2D materials in addressing the challenges.

\begin{abstract}
Since the discovery of graphene, the star among new materials, there has been a surge of attention focused on the monatomic and monomolecular sheets which can be obtained by exfoliation of layered compounds. Such materials are known as two-dimensional (2D) materials and offer enormous versatility and potential. The ultimate single atom, or molecule, thickness of the 2D materi-

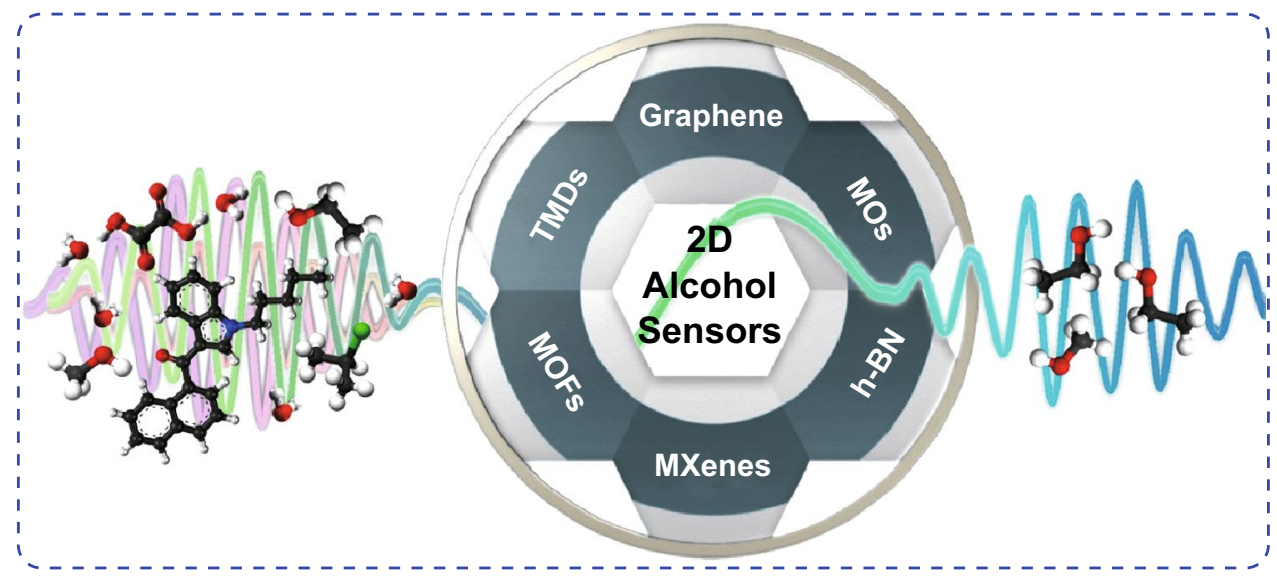
als sheets provides the highest surface to weight ratio of all the nanomaterials, which opens the door to the design of more sensitive and reliable chemical sensors. The variety of properties and the possibility of tuning the chemical and surface properties of the $2 \mathrm{D}$ materials increase their potential as selective sensors, targeting chemical species that were previously difficult to detect. The planar structure and the mechanical flexibility of the sheets allow new sensor designs and put $2 \mathrm{D}$ materials at the forefront of all the candidates for wearable applications. When developing sensors for alcohol, the response time is an essential factor for many industrial and forensic applications, particularly when it comes to hand-held devices. Here, we review recent developments in the applications of 2D materials in sensing alcohols along with a study on parameters that affect the sensing capabilities. The review also discusses the strategies used to develop the sensor along with their mechanisms of sensing and provides a critique of the current limitations of 2D materials-based alcohol sensors and an outlook for the future research required to overcome the challenges.
\end{abstract}

KEYWORDS Sensors and biosensors; Alcohol probes; Electrochemical detectors; Ethanol metabolites; 2D materials 


\section{Introduction}

Developing a selective, sensitive, fast, and reliable measurement of alcohol is important in many fields including a wide range of industries, such as pulp or food industries, clinical, and forensic assays and also agricultural and environmental analysis. However, ensuring the safety and quality of food and also medical products can be complicated, and there is always a need for developing new generation sensors with more modifications [1-5]. Volatile alcohols such as ethanol are often found in workplaces and laboratories, as well as medical, pharmaceutical, and food industries, and long-term exposure to even low concentration of alcohol vapour can cause eyesight disturbance, nasal and mucous membrane inflammation, conjunctival inflammation, respiration disruption, nerve disease, lung irritation, and even death. Thus, monitoring alcohols in the air, because of their flammable nature, is essential in certain working places [6, 7]. In addition to chemical and industrial studies, adulterated alcoholic beverages present forensic interest due to possible application in a criminal activity [8].

Several methods have been used to measure different analytes in complex matrixes including chromatography, immune-chromatography, mass spectrometry, nuclear magnetic resonance, polymerase chain reaction, ultraviolet-visible spectroscopy, Fourier-transform infrared spectroscopy (FTIR) and IR, surface-enhanced Raman spectroscopy (SERS) and Raman, circular dichroism spectroscopy, spectrofluorimetric, which all are still applicable [9-20], but they have their boundaries, and some of these techniques suffer from low sensitivity and selectivity on their own. Issues of portability, slow responses, and complicated operation could also be mentioned as some of their problems [21]; thus, there is a need for new analytical procedures to provide rapid, specific analysis, and simple result interpretation [22]. Developing a new generation of nano-sized detectors to replace conventional methods is one of the possible ways to solve these issues. Nanosensors offer a range of applications, especially in the area of chemical and biological sensing, because of their large surface area, biocompatibility, and vast range of properties.

Several nanomaterials and nanostructures have been used in developing alcohol sensors. Enzyme-based sensors that change colour in response to alcohol oxidation are one example. The dip-stick sensor was developed by immobilisation of a selective enzyme over a polyaniline film and casted over a cellulose layer, so a colour change from green to blue was used as a proof of alcohol presence $(>1 \%)$ in the sample [23]. The sensor was sensitive to a range of alcohols, yet the sensitivity decreased with increasing the size of the aliphatic chain. Nanostructures based on metal oxides were also studied in the literature for alcohol sensors due to high density of functional groups on its surface that can readily react with the alcohol substances. For example, Zhu et al. fabricated sensors using $\mathrm{Ag}-\mathrm{TiO}_{2}$ core-shell nanostructure and used it to sense ethanol gas at room temperature. The detection limit was reported to be as low as $0.15 \mathrm{ppm}$ [24]. However, the linear range of the sensor was short, covering 0.15 to $5 \mathrm{ppm}$. Nanoporous silicon was also used to detect ethanol gas at room temperature by monitoring the changes in the resistance [25]. The detection limit of the nanoporous pillar array was reported to be $50 \mathrm{ppm}$ to sense ethanol in air, yet its selectivity to other alcohol was not studied.

A recent study shows that a new hybrid carbon nanostructure made of graphene and double-walled carbon nanotube (G-DWCNT) was able to detect ethanol gas. The response time of the G-DWCNT sensor was $428 \mathrm{~s}$, which is slightly faster than solo DWCNT (480 s) [26]. Some of the onedimensional nanoparticles also offer long linear ranges, such as the $\mathrm{SnO}_{2}$-functionalised gallium nitride nanowires (GaN-NWs) UV-assisted sensor developed by Bajpai et al., which was able to sense various alcohols from 1 to $5000 \mathrm{ppm}$. However, the percentage response of this sensor to smaller alcohols (methanol and ethanol) was stronger than alcohols with longer aliphatic chains. Current was increased when the UV light was on and decreased when it was off; since the current was changing in the presence of carrier gas (breathing air), the current recorded with $40 \mathrm{sccm}$ of air under UV was used as a reference for their study [27]. Stannum-doped mesoporous nickel oxide nanowires are another ethanol gas sensor which was able to sense ethanol in a linear range from 5 to $1000 \mathrm{ppm}$ at $340{ }^{\circ} \mathrm{C}$. The author argued that Sn doping increased the total resistance of the target gas and reported that doping increased the sensitivity up to 15.60 from 2.16 reported for pure NiO NWs [28]. The alcohol gas sensor developed from $\mathrm{Zn}(\mathrm{II})$ ions and benzene tricarboxylic acid (btc) as anionic organic linkers is an example of metal organic frameworks-based alcohol sensors, where in the presence of alcohol gases, through an exchange mechanism, alcohols will replace waters in the structure of $\mathrm{Zn}_{3}(\mathrm{btc})_{2} \cdot 12 \mathrm{H}_{2} \mathrm{O}$ 
(Zn-btc) [29]. MOF-based alcohol sensor, which was able to detect gaseous alcohol in ppm levels, was made of two zeolitic imidazolate framework materials (ZIF-8 and ZIF93) grown on fibre optic-based surface plasmon resonance to serve as optical sensors. ZIFs have small pores offering high chemical stability which make them good candidates for sensing purposes, and they were able to sense $\mathrm{MeOH}$ with LoD of about 2.5 ppm (ZIF-8-SPR probe) and n-BuOH with LoD of around $73 \mathrm{ppm}$ (ZIF-93-SPR probe) [30].

Optical sensing systems are also well-studied methods of sensing alcohols. Over two decades ago, fibre optics near-infrared spectroscopy was applied to measure alcohol levels [31], yet in more recent times, more sensitive methods in conjunction with novel nanoparticles have been introduced. Recently developed hybrids of fibre optics with multi-walled carbon nanotubes $/ \mathrm{Co}_{3} \mathrm{O}_{4}$ were reported to offer high sensitivity (35 counts/ppm for ethanol and 51 counts/ppm for ammonia). The sensor also showed good selectivity in gas samples [32]. Another alcohol sensor was developed from gold-deposited surface plasmon resonance (SPR)-based glass rod sensor, which was coated with an $\alpha$-mercaptoethyl- $\omega$-methoxy polyoxyethylene (PEG thiol) layer and a Teflon AF2400 over-layer. The sensor offered good selectivity for water and ethanol [33]. Turn-on fluorescence based on terphenyl-ol derivatives is another example of optical sensors. The mixture of terphenyl-ol and sodium carbonate was found to respond selectively to ethanol by emitting a sky-blue light; it is also reported that combination of that mixture with water-absorbent polymer leads to better detection limit for sensing ethanol [34]. The optical fibre developed from Si quantum dots (QDs) was able to detect ethanol and water after $15 \mathrm{~s}$ exposure. The response was based on the changes in the fluorescence intensity of Si-QDs, which increases when they are exposed under blue light irradiation to alcohol and water vapours. The sensor suffers from agglomeration of the QDs on the fibres surface which leads to response variations in different samples [35].

When it comes to sensory applications, four specific properties of two-dimensional (2D) nanostructures make them suitable candidates: (a) the electron confinement in these materials without interlayer interactions, especially in monolayer structures, enables compelling electronic properties compared to other nanomaterials and makes them attractive candidates for electrochemical sensory applications.
Easier flow of electrons throughout 2D structures, due to minimised interactions, leads to faster response to analytes in electrochemical sensors; (b) the atomic (or molecular) thickness offers them maximum mechanical flexibility and strength which leads to development of more enduring sensors; (c) the optical transparency, making them promising for the fabrication of highly flexible and transparent optical and electrochemical sensors, which make them favourable for developing modern wearable devices and tattooed sensors; (d) the large specific surface area allows 2D materials to interact more with the environment which makes them highly favourable for sensory applications and development of highly sensitive surfaces [36-41]. Therefore, materials with ultrathin 2D morphologies have received great interest for their possible applications in sensors and biosensors, particularly for drug and alcohol detection.

Furthermore, 2D materials could promise a range of new or optimised behaviours. As an example, ultrathin 2D nanomaterials, especially single-layer nanosheets, where interlayer interactions are absent or limited, prepare the media suitable for unique electrical properties compared to other nanomaterials [42]. They also possess exceptional properties, due to their finite bandgap, superior flexibility, absence of dangling bonds, and significant resistance to short channel effects, which all could suggest a new generation of smart electronic, optoelectronic, and energy devices [43-59], where the first two promise the modern generation of sensors and biosensors and the last one offers developed, long lasting batteries, and energy devices. In addition, 2D layered nanomaterials are advantageous for gas sensing application specifically due to their large surface area, which facilitates surface reactions [60].

\section{2D Materials as Sensors and Biosensors}

2D materials take in a large family of organic and inorganic compounds and encompass a wide range of elemental compositions and properties. While graphene and graphenebased materials are at the forefront of the studied sensor materials, other 2D materials are also receiving increasing attention from both the academic and industrial communities. In this section, we review the structures and properties of the most relevant 2D materials to sensors. There are far more 2D materials than will be discussed in the following sections, such as phosphorene [61], silicene [62], 
antimonene [63], and 2D polymers [64], but here we discuss only stable materials with sensory applications in detecting alcohols.

\subsection{Graphene and Graphene Oxide (GO)}

Carbon nanotubes, fullerenes, mesoporous carbons, graphene nanosheets, and carbon dots are different types of carbonaceous nanomaterials [65-69], which are mostly studied for their sensory applications. Yet none of the carbon materials can match graphene in this area, owing to its superior surface area, high thermal, and electrical conductivity, excellent mechanical strength, and low manufacturing cost and simple synthesis. Despite the fact that many other 2D materials have been introduced after the discovery of graphene [70], graphene is still considered as the most important known 2D material, because of the mentioned characteristics.

Graphene is a layer of carbon atoms with packed hexagonal structure with $s p^{2}$ carbon bonds. One of the unique properties of graphene is its working as a zero-bandgap 2D semiconductor with a tiny overlap between the valence and conduction bands. It can also exhibit a strong ambipolar electric field effect in a way that the charge carrier concentrations of up to $10^{13} \mathrm{~cm}^{-2}$ and room temperature mobility of approximately $10,000 \mathrm{~cm}^{-2} \mathrm{~s}^{-1}$ are measured $[36,70,71]$.
Also, an unusual half integer quantum hall effect for both electron and hole carriers in graphene has been observed by adjusting the chemical potential using the electric field effect $[72,73]$. In addition, graphene is highly transparent, with absorption of about $2.3 \%$ towards visible light [74]. Its thermal conductivity is measured with a value of $5000 \mathrm{~W} \mathrm{mK}^{-1}$ for a single-layer sheet at room temperature [75]. Moreover, graphene has excellent mechanical strength and is known as a very firm material; Young's modulus of graphene is approximately 1 Tera Pascal (TPa) [76], and it has proved to be one of the strongest materials ever measured [76, 77]. Thermal stability of graphene makes it a suitable candidate for high-temperature gas sensing, while its mechanical strength offers long-lasting sensors. In addition, its fast electron mobility means faster response towards the analyte, which is highly favourable for electrochemical sensors. High transparency of graphene turns it into a better choice for developing wearable devices and tattooed sensors.

With regard to the sensory applications, other graphene derivative materials have been used successfully. As shown in Fig. 1, 2D carbon-based nanostructures, depending on the number of oxygen groups attached to their surface, could be called graphene oxide (GO) or reduced graphene oxide (rGO) [78]. The oxygen functional groups, such as epoxides, carboxyl, hydroxyls, and alcohols, are located on the edge and surface of the sheet with a carbon to oxygen ratio of approximately 2:1 for fully oxidised GO [79].

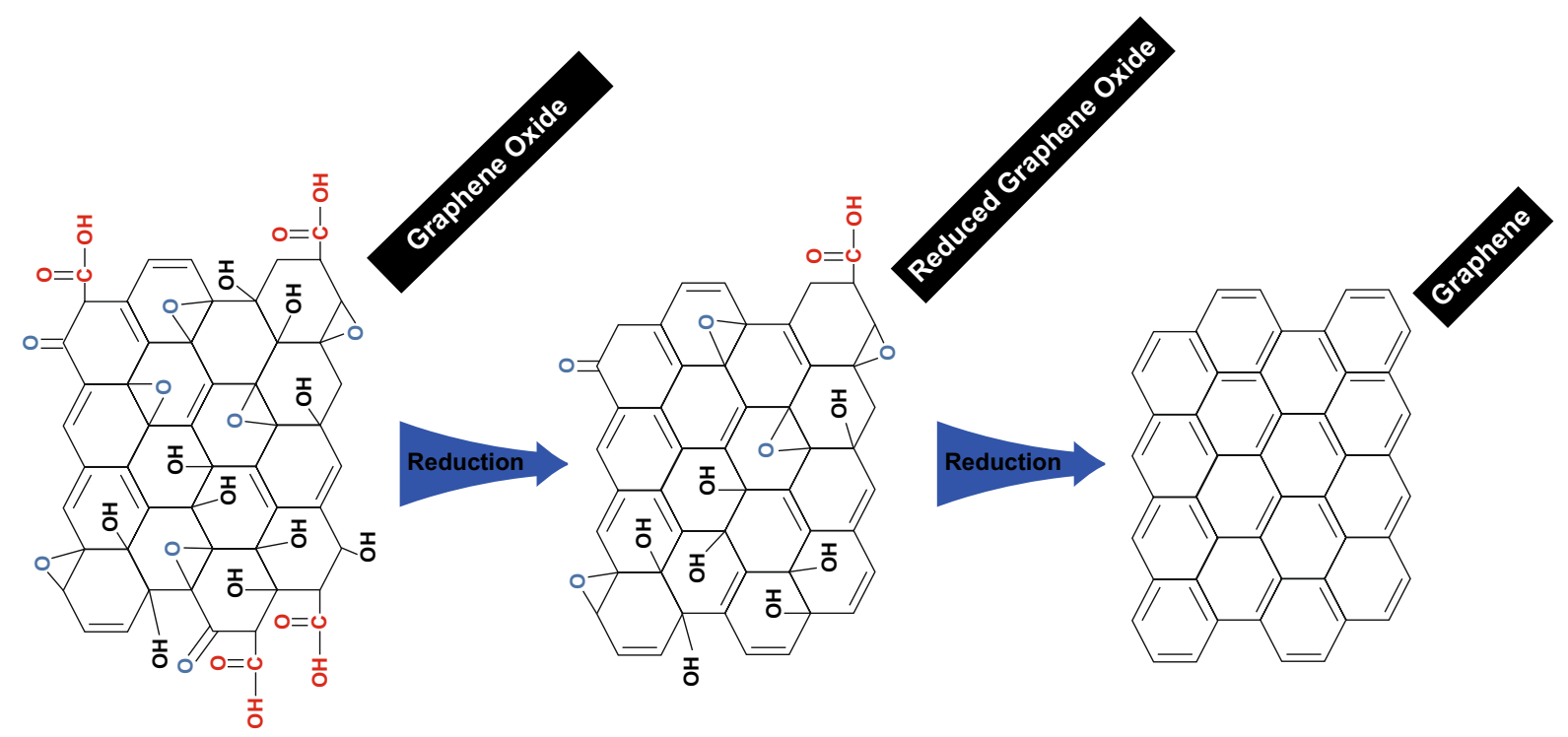

Fig. 1 Comparing graphene oxide, reduced graphene, and highly reduced (cleared) graphene 
GO is produced by subjecting graphite to a strong oxidising atmosphere. Brodie demonstrated the first synthesis method of GO by adding potassium chlorate to a slurry of graphite in fuming nitric acid [80]. Staudenmaier improved this method by adding the chlorate in small portions throughout the reaction [81]. The process is slow and involves the generation of the toxic gas(es) $\mathrm{NO}_{2}, \mathrm{~N}_{2} \mathrm{O}_{4}$, and/or $\mathrm{ClO}_{2}$; the latter also being explosive [82]. Hummers and Hoffman introduced the most currently used method to prepare GO [83]. They oxidised graphite with $\mathrm{KMnO}_{4}$ and $\mathrm{NaNO}_{3}$ in concentrated $\mathrm{H}_{2} \mathrm{SO}_{4}$. After oxidising the bulk graphite, GO sheets are exfoliated from the oxidised bulk via sonication in aqueous solution. Several other methods have been recently suggested to produce GO based on the electrochemical oxidation in aqueous solution [84].

Many different methods have been developed for reducing GO to recover the graphene properties. These methods can be broadly classified as chemical, thermal, electrochemical, or a mixed reduction process. Chemical processes involve the use of reducing agents such as hydrazine [85], hydrohalic acids, $\mathrm{NaBH}_{4}$ solutions [86], vitamin C [87], microorganisms [88], and amino acids [89]. The chemical reduction could also be achieved with the help of electropositive elemental metals, such as iron [90], zinc [91], and aluminium [92]. The degree of reduction, as identified by the $\mathrm{C} / \mathrm{O}$ ratio, depends on the reducing power of the agents. Chemical reduction methods usually suffer from high cost and may produce toxic gases or waste. Thermal reductions involve heating GO in an inert or reducing atmosphere and removal of oxygen groups in the form of carbon oxides or hydrocarbon gases. The thermal methods generally produce materials with a high $\mathrm{C} / \mathrm{O}$ ratio but suffer from high defect density due to the removal of carbon atoms from the graphene basal plane to form the carbon gases [93]. Electrochemical reduction usually takes place at the cathode, either by the direct deoxidation of $\mathrm{GO}$ or by electrodepositing a reducing agent [84]. Some of the oxidation methods of graphite to GO and the chemical reduction of GO by some reductants are shown in Fig. 2.

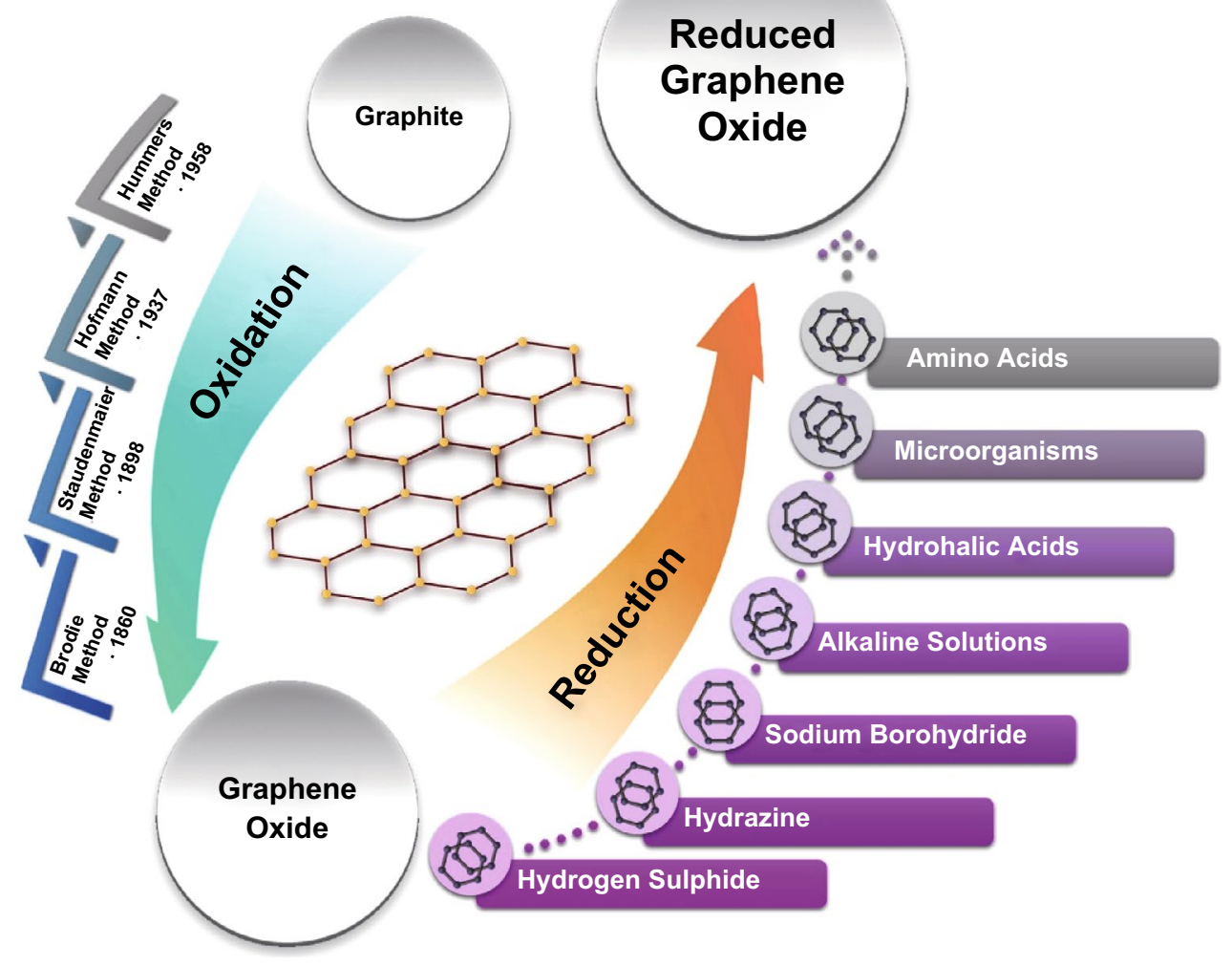

Fig. 2 Schematic representation of some of the introduced GO and rGO production methods 
Both graphene and GO could be used as sensors and biosensors, but the functionalisation of GO, because of its oxygen groups, is much easier than the reduced form. However, both forms could be used as a base material for developing a sensor. Graphene and GO have been studied for sensory application in two main areas: (a) in electrochemistry [94-97], to develop electrochemical sensors based on their conductive behaviour and (b) in spectrofluorometry [98-101], to develop fluorescent probes based on their quenching ability. Other optical methods exist, such as infrared sensors [102], porous sensors [103], and bent sensors [104], but they are rarely used.

In order to develop more sensitive and selective sensors, several methods have been suggested to alter the chemical and physico-chemical properties of graphene and GO. The term functionalised graphene is commonly used to describe chemically modified graphene. Several methods of functionalisation have been suggested including polymer coating, heteroatom doping, attaching to molecular imprinted polymers (MIP), coating with nanoparticles, and direct bonding to an organic or bio-organic molecule [105-110]. It must be mentioned that when it comes to functionalisation, graphene oxide is easier to functionalise than pristine graphene, mainly because the oxygen functional groups could work as a link to attach the foreign molecules and the defects on the GO provide active nucleation sites. One method to achieve GO functionalisation involves using the carboxylic acid groups of GO for attaching to an amine group, which enables attachment of small porphyrins to large-size structures like fullerene $\left(\mathrm{C}_{60}\right)$ [111-113] on the graphene.

\subsection{Transition Metal Dichalcogenides (TMDs) and Transition Metal Carbides, Nitrides, and Carbonitrides (MXenes)}

Layered metal chalcogenides are made of stacked planes of covalently bonded chalcogen and metal atoms, and the adjacent layers are connected together by van der Waals interactions. The ability to prepare these groups of nanosheets in high yield and large scale via various methods, such as mechanical exfoliation [114], electrochemical lithiation [115], liquid exfoliation with sonication [116], and chemical vapour deposition (CVD) growth [117], has led to increasing studies on their hybridisation with other materials to create novel functional composites, aiming to engineer their chemical, physical, and electronic properties and thus achieve good performance for some specific applications.

One of the most popular applications of TMDs is using them as photodetectors, gas sensors, moisture sensors, and biosensors [118-124]. Among members of this family, sulphides and selenides of Mo and $\mathrm{W}$ are the most studied with several investigations on tuning their properties through chemical functionalisation or pairing them with other $2 \mathrm{D}$ materials, such as graphene, through van der Waal forces to form what is known as 2D heterostructures [124]. These hybrids possess very specific morphological and physical properties which make them promising candidates for various applications, such as sensing $\mathrm{H}_{2} \mathrm{O}_{2}$ or biomolecules like DNA, and tumours [125-127].

A recently discovered transition metals-based 2D family, which has grown rapidly, is transition metal (mostly groups 13 and 14) carbides and carbonitrides, known as MXenes. More than 70 types of MXenes have been synthesised and reported until now [128]. $\mathrm{Ti}_{3} \mathrm{C}_{2}$ was the first member of this group to be discovered, which was synthesised by exfoliation of $\mathrm{Ti}_{3} \mathrm{AlC}_{2}$ in 2011 [129] and opened a new door to the development of these $2 \mathrm{D}$ materials.

There are various methods suggested for synthesizing different MXenes. However, most of them follow the basic idea of developing a bulk MAX with structure of interest and then removing $\mathrm{M}-\mathrm{A}$ bonds with the help of fluorinated agents like HF [130]. However, stirring or sonicating in the presence of $\mathrm{KF}, \mathrm{NaF}$, and $\mathrm{LiF}$ at high temperatures $\left(550^{\circ} \mathrm{C}\right)$ or other agents such as $\mathrm{NH}_{4} \mathrm{HF}_{2}$ [131] or $\mathrm{LiF} / \mathrm{HCl}$ [132] as a replacement of HF produces the same results [133].

The most developed application of MXenes that remains in its first principals is their use in modern sensor development. Among such sensors are ultrathin dopamine sensors with an acceptable detection limit of about $100 \mathrm{nM}$ [134], and flexible piezoresistive sensors with a fast response of about $30 \mathrm{~ms}$ [135]. Also, MXenes show advantageous applications as biosensors while coupling with other nanoparticles [136].

\subsection{Metal Oxides (MOs) and Metal-Organic Frameworks (MOFs)}

2D MOFs are 2D and 3D solids mainly produced through self-assembly of metal ions and organic units of interest [137]. 2D MOF layers with similar dimension-related 
properties to other $2 \mathrm{D}$ frameworks such as large surface areas, high intrinsic porosities and abundant accessible active sites could be an attractive option for use in various functional sensory devices. MOFs have shown unique competitive advantages over other inorganic peers when applied in constructions of flexible or transparent devices [138-141].

2D MOFs can be synthesised through physical or chemical exfoliation of their bulk layered MOFs to form singlelayer or few-layer MOFs [142-146]. Bottom-up methods such as the coordination interaction between organic precursors and metal ions components have also been used to prepare 2D MOFs. An important factor in this method is to adjust the growth rates of different crystal facets by selectively restricting the growth along the vertical direction, but allowing lateral growth in two dimensions [139, 147-152]. Other than high specific surface areas, the ordered porosity and abundant redox active sites in MOFs promise a superior adsorption-desorption characteristic towards gas, ions, and organic species [153-155]. MOFs, comprising lightharvesting chromophore bridging linkers or photoactive lanthanide ions $\left(\mathrm{Ln}^{3+}\right)$, usually display luminescent nature under ultraviolet or visible excitation; the close interaction between fluorescent MOFs and analyte can change fluorescence behaviours of MOFs which provides an opportunity for the development of fluorescent sensing platforms to detect various analyte species [156-160].

MOs have been shown to be suitable candidates for chemical and bio-sensors. Nanotubes, nanoparticles, and other nanostructures of oxides of zinc, iron, cerium, tin, zirconium, titanium, and magnesium have shown ability to detect various molecules in solutions with high accuracy [161]. 2D MOs possess exceptional optical and electrical properties and high surface reaction activity which, along with their strong adsorption ability, makes them promising candidates for sensory applications [162]. Moreover, a large group of layered transition metal oxide compounds have the cationexchange capability which could lead to the development of electrochemical sensory applications.

Individual 2D MOs, such as $\mathrm{MnO}_{2}$ [163] and $\mathrm{ZnO}$ [164], which have been used for detecting analytes (such as $\mathrm{H}_{2} \mathrm{O}_{2}$ ), can be fixed on support or be used in suspended form for sensing purposes [165]. Considering the fact that lower concentration of MOs can be applied for coating another base material, it seems to be a more logical option to develop sensors compared to employing MOs as the only compartment of a sensor responsible for both sensing and transducing.
Looking at the applications of MO-based sensors in forensic and industrial studies, we find a range of sensitive alcohol and drug detectors based on these 2D sheets, such as ultrathin $\mathrm{WO}_{3}$ layers which present an acceptable sensitivity for alcohols and are able to detect very low concentrations in a wide linear range [166]. ZnO nanosheets also function well as ethanol sensors at different temperatures [167]; before them, mostly one-dimensional MO nanoparticles were known for their alcohol detection properties [168-172]. The study of alcohol sensing applications of $\mathrm{WO}_{3}$ shows that by increasing the number of carbons, the sensitivity and response of sensor decrease; however, the recovery time for smaller alcohols was higher than their response time, which could also be related to slow evaporation rate of larger alcohols [166]. Porous $\mathrm{ZnO}$ sensors show various sensing behaviour against gases in different temperatures; they are able to detect chlorobenzene at relatively low operating temperatures $\left(150{ }^{\circ} \mathrm{C}<T<250{ }^{\circ} \mathrm{C}\right)$ and detect ethanol at relatively higher temperatures $\left(250^{\circ} \mathrm{C}<T<450{ }^{\circ} \mathrm{C}\right)$. MO-based sensors have the potential to be highly affected by temperature and the weight of analyte molecules [167].

\section{$2.4 h$-Boron Nitride ( $h$-BN)}

Boron nitride consists of equal numbers of boron and nitrogen atoms. 2D hexagonal boron nitride $(h-\mathrm{BN})$ is one of main stable BN allotropes and is actually an isomorph of graphene and is also known as "white graphene" [173]. It is an electrical insulator with an ultra-flat surface, highly stable with a honeycomb $s p^{2}$-hybrid layer structure, while sub-lattices are occupied by equal numbers of boron and nitrogen atoms alternatingly [174]. The first isolation and experimental study of 2D $h$-BN were reported in 2008 [175].

Stable BN allotropes (2D $h$-BN and 3D $c$-BN) have been a studied for a long time because of their low density, high thermal conductivity, electrical insulation, superb oxidation resistance, excellent inertness, and low friction coefficient. 2D $h$-BN nanostructures possess a unique combination of these advantageous properties, which promotes their usage in various applications such as their use as dielectric substrates in graphene electronic devices, composite fillers, thermally robust catalytic and sensing substrates, highly durable field emitters, hydrophobic films, and so on [176-180]. At room temperature, the thermal conductivity of $h$-BN is up to $400 \mathrm{Wm}^{-1} \mathrm{~K}^{-1}$, which is higher than the 
majority of metals and ceramic materials [181]. In addition, 2D $h-\mathrm{BN}$ is transparent in infrared and visible light and has no absorption in the visible range, but has absorption spectroscopy in the ultraviolet region (a strong peak around $251 \mathrm{~nm}$ ) and a good photoluminescence property [182-184]. The shifts in ultraviolet, or emission peaks of $h$-BN or its derivatives in the presence of various analytes could be examined for sensory studies.

Various methods have been used to synthesise $h$-BN nanostructures, similar to the well-known techniques utilised for the growth of other 2D materials, including chemical vapour deposition, chemical exfoliation, mechanical cleavage, solidstate reactions, substitution reactions, high-energy electron irradiation, and unzipping nanotubes [178, 185-188]. CVD [189] on metallic surfaces such as $\operatorname{Pt}(111), \operatorname{Ru}(001)$, and $\mathrm{Ni}(111)$ is one of the methods of preparation of layered $h$-BN by a chemical-solution-derived process. Mechanical exfoliation [175] and liquid exfoliation [190] are other supported and confirmed $h$-BN synthesised methods, where both are almost similar, but the latter one occurs through a vigorous stirring in a solution like DMF.

$h$-BN has also been used for various sensory applications, including the use of a composite of $h$-BN with graphene quantum dots as an electrochemical sensor for detecting serotonin in $10^{-13} \mathrm{M}$ concentrations in urine samples [191]. In addition, another study on the properties of $h$-BN proved that the atomic layers of boron nitride could work as a resistance-based gas sensor and the electrical resistance of the surface was changed as it underwent reduction with tested $\mathrm{CH}_{4}$ gas [192].

\section{2D Alcohol Sensors and Biosensors}

The general structure of any chemical sensor (optical/electrochemical) is illustrated in Fig. 3. Chemical sensors contain two basic components connected in series: a chemical recognition system (receptor) and a physico-chemical transducer. In some cases, sensors might use a third compartment to do the amplification process, known as the amplifier [193, 194].

In order to develop a marketable product, the sensor should offer simplicity, stability, and easy usage. Also, based on the applications of the final product, it needs to be modified in different ways; for example, field sensors require portability, while pharmaceutical and medical studies ask for implantable probes for in vivo monitoring of analytes. Miniaturisation is another important factor, which reduces sample size required for analysis and also provides the

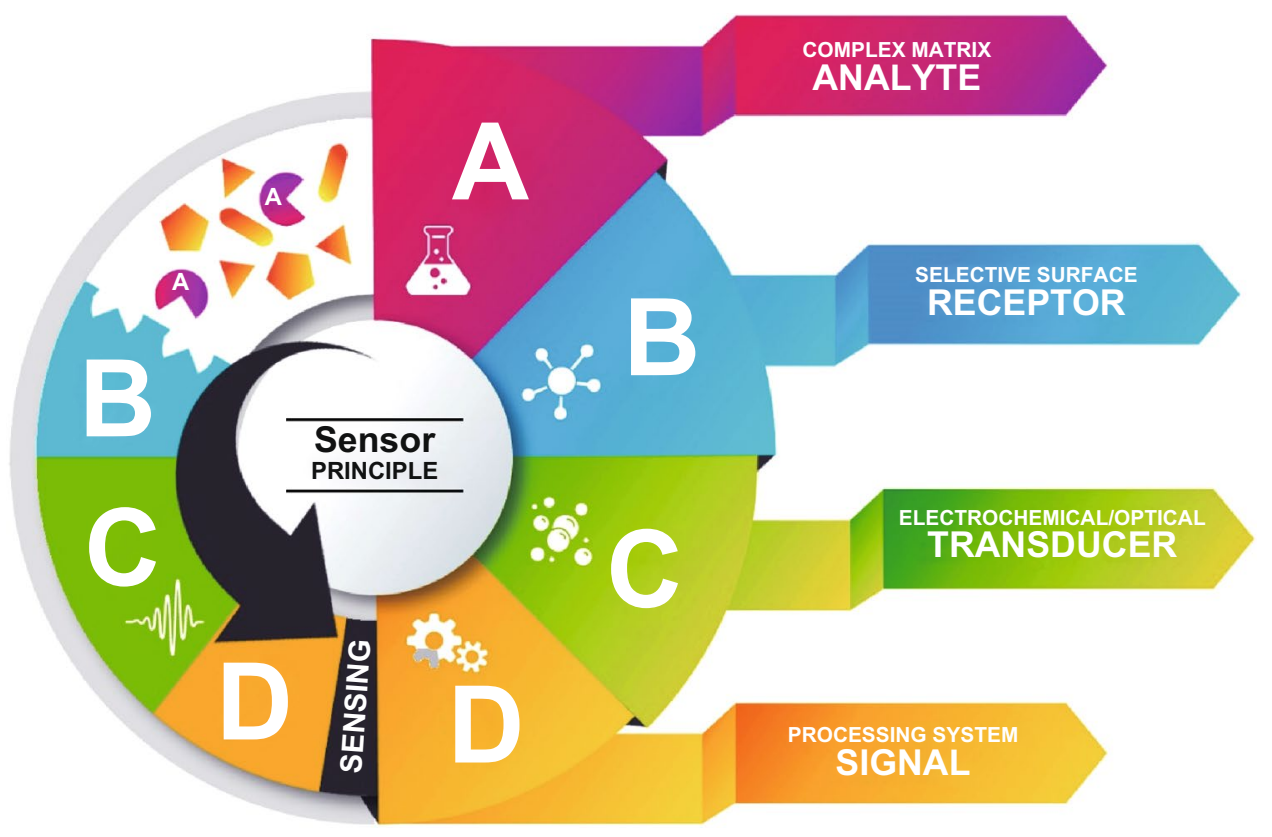

Fig. 3 General scheme of a sensor. The interaction of an analyte with the selective receptor, coupled to a transducer, transfers a measurable signal to processing systems 
possibility of packing multiple sensors in order to analyse several analytes at the same time, such as searching for different recreational drugs in one drop of blood. The nature of 2D nanomaterials provides the bed of miniaturised and portable sensors, while their size also allows in vivo studies as well.

2D materials can be used in sensors for four purposes: as a supporting agent that amplifies or facilitates the sensing; a transducer; a receptor; or both receptor and transducer at the same time. Working as a "supporting agent" means using them for other purposes that develop the sensing mechanism, but they are not a part of the main sensor, like using them as a conductive additive to the electrode or as an electrolyte solution to improve the sensor response. A transducer is responsible for transferring signals from the receptor to the signal processing system. Highly conductive 2D materials, such as graphene, are identical materials for the transducer and can decrease the response time of the sensor. The receptor is the main part of a sensor that directly deals with the analyte and

Table 1 Analytical parameters of 2D-based alcohol sensors and biosensors, sorted by LoD and type

\begin{tabular}{|c|c|c|c|c|c|c|}
\hline Nos. & Analyte detected & Sensor type & Sensing materials & Limit of detection & Sensing matrix & References \\
\hline 1 & Alcohols & Electrochemical sensors & Gr-Ns/BCNs & $10 \%$ & Liquid and gas & [197] \\
\hline 2 & Ethanol and propanol & & $\mathrm{PVA} / \mathrm{CuO} / \mathrm{Gr}-\mathrm{NPls}$ & $1800 \mathrm{ppm}$ & Gas & [198] \\
\hline 3 & $\begin{array}{l}\text { Ethanol, methanol, and isopro- } \\
\text { panol }\end{array}$ & & rGO arrays & $1500 \mathrm{ppm}$ & Gas & [199] \\
\hline 4 & Methanol & & $\mathrm{rGO} / \mathrm{FL}-\mathrm{NiO}$ & $100 \mathrm{ppm}$ & Gas & [200] \\
\hline 5 & Ethanol & & $\mathrm{Co}_{3} \mathrm{O}_{4}$-HHMSs & $100 \mathrm{ppm}$ & Gas & [201] \\
\hline 6 & $\begin{array}{l}\text { Ethanol, ammonia, methanol, } \\
\text { and acetone }\end{array}$ & & $\mathrm{TiO}_{2} / \mathrm{GO}$ & $100 \mathrm{ppm}$ & Gas & [202] \\
\hline 7 & Methanol & & $\mathrm{ZnCo}_{2} \mathrm{O}_{4}$ & $100 \mathrm{ppm}$ & Gas & [203] \\
\hline 8 & Ethanol & & $\mathrm{SnO}_{2}$ & $100 \mathrm{ppm}$ & Gas & [204] \\
\hline 9 & Ethanol & & $\mathrm{Au}-\mathrm{NPs} / \mathrm{SnO}_{2}$ & $70.2 \mathrm{ppm}$ & Gas & [205] \\
\hline 10 & Ethanol & & GO/Melamine & $70 \mathrm{ppm}$ & Gas & [206] \\
\hline 11 & Alcohols & & $\mathrm{TiO}_{2} / \mathrm{MoS}_{2}$ & $50 \mathrm{ppm}$ & Gas & [207] \\
\hline 12 & Ethanol & & $\mathrm{SnO}_{2} / \mathrm{MoS}_{2}$ & $50 \mathrm{ppm}$ & Gas & [208] \\
\hline 13 & Ethanol & & $\mathrm{ZnO} / \mathrm{MoS}_{2}$ & $50 \mathrm{ppm}$ & Gas & [209] \\
\hline 14 & Ethanol & & fSGO electrolyte film & $25 \mathrm{ppm}$ & Gas & [210] \\
\hline 15 & Ethanol & & $\mathrm{ZnO} / \mathrm{GO}$ & $10 \mathrm{ppm}$ & Gas & [211] \\
\hline 16 & Ethanol and NADH & & $\mathrm{Au}-\mathrm{AgNPs} / \mathrm{P}(\mathrm{Cys}) / \mathrm{rGO}$ & $5 \mathrm{ppm}$ & Liquid & {$[21]$} \\
\hline 17 & Ethanol & & $\mathrm{SnO}_{2}$ & $5 \mathrm{ppm}$ & Gas & [212] \\
\hline 18 & Ethanol & & $\alpha-\mathrm{Fe}_{2} \mathrm{O}_{3} / \mathrm{MoS}_{2}$ & $1 \mathrm{ppm}$ & Gas & [213] \\
\hline 19 & Ethanol & & $\mathrm{Co}_{3} \mathrm{O}_{4}$ & $0.2 \mathrm{ppm}$ & Gas & [214] \\
\hline 20 & Ethanol, acetone, and ammonia & & $\mathrm{Ti}_{3} \mathrm{C}_{2} \mathrm{~T}_{x}$ & $100 \mathrm{ppb}$ & Gas & [215] \\
\hline 21 & Ethanol and acetone & & $\mathrm{ZnSnO}_{3}$ & $50 \mathrm{ppb}$ & Gas & [216] \\
\hline 22 & $\begin{array}{l}\text { Ethanol, methanol, acetone, and } \\
\text { ammonia }\end{array}$ & & $\mathrm{Ti}_{3} \mathrm{C}_{2} \mathrm{~T}_{x}$ & $34 \mathrm{ppb}$ & Gas & [217] \\
\hline 23 & Ethanol & & $h-\mathrm{BN}$ & NA & Gas & [218] \\
\hline 24 & Ethanol & & Triphenylene frameworks/G & NA & Gas & [219] \\
\hline 25 & $\begin{array}{l}\text { Ammonia, ethanol, methanol, } \\
\text { etc. }\end{array}$ & & $\mathrm{WO}_{3} / \mathrm{WS}_{2}$ & NA & Gas & {$[220]$} \\
\hline 26 & Ethanol and methanol & Optical sensors & $\mathrm{NaF} / \mathrm{G}$ & NA & Liquid & {$[102]$} \\
\hline 27 & Alcohols and ketones & & $\mathrm{Au}-\mathrm{rGO} / \mathrm{SnO}_{2} / \mathrm{ZnO} \mathrm{NWs}$ & $11 \mathrm{ppm}$ & Gas & [221] \\
\hline 28 & Ethanol & & $\mathrm{Ag} / \mathrm{TiO}_{2}$ & $5 \mathrm{ppm}$ & Gas & [222] \\
\hline 29 & $\begin{array}{l}\text { Ethanol, methanol, and isopro- } \\
\text { panol }\end{array}$ & & GO-BPOF & 9-14 $\Delta$ RIU* & Liquid & {$[104]$} \\
\hline 30 & Alcohols & & $\mathrm{MoS}_{2}$ & $4.8 \times 10^{-6} \mathrm{RIU}^{*}$ & Liquid & [223] \\
\hline
\end{tabular}

$* R I$ refractive index-more details in the reference 
selectivity, accuracy, and precision of a sensor directly related to the receptors.

Many alcohol sensing systems (examples listed in Table 1) are electrochemical sensors, which are made of a 2D material coupled with another compartment, such as a MO nanoparticle, for selective detection. The fact that $2 \mathrm{D}$ sensors could bring astonishing detection limits along with high selectivity in coupled forms could promise a bright future ahead of them. Reduced graphene oxide (rGO) and its derivative are at the forefront of $2 \mathrm{D}$ materials for sensor applications due to many factors such as availability, well-known chemistry, and the ability to tune the properties further by attaching new molecules to the basal plane. Analytes, such as buprenorphine, heroin, morphine, and noscapine $[195,196]$, can be detected with GO or rGO without any further modifications down to a detection limit of $0.2 \mu \mathrm{M}$. However, for small molecules like alcohols, especially in extreme situations such as high temperatures or high/low $\mathrm{pH}$, graphene alone cannot detect low concentrations with reasonable sensitivity. The sensitivity of the graphene-based electrode can be enhanced by either attaching functional groups to the graphene basal plane or by mixing graphene with other organic or inorganic materials to form hybrids. Several wet chemical methods, as well as various functional groups, have been used to modify the graphene properties and improve the interaction at the surface-electrolyte interface (Fig. 4).

Jiang et al. [210] attached sulphonyl groups to the surface of GO to increase its sensitivity and selectivity towards ethanol. Sulphonyl functionalisation of graphene oxide was accomplished with the help of 3-mercaptopropyl trimethoxysilane and then oxidation of its thiol group, which will finally form dark brown films. The sulphonic treated graphene oxide, or better rGO, was claimed to offer an increase in the conductivity and thermal stability of the sensor, while free-standing sulphonic acid-functionalised graphene oxide (fSGO) offers high selectivity for ethanol, compared to other chemicals like acetone. The sensor presented fast response

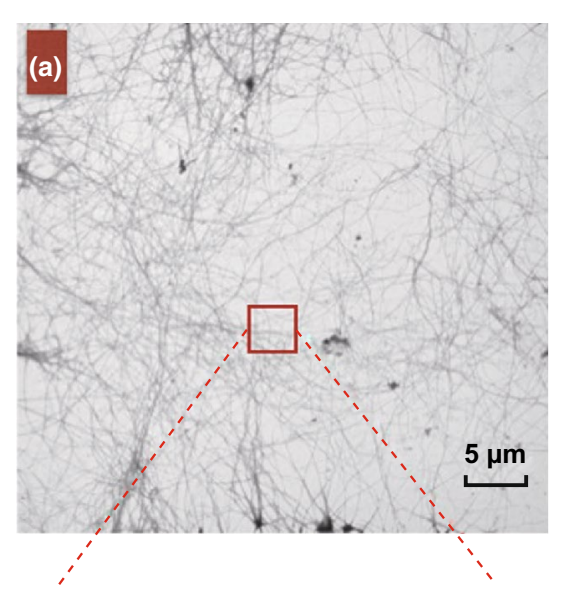

(d)
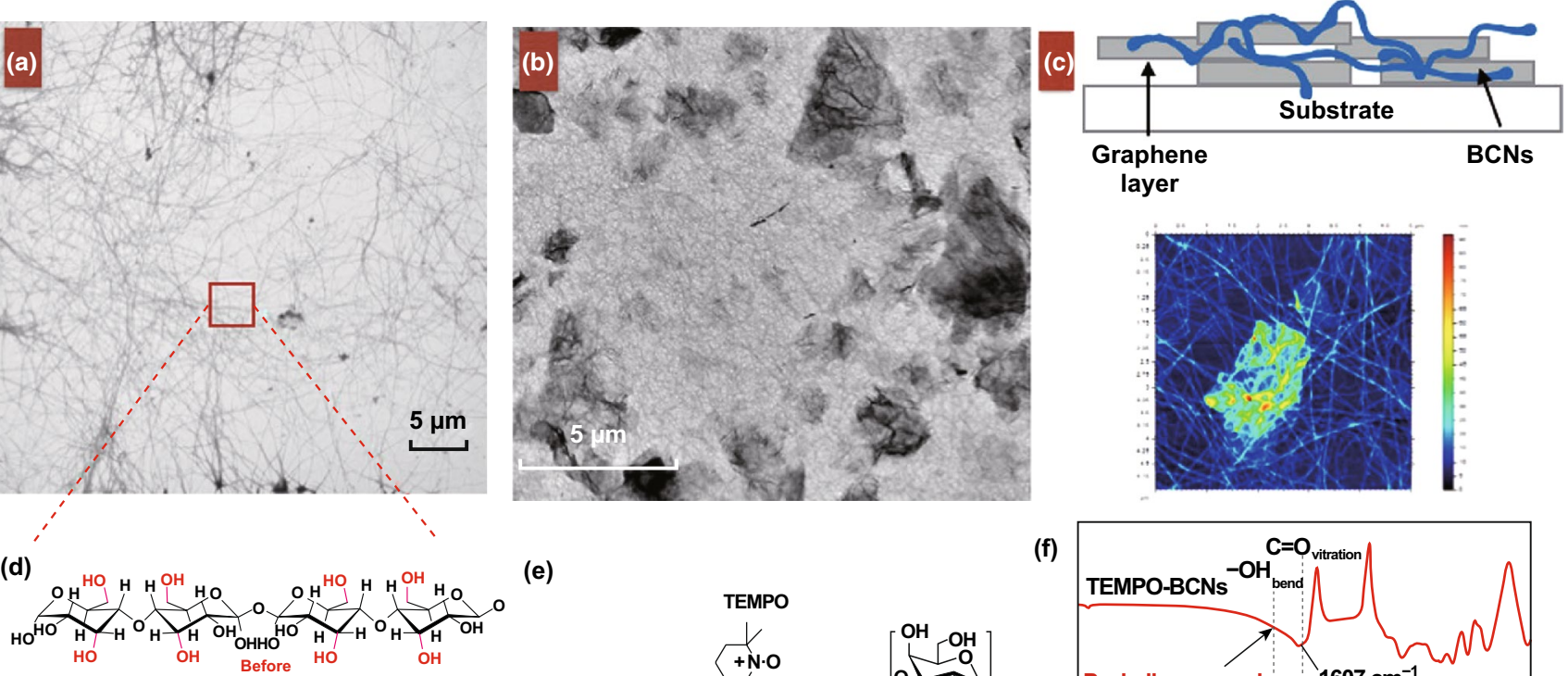

(e)
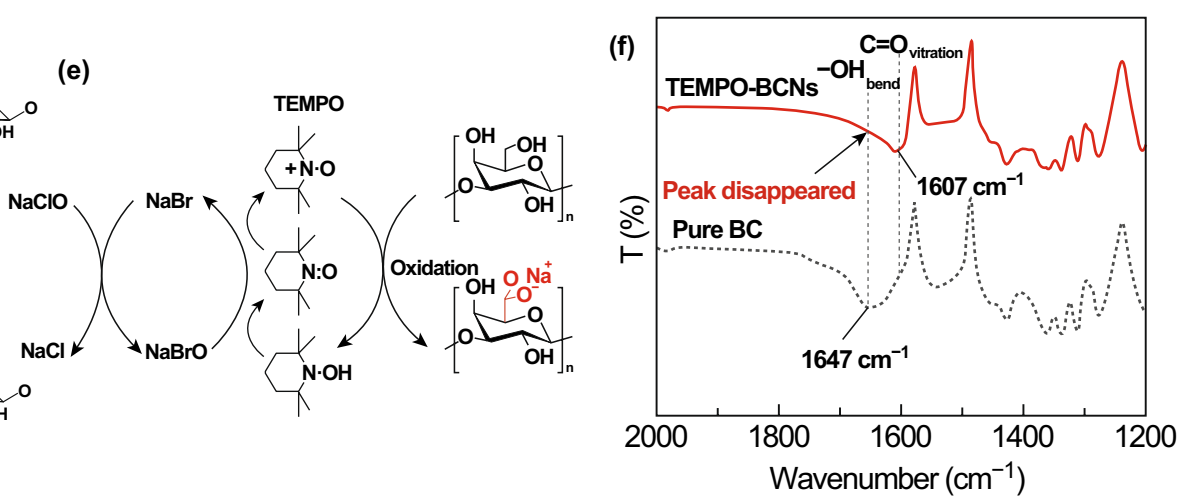

Fig. 4 a TEM image of BCNs derived from BC gels. b TEM image of a graphene-BCN membrane. c AFM image of the structure of the graphene-BCN sensor. d Molecular structure of BCNs before and after modification with TEMPO. e Chemical reaction on BCNs caused by TEMPO-modification. f FTIR spectra of pristine BCNs and modified BCNs. Adapted with permission from Ref. [197]. Copyright 2017 Nature 
time (50 s) and low detection limit (25 ppm) and offers high proton conductivity. Furthermore, humidity tests showed that by increasing the humidity, the resistance of the sensor decreases, which resulted in an increase in the response. The structure of the sensor was based on an alcohol fuel cell, which can be used in the construction of portable breathalysers. Despite the fact that graphene oxide offers thermal stability [224] up to $300-400{ }^{\circ} \mathrm{C}$ where it loses its oxygen functional groups [82], but it is poorly conductive [225] and there is a chance that graphene oxide actually reduced during the synthesis or functionalisation.

It has been suggested that the catalytic ability of noble metal nanoparticles (NMNP) such as Au [205, 221], Ag [222], or their bimetallic combination [21] could improve the sensitivity of the sensors towards alcohols. A biosensor has been recently fabricated from metal alloys, amino acids, and rGO and applied to study alcoholic and non-alcoholic beverages. The recovery values of this sensor demonstrated a good accuracy for detecting ethanol [21] as a result of this combination. The modified glassy carbon electrode (GCE/ $\mathrm{Au}-\mathrm{AgNPs} / \mathrm{P}(\mathrm{L}-\mathrm{Cys})-\mathrm{rGO}$ ) was prepared in three steps; firstly, gold and silver nanoparticles co-electrodeposited on the surface of the electrode. Afterwards, electropolymerisation technique was used to add a layer of poly(L-cysteine) coating. The electrochemically reduced graphene oxide film was electrodeposited onto the surface of the GCE/ $\mathrm{Au}-\mathrm{AgNPs} / \mathrm{P}$ (L-Cys) electrodes via electroreduction of GO by cyclic voltammetry $(10$ cycles between +0.60 and $-1.5 \mathrm{~V}$ at a scan rate of $25 \mathrm{mV} \mathrm{s}^{-1}$ ). The biosensor was developed through enzyme immobilisation (addition of enzyme solution containing alcohol dehydrogenases) and spreading a 2.0 $\mu \mathrm{L}$ nafion solution on the surface of the electrode. The developed biosensor was able to selectively detect both ethanol $(\mathrm{LoD} 5.0 \mu \mathrm{M})$ and nicotinamide adenine dinucleotide (LoD $9.0 \mathrm{nM})[21]$.

Another sensors for alcohol detection can be produced from bacterial cellulose nanofibres (BCNs) and graphene [197]. Extracted BCNs are reported to be highly crystalline (up to $90 \%$ ) with ultrafine (2-50 nm) fibres, which offers high flexibility, high tensile strength, and moduli; their natural water absorbing characteristics lead to formation of porous foams after water removal [226, 227]. Thin films were fabricated under direct pressure over a gold electrode through vacuum-filtration and lamination technique. The whole system was fabricated over a plastic substrate $(0.005$, Clear Dura-Lar), and in order to increase the adhesion between the electrode and substrate, Ti was added to the gold electrode. The sensor offers reasonable sensitivity for both liquid and gas analytes which was suggested to be the result of the absorption characteristics of BCN. Different thicknesses were tested and $225 \mathrm{~nm}$ reported as the best thickness with optimum sensitivity. Despite the sensor's good response to ethanol, its selectivity and response to other similar chemicals were not tested.

Thangamani et al. [198] mixed polyvinyl alcohol (PVA) and $\mathrm{CuO}$ nanoparticles with 6-8 $\mathrm{nm}$ thickness graphene nanoplatelets to fabricate a thin film using a colloidal blending method. PVA is reported to offer gel and film forming abilities, and also good porosity [228] Water solubility of PVA turns it into a popular organic additive to develop hybrid films [229-231]. Different ratios of $\mathrm{CuO}$ to graphene were tested, and the thickness of the film was in the range of $60-70 \mu \mathrm{m}$. The sensing properties of the film were investigated by recording the changes of the films electric resistance after exposure to different alcohol vapours in a controlled atmosphere test chamber. The change of the film resistance was attributed to the absorption/desorption of oxygen species and the subsequent reaction between oxygen species and the alcohol vapour molecules on the surface of the nanocomposites film. The reaction of the oxygen species (either $\mathrm{O}^{-2}$ (ads) and/or $\left.\mathrm{O}^{-}{ }_{(\text {ads) }}\right)$ with the alcohol generated electrons on the composite surface that changes the resistivity of the film. It was reported that by increasing the graphene loading, the sensitivity of the sensor increased due to the improvement in the film conductivity. However, above certain loading levels $(0.5 \mathrm{wt} \%)$, the sensing behaviour declined due to the filler concentration being above the percolation limit. The sensor shows more sensitivity for propanol than ethanol. Also, the temperature had a considerable effect on the sensitivity due to the change of the absorption of oxygen species from physisorption type into a chemisorption type, which usually has stronger bonds with the substrate and increases the resistance of the film.

In order to increase the selectivity of rGO sensors, Lipatov et al. fabricated a large array of rGO devices by drop casting GO from a dilute suspension on KAMINA multisensor chip followed by gentle annealing at $150{ }^{\circ} \mathrm{C}$ under vacuum. A thin film of less than $10 \mathrm{~nm}$ thickness (approximately 10 layers of graphene) covered $39 \mathrm{Pt}$ electrodes of the chips (100-3000 $\mu \mathrm{m}^{2}$ each) and the gap between them $(\sim 90 \mu \mathrm{m})$, forming 38 devices (Fig. 5). The sensing properties of the 

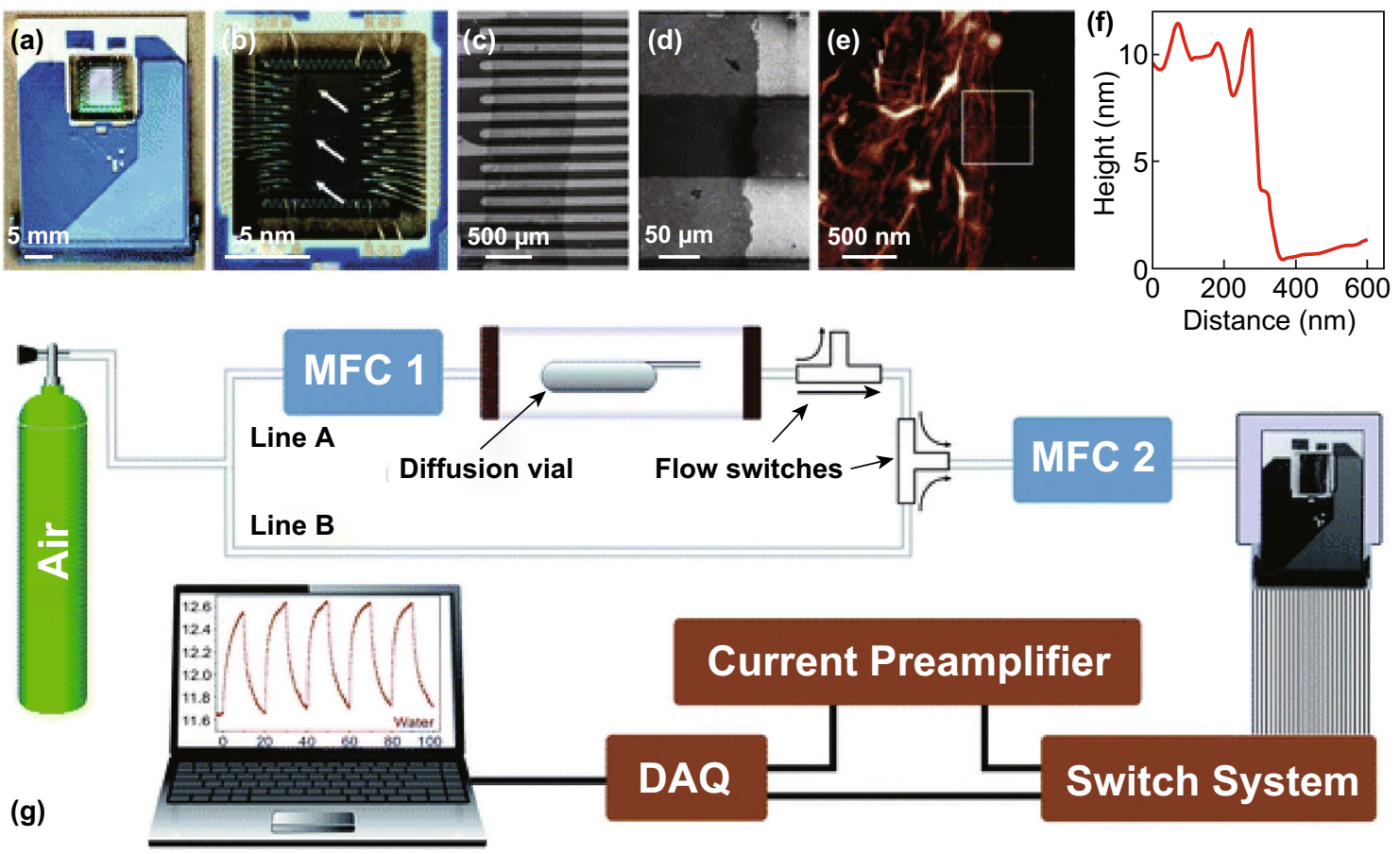

Fig. 5 a rGO-based multisensor array. b-e SEM and AFM images of the chip. $\mathbf{f}$ A height profile of the film. $\mathbf{g}$ Schematic of the experimental set-up for sensor measurements. Adapted with permission from Ref. [199]. Copyright 2013 Royal Society of Chemistry

integrated array devices were measured by recording the change of the resistance during the exposure to $20 \mathrm{sccm}$ flow of synthetic air with different concentrations of alcohol vapours. The resistance of the rGO device was found to increase with the time of exposure to alcohol gases, but then recovered the original conductivity when purged with dry air. The increase in resistance is quick at the first stage of alcohol exposure due to the fast kinetics of molecules adsorption at the low-energy binding sites, such as $s p^{2}$ carbon domains. The rate of the adsorption then decreased as soon as the low-energy sites are occupied and the alcohol molecules are forced to bind to high-energy binding sites, such as defects and oxygen functional groups. Interestingly, the response of the rGO devices was different for different analytes. There were characteristic patterns for ethanol, methanol, isopropanol, and water that could be used to distinguish between different types of alcohol. It was also suggested that the selectivity of the rGO array devices might be enhanced if graphene is covalently functionalised with diazonium groups.

Lipatov's suggested electronic-nose system was able to deal with the lack of sensitivity [199]. E-nose systems, other than selective chemical receptors, are strongly dependent on digital signal processing and pattern recognition procedures $[232,233]$. The e-nose, calibrated with standards and signals from every individual sensor collected at the beginning, and the overlapped selectivity turns into a recognition algorithm which gives the sensing system the ability to detect the element of interest by comparison with the results of standard samples. The unique structure of graphene and its defects increase the chance of absorbing gas molecules when exposed to air, which changes the conductivity of this complex material and leads to detection. Every chemical tested (water, isopropanol, methanol, and ethanol) lead to losing the calibration of the e-nose by increasing the resistance, and it needs to purge with dry air to recover and respond accurately [199].

Zhang et al. [206] introduced porous melamine/GO sponge composite (GOMS) for selective ethanol sensing, and the sensor benefits from reasonably fast self-recovery. In order to form the composite, melamine sponge was first cut to size $\left(3 \mathrm{~cm}^{3}\right)$ and dipped into GO solution and pressed until all of the trapped air removed and freeze-dried. The immersing process tested for different concentrations of GO and the highest tested concentration $\left(12 \mathrm{mg} \mathrm{mL}^{-1}\right)$ offered a better conductive network and a larger response comparing 
to others. The sensor was tested among different gases, and it showed sensitivity towards acetone, methanol, and ethanol; though its sensitivity for ethanol was greatest, the sensor covered a wide linear range from 70 to $1670 \mathrm{ppm}$, which is higher than previously reported sensors such as graphene/ $\mathrm{ZnO}$ with the linear range of $10-50 \mathrm{ppm}$ [234] or $\mathrm{MoS}_{2} /$ thiolat with a working range of 1-1000 ppm [235] for ethanol. Organic molecules incorporated with 2D materials such as graphene can also be used for sensing alcohols. Research on the applications of triphenylene frameworks in coordination with graphene layers conducted by Mathew and his team in 2017 [219] produced 16 different triphenylene derivatives. They successfully made a field effect transistor from a combination of graphene and one of their products, which showed a high and reversible response to ethanol vapour. The sensor was fabricated by placing a layer of graphene on Si wafer and then immobilising a certain developed triphenylene over it. Hydrogen bonding between ethanol and the amide functionality of applied triphenylene provides higher sensitivity towards ethanol compared to other tested gases $\left(\mathrm{NH}_{3}, \mathrm{CO}_{2}\right.$, and $\left.\mathrm{H}_{2}\right)$, at room temperature.

Hierarchical flower-like (FL) $\mathrm{NiO}$ in a heterostructure with rGO was used to detect methanol, acetone, and ethanol under high humidity. Acetate salt of nickel was used to decorate graphene oxide with nickel oxide through a hydrothermal process. The final flower-like nanostructure was achieved by a thermal treatment step ( $1 \mathrm{~h}$ heating at $140{ }^{\circ} \mathrm{C}$ in an autoclave, followed by $3 \mathrm{~h}$ calcination at $250{ }^{\circ} \mathrm{C}$ of washed product), in which graphene oxide was reduced and nickel hydroxide was decomposed to give $\mathrm{NiO}$. The specific surface area of the developed complex was measured by the Brunauer EmmeV Teller (BET) method and proved that addition of graphene improved the specific surface area of the sensor $(5 \% \mathrm{rGO} / \mathrm{FL}-\mathrm{NiO}$ and $10 \% \mathrm{rGO} / \mathrm{FL}-\mathrm{NiO}$ offered a specific surface area of 165 and $160 \mathrm{~m}^{2} \mathrm{~g}^{-1}$, respectively). A paste of $\mathrm{rGO} / \mathrm{FL}-\mathrm{NiO}$ in isopropanol was casted over an alumina electrode substrate with gold arrays and dried at $250{ }^{\circ} \mathrm{C}$. The interaction between the nano-flowers with methanol vapour affected the resistance of the sensor and leads to detection. The sensor showed the highest sensitivity against methanol, but could also sense acetone and ethanol as well [200]. Comparison of results suggested that addition of rGO could enhance the behaviour of the sensors to some extent, and authors noted that $5 \%$ rGO offered the best results; higher concentrations of rGO will wrap the Ni nanoparticles in a way that it actually blocks their active sites and weakens the response. However, it was suggested that higher amounts of rGO will decrease the working temperature of the sensor from 220 (for pure $\mathrm{FL}-\mathrm{NiO}$ ) to $180{ }^{\circ} \mathrm{C}$.

A composite made of $\mathrm{TiO}_{2}$ and graphene is one of the few reported $2 \mathrm{D}$ sensors to offer room temperature alcohol detection, which uses the photocatalysis behaviour of $\mathrm{TiO}_{2}$ for this purpose. A homogenous solution $\mathrm{GO}$ with $\mathrm{TiO}_{2}$ nanoparticles was prepared in ethanol by sonicating for $2 \mathrm{~h}$. A thin film of the nanocomposite was then prepared by drop casting $10 \mathrm{mg}$ of the solution over a clean layer of polyimide. The composite sensor offered an enhanced normalised gas response for methanol, ethanol, and ammonia compared to pure GO layer; however, these nano-complexes suffer from short lifetime, and to deal with this issue, UV treatment of the sensor was performed that increased the lifetime of the detector up to 1 month and improved its resistance against water [202]. The UV-treated sample coloured differently, and this treatment also affected the behaviour of the sensor in a way that reduced the sensitivity of the sensor to different gasses and produced a higher response (normalised gas response) for ethanol than methanol.

Studies on different nano-morphologies of $\mathrm{ZnO}$ proved very good selectivity for ethanol as well, and the combinations of $\mathrm{ZnO}$ with $\mathrm{GO}$, rGO, or other metal oxides lead to the development of various types of selective sensors [236-238]. Covering the surface of graphene oxide with rodlike nanoparticles of $\mathrm{ZnO}$ by a hydrothermal reaction is one example that leads to the fabrication of another sensor that responds selectively to relatively low concentrations of ethanol (10 ppm) [211], which offers a high response at different tested concentrations. The mechanism of sensing in $\mathrm{ZnO}$ nanoparticles is similar to other semiconductor gas sensors, where it is expected to adsorb some oxygen molecules when exposed to air, which would trap electrons from the conduction band of $\mathrm{ZnO}$ and produce adsorbed $\mathrm{O}_{2}^{-}, \mathrm{O}^{-}$, or $\mathrm{O}^{2-}$. In an ethanol atmosphere, ethanol molecules could react with the adsorbed oxygen to form $\mathrm{H}_{2} \mathrm{O}$ and $\mathrm{CO}_{2}$ accompanied by the release of electrons and thus decreasing the resistance of the sensor [211, 239-241].

A further study on $\mathrm{TiO}_{2}$ composites for alcohol sensing followed a different method, where $2 \mathrm{D} \mathrm{MoS}$ was used to decorate $\mathrm{TiO}_{2}$ nanotubes [207]. The composite was produced through a hydrothermal reaction at $180{ }^{\circ} \mathrm{C}$, and the final product showed reasonably good sensitivity for ethanol (14.2). The highest response appears at $150{ }^{\circ} \mathrm{C}$ increasing the temperature caused the sensitivity of the sensor to 

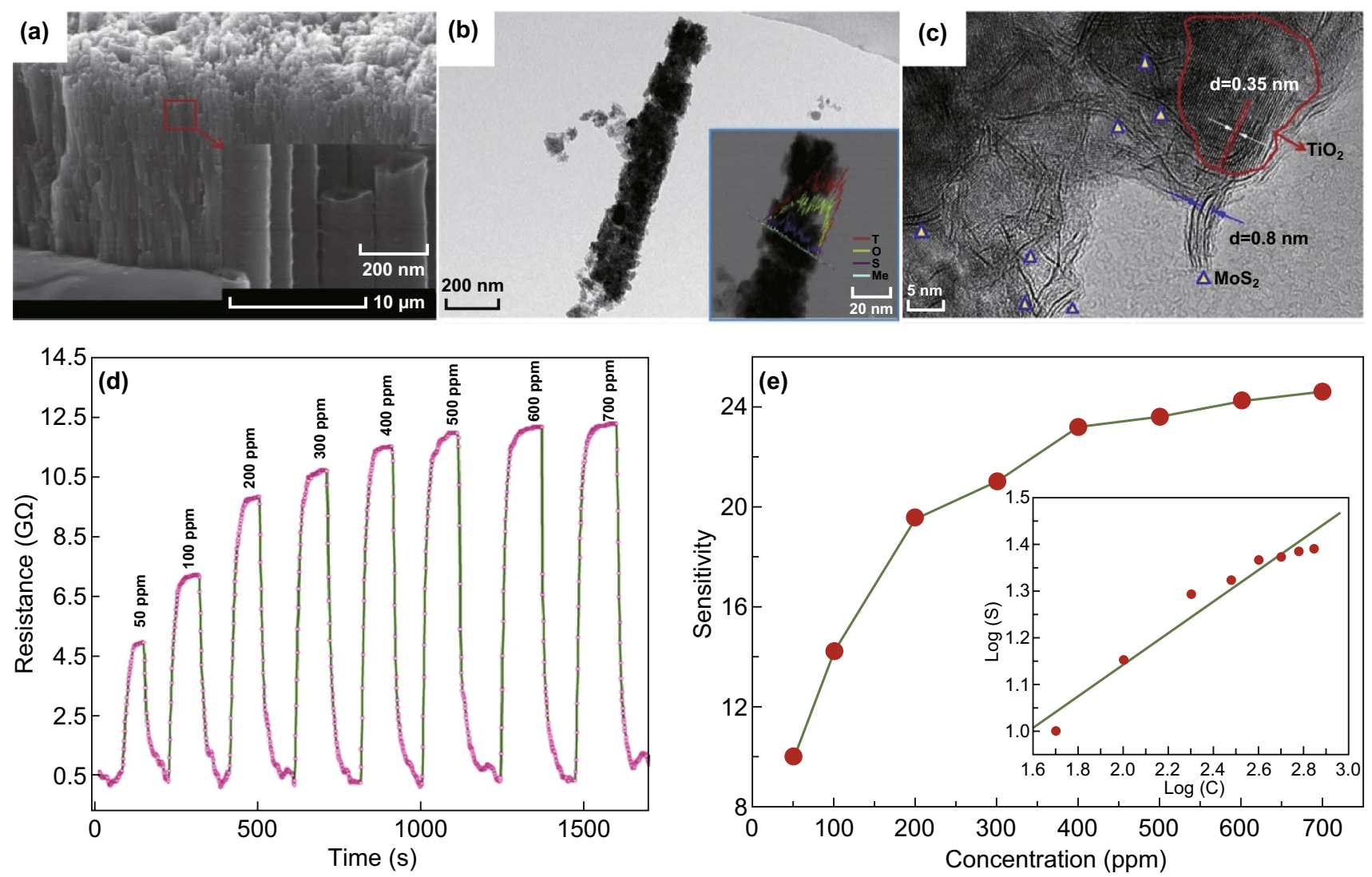

Fig. 6 a SEM image of the $\mathrm{TiO}_{2}$ nanotubes, and the inset showing the opening top of the tubes, $\mathbf{b}, \mathbf{c} \mathrm{HRTEM}^{\mathrm{images}}$ of the $\mathrm{MoS}_{2}-\mathrm{TiO}_{2}$ composites, and the elemental distribution in the inset of $\mathbf{b}, \mathbf{d}$ the response and recovery curves of the $\mathrm{MoS}_{2}-\mathrm{TiO}_{2}$ sensor to various ethanol concentrations from 50 to $700 \mathrm{ppm}$ at $150{ }^{\circ} \mathrm{C}$. e Sensitivity of the $\mathrm{MoS}_{2}-\mathrm{TiO}_{2}$ sensor at different concentrations of ethanol. Adapted with permission from Ref. [207]. Copyright 2016 Elsevier

decrease; however, at $300{ }^{\circ} \mathrm{C}$, the sensitivity increased again, but the response was not as high as at $150{ }^{\circ} \mathrm{C}$. The sensitivity of the composite was reported to be 11 times more than $\mathrm{TiO}_{2}$ nanotube, yet the sensor suffers from lengthy response and recovery times (Fig. 6). Despite the similarities of various semiconductors' sensing mechanism, which mainly comes from their interactions with oxygen and changing the resistance, they are not exactly the same. Non-decorated $\mathrm{TiO}_{2}$ nanotubes are $n$-type semiconductors, and after exposure to alcohols, electrons (which come from absorbed oxygen) are released back to the conduction band of $\mathrm{TiO}_{2}$ and finally decrease the resistance. However, $\mathrm{TiO}_{2}$ nanotube is covered with a $p$-type semiconductor $\left(\mathrm{MoS}_{2}\right)$, the alcohols replace the absorbed oxygen and release free electrons to neutralise the holes in the $p$-type semiconductor, which results in increased resistance. $\mathrm{TiO}_{2}$ showed selective behaviour for certain alcohols in its various nano-morphologies in both high and low temperatures, and it is expected that other complex of this semiconductor with other 2D nanomaterials offers promising applications for alcohol sensing.

It can be seen that among the 2D alcohol sensors presented in Table 1, MXene-based sensors are performing very well with LoD at ppb levels which even surpassed many modified 2Ds, without forming any secondary complexes or adding modifications. Another important characteristic of $\mathrm{Ti}_{3} \mathrm{C}_{2} \mathrm{~T}_{x}$ sensors is their ability to sense gases at room temperature [217] similar to $\mathrm{TiO}_{2}$, yet they have a longer service life. Although MXene sensors suffer from low selectivity and they may react with other gases including ammonia and acetone, they exhibit selectivity towards hydrogen-bonding gases over acidic gases [215]. This is probably due to the several functional groups on the MXenes surface and applying other transition metals, or further modifications could improve their selectivity. Density functional theory (DFT) investigations on the sensing mechanism of $\mathrm{Ti}_{3} \mathrm{C}_{2} \mathrm{~T}_{x}$ and its behaviour against different gases, $\mathrm{Ti}_{3} \mathrm{C}_{2}(\mathrm{OH})_{2}$ displayed a 
strong binding energy potential. Also, hydroxyl-group terminated MXenes displayed stronger gas adsorption compared to oxygen-group terminated MXenes. Therefore, it is assumed that the outstanding gas adsorption properties of the hydroxyl groups on $\mathrm{Ti}_{3} \mathrm{C}_{2} \mathrm{~T}_{x}$ largely contribute to the high sensitivity observed in experimental studies [215]. That could justify the lack of selectivity of $\mathrm{Ti}_{3} \mathrm{C}_{2} \mathrm{~T}_{x}$ against tested gases such as ethanol, methanol, etc., which also have been reported as electron donor gases [217, 242].

It should be noted here that while $\mathrm{Ti}_{3} \mathrm{C}_{2} \mathrm{~T}_{x}$ was prepared by the same method in Refs. [194, 195], through etching $\mathrm{Al}$ from bulk $\mathrm{Ti}_{3} \mathrm{AlC}_{2}$ powders using $\mathrm{LiF}$ and $\mathrm{HCl}$, but the fabrication of electrode was different. Lee et al. [217] used a drop casting method over a flexible polyimide film, while Kim et al. [215] used vacuum filtration method to produce free standing membrane of $\mathrm{Ti}_{3} \mathrm{C}_{2} \mathrm{~T}_{x}$, which then transferred on thin $\mathrm{SiO}_{2}$ wafers. In the latter study, for better comparison of MXenes sensing abilities, thin layer of black phosphorous, $\mathrm{MoS}_{2}$, and rGO were also prepared and casted with the same method, where first subjected to vacuum filtration through a porous anodised aluminium oxide membrane (AAO) filter, and then, films separated from filter by dissolving alumina membrane with a $\mathrm{NaOH}$ aqueous solution before placing on a $\mathrm{SiO}_{2}$ wafer and drying. The comparison selectivity results for $100 \mathrm{ppm}$ of different analytes showed that $\mathrm{BP}$ and $\mathrm{MoS}_{2}$ casted with this method showed the highest response against ammonia, while $\mathrm{Ti}_{3} \mathrm{C}_{2} \mathrm{~T}_{x}$ was more responsive to ethanol and acetone. Also, electrical noise of each sensor was tested by measuring the resistance during $\mathrm{N}_{2}$ introduction, where BP showed the highest and $\mathrm{Ti}_{3} \mathrm{C}_{2} \mathrm{~T}_{x}$ displayed the lowest noise level [215].

In general, adding metal oxide nanoparticles to the active materials increases the selectivity of the sensors towards alcohol. The morphology, structures, and the interaction with other components in the composites play a crucial role in the performance of metal-oxides-enhanced 2D sensors. By comparing 2D nanomaterials decorated with nanoflower, hallow-spheres or rod-like metal oxides, as listed in Table 1, ultrathin 2D morphologies like $\mathrm{ZnSnO}_{3}$ [216] and $\mathrm{Co}_{3} \mathrm{O}_{4}$ [214] offer the best sensitivity. In addition, 2D layers offer faster response and recovery times, compared to their exact molecular formula formed other nano-morphologies. For example, 2D $\mathrm{ZnSnO}_{3}$ nanosheets [216] with a response and recovery time of 0.36 and $9 \mathrm{~s}$, respectively, comparing to its nanorods (5 s) [243], hollow fibres (less than 10 s) [244], nanocubes (4 s) [245], and nanocages (2 s) [246], give the fastest response against ethanol. This could be attributed to the large specific surface area offered by 2D morphology, which facilitates the alcohol gas diffusion within the electrode. $2 \mathrm{D} \mathrm{ZnSnO}_{3}$ was developed from $3 \mathrm{D} \mathrm{ZnSn}(\mathrm{OH})_{6}$ cubes as a result of the hydrothermal reaction, where the cubes first decompose and then re-crystallised into porous nanosheets with a thickness of about $15-20 \mathrm{~nm}$, by increasing the pressure and temperature. The developed 2D sensor was tested with various gases and showed the best response at $320{ }^{\circ} \mathrm{C}$ for ethanol $(\sim 4.5 \mathrm{Ra} / \mathrm{Rg})$, but it was also sensitive to other gases and generated a detectable signal for gases like $\mathrm{H}_{2} \mathrm{~S}, \mathrm{NH}_{3}$, and acetone [216]. The same temperature effect is also reported for various MO-based alcohol sensors such as $\mathrm{Cr}_{2} \mathrm{O}_{3}$ [247], $\mathrm{ZnCo}_{2} \mathrm{O}_{4}$ [203], and $\mathrm{Co}_{3} \mathrm{O}_{4}$ [201], which shows the importance of operating temperature on the response semiconductor of gas sensors (Fig. 7).

Another example of 2D metal oxide alcohol sensor was the work of Yin et al. when they used $\mathrm{ZnCo}_{2} \mathrm{O}_{4}$ nanosheets to detect various gases [203, 248-250]. The $\mathrm{ZnCo}_{2} \mathrm{O}_{4}$ nanosheets were grown over a small piece of $\mathrm{Ni}$ foam substrate through a hydrothermal process at $200{ }^{\circ} \mathrm{C}$. The produced nanosheets have a hexagonal structure with a thickness of ca. $84 \mathrm{~nm}$. It was reported that urea affected the thickness of the nanosheets in a way that adding extra $0.5 \mathrm{mmol}$ leads to increasing the thickness of the nanoparticles to $100 \mathrm{~nm}$, but their regular hexagonal sheet structure remained the same; yet, adding $2 \mathrm{mmol}$ urea increased the thickness to $70 \mathrm{~nm}$ and leads to aggregation and stacking of nanosheets together. When used as a sensor for various gases at $400{ }^{\circ} \mathrm{C}$, the sensor signals, measured as the ratio between the resistance before and after gas exposure, were 9, 7.5, 5.1, and 2.0 to methanol, ethanol, formaldehyde, and ammonia, respectively. These results indicated good selectivity towards methanol, especially at a concentration below $300 \mathrm{ppm}$ and high temperature $\left(400{ }^{\circ} \mathrm{C}\right)$. The sensor also responded to high concentrations of volatile ethanol. In addition, $\mathrm{ZnCo}_{2} \mathrm{O}_{4}$ nanosheets sensor exhibited short response $(25 \mathrm{~s})$ and recovery time (23 s) at $400{ }^{\circ} \mathrm{C}$ for $100 \mathrm{ppm}$ methanol.

Two-dimensional nanoparticles can also be used as the building blocks to construct larger porous microstructures. Tan and co-workers presented a new model of fabricated semiconductor sensors, where they fabricated 3D microspheres from 2D (3 nm thick) nanosheets (Fig. 8) through a hydrothermal reaction [201]. In order to study the gas sensing abilities of the developed nanostructure, hollow and hollowed-out $\mathrm{Co}_{3} \mathrm{O}_{4}$ microspheres $\left(\mathrm{Co}_{3} \mathrm{O}_{4}\right.$-HHMSs $)$ powder is 

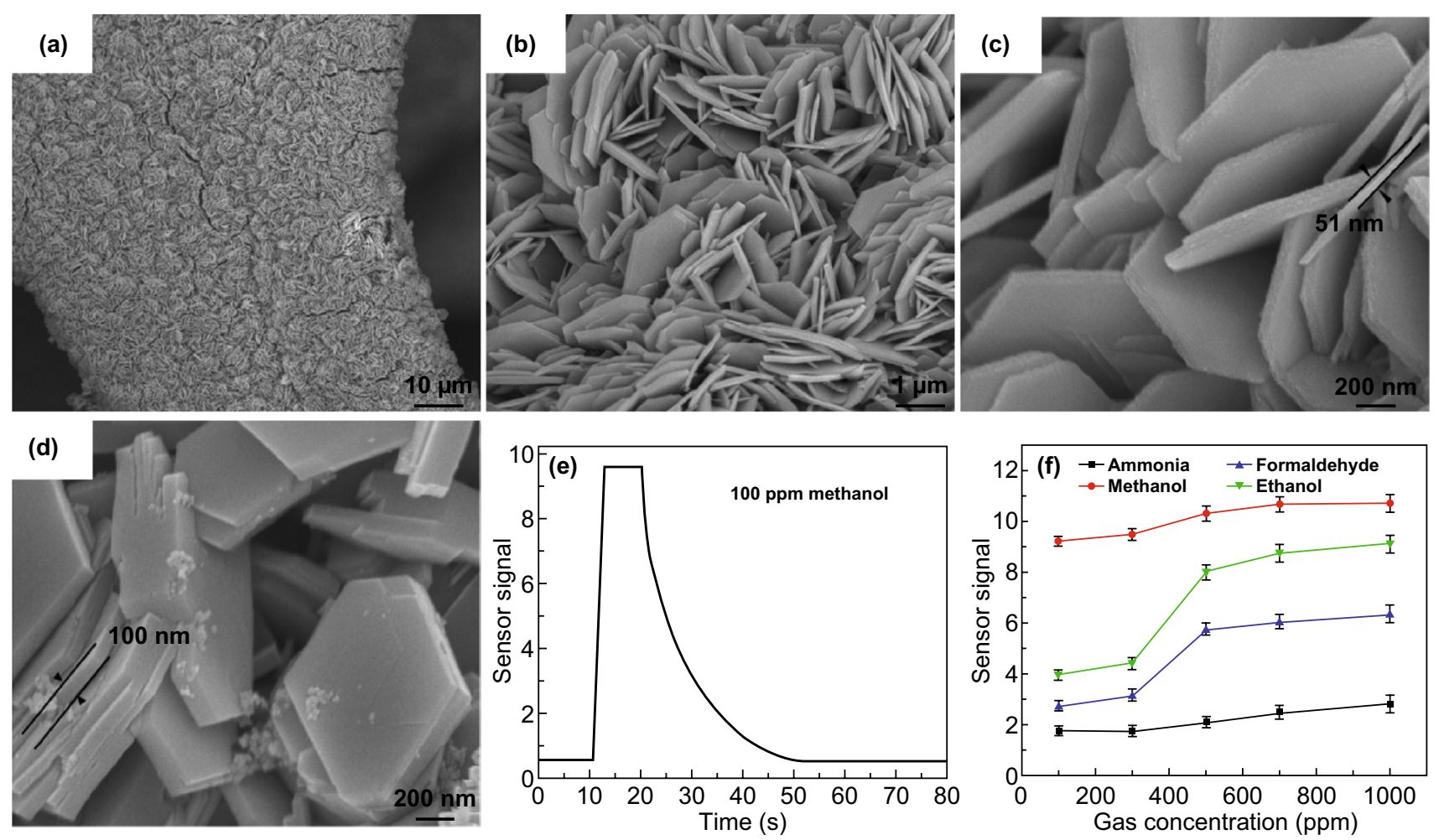

Fig. 7 a-c SEM images at different magnification of hexagonal $\mathrm{ZnCo}_{2} \mathrm{O}_{4}$ grown on Ni foam using 0.2 mmol urea, $\mathbf{d}$ SEM image showed the increase in the sheets thickness with increasing the urea content, e sensor signal-time curve showing the fast response and slow recovery of the sensor, $\mathbf{f}$ the effect of the concentration on the sensor signal for various gases. Adapted with permission from Ref. [203]. Copyright 2018 Elsevier

first dispersed in water, before casting on an aluminium tube; then, Au electrodes equipped with Pt wires fixed on both ends of the tube. Dried powder forms a layer with thickness of $50 \mu \mathrm{m}$ on the tube, and Ni-Cr alloy coil is fixed inside the aluminium tube as a heater. The sensor showed a very fast response $(0.1 \mathrm{~s})$ and recovery times $(0.7 \mathrm{~s})$ and offered a good selectivity towards ethanol at $220^{\circ} \mathrm{C}$.

Growing the ultrathin $\mathrm{Co}_{3} \mathrm{O}_{4}$ nanosheets on carbon foam templates is another way of fabricating high surface area electrode for sensors. Here, the carbon foam provides a backbone that protects the electrode integrity and also provides a conductive substrate that facilitates the movement of any electron that might result from adsorption reaction. It was not a surprise that $\mathrm{Co}_{3} \mathrm{O}_{4}$ nanosheets on carbon foam offer a lower working temperature of about $100{ }^{\circ} \mathrm{C}$ [214]. The $2 \mathrm{D} \mathrm{Co}_{3} \mathrm{O}_{4} p$-type semiconductor and on $\mathrm{N}$-doped carbon foam the sensor provides the detection limit of $0.2 \mathrm{ppm}$ for ethanol, which is one of the lowest values offered by $2 \mathrm{D}$ based sensors to date. The synthesis started with heating the carbon foam in a diluted mixture of sulphuric acid and nitric acid for $6 \mathrm{~h}$, then a mixture of dissolved cobalt(II) nitrate and glucose was added on the foam, and after each few drops the foam is dried and the procedure repeated for several times. Then, the foam is transferred to a Teflon-lined autoclave filled with a mixture of cobalt(II) nitrate salt, water, and hexamethylenetetramine and heated to $120{ }^{\circ} \mathrm{C}$ before annealed at $250{ }^{\circ} \mathrm{C}$ to develop mesoporous $\mathrm{Co}_{3} \mathrm{O}_{4}$ nanosheets/N-doped carbon foam composite. The resistance of the obtained composite changed in the presence of ethanol and showed a good selectivity; yet its lengthy and complicated synthesis along with the longer response (45 s) and recovery ( $140 \mathrm{~s}$ ) times compared to other $\mathrm{Co}_{3} \mathrm{O}_{4}$-based sensors $[251,252]$ are some of the drawbacks of this sensor.

Noble metal nanoparticles (NMNPs) are considered good catalysts for the dissociation of molecular oxygen species at a relatively low temperature. Hence, it was suggested that NMNPs facilitate gas molecules adsorption on the surface of metal oxides easier, resulting in higher-performance metal oxide-based sensors [205]. Liu et al. synthesised hexagonal $\mathrm{SnO}_{2}$ nanosheets loaded with 

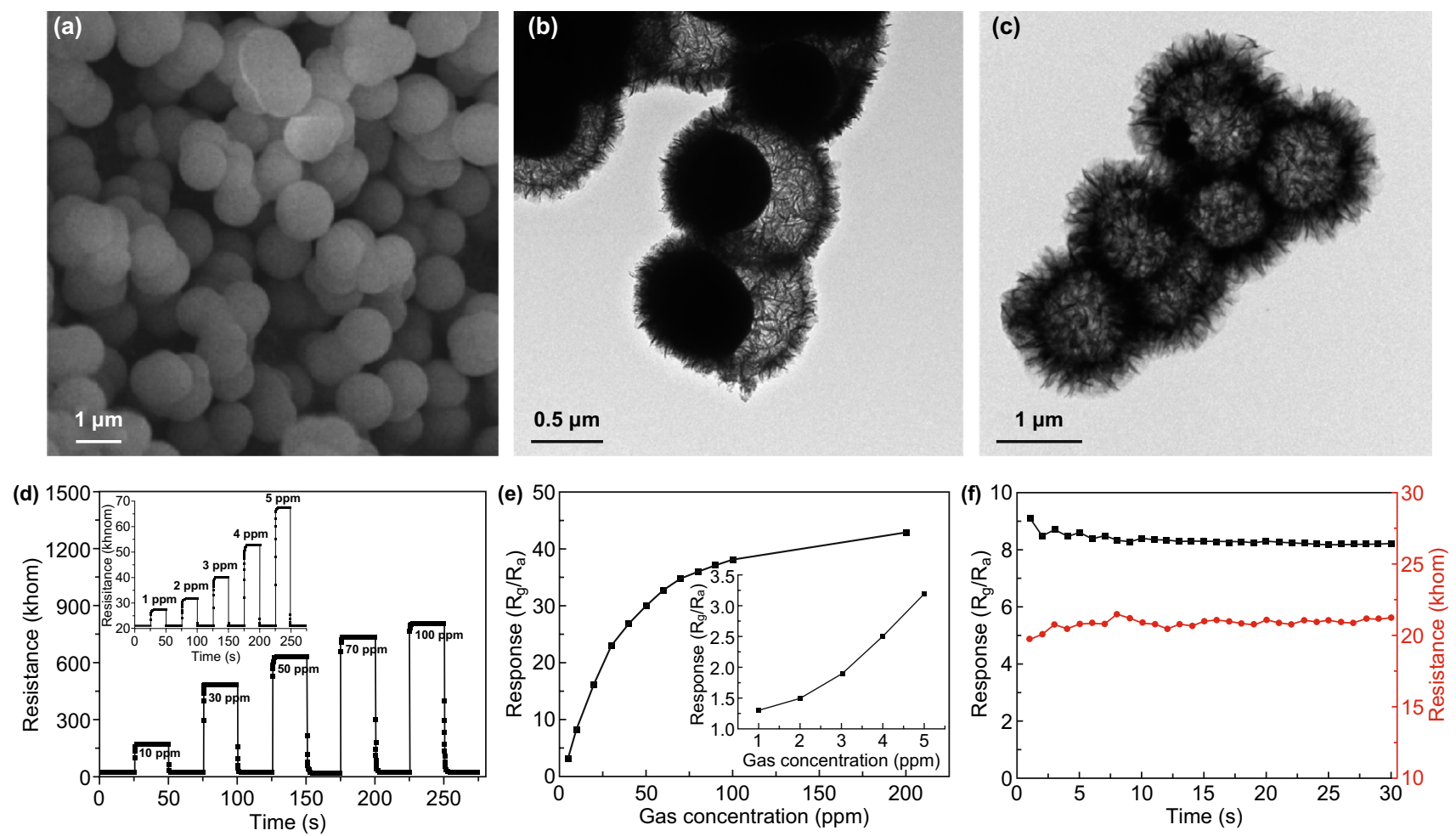

Fig. 8 a SEM image of the $\mathrm{Co}_{3} \mathrm{O}_{4}$ microspheres, b, $\mathbf{c}$ TEM images of the hollow $\mathrm{Co}_{3} \mathrm{O}_{4}$ microspheres showing that the microspheres are composed of $2 \mathrm{D}$ nanosheets, $\mathbf{d}$ dynamic gas sensing transients of the sensors to ethanol with different concentrations at $220{ }^{\circ} \mathrm{C}$. e Response of the sensor to various ethanol concentrations at $220{ }^{\circ} \mathrm{C}$. f Long-term stability of the sensor to $30 \mathrm{ppm}$ ethanol at $220{ }^{\circ} \mathrm{C}$. Adapted with permission from Ref. [201]. Copyright 2017 Elsevier

$\mathrm{Au}$ nanoparticles that showed excellent performance for sensing ethanol gas. Firstly, $\mathrm{SnS}_{2}$ was produced inside a Teflon-lined hydrothermal reactor after $20 \mathrm{~h}$ heating at $180{ }^{\circ} \mathrm{C}$; then, it turned to $\mathrm{SnO}_{2}$ by $2 \mathrm{~h}$ heating at $500{ }^{\circ} \mathrm{C}$ in air. Then, Au NPs decorated the surface of developed $\mathrm{SnO}_{2}$ nanosheets by adding a mild base $\left(\mathrm{NaBH}_{4}\right)$ to the stirring mixture of obtained $\mathrm{SnO}_{2}, \mathrm{HAuCl}_{4}$, and lysine. The produced structure composed of aggregates of $\mathrm{SnO}_{2}$ nanosheets with a pore diameter of 5-10 nm and high specific surface area $\left(64.2 \mathrm{~m}^{2} \mathrm{~g}^{-1}\right)$ over gold nanoparticles [253]. The $\mathrm{SnO}_{2} / \mathrm{Au}$ nanocomposite showed maximum gas response at $260{ }^{\circ} \mathrm{C}$. The ethanol gas response was almost 3.5 times more when $\mathrm{SnO}_{2}$ nanosheets were decorated with $\mathrm{Au}$, proving the crucial role of the noble metal NPs on improving the sensitivity of the sensor [205]. The effect of $\mathrm{Au}$ addition was less pronounced when sensing other gases, acetone, and ammonia, probably because the sensitivity towards these gases was low. Therefore, $\mathrm{SnO}_{2} / \mathrm{Au}$ nanocomposite sensor was selective towards ethanol which agrees with other $\mathrm{SnO}_{2}$ nanosheets sensor studies [204].
Another porous nanosheets of $\mathrm{SnO}_{2}$ sensor for ethanol detection were recently developed by Zhao et al. [212]. GO was used as a template for $\mathrm{SnO}_{2}$ nanosheets growth in a hydrothermal process, and oxides functional groups at the surface helped to direct the development of the porous structure. It was found that GO was also controlling the size and thickness of $\mathrm{SnO}_{2}$ nanosheets. By increasing the amount of graphene oxide, the size of $\mathrm{SnO}_{2}$ nanosheets gets smaller from several micrometers to a few tens of nanometres. After the end of hydrothermal treatment, GO was removed by annealing at $500{ }^{\circ} \mathrm{C}$ in air, giving a hierarchical porous microstructure with the porous size in the range from 2 to $20 \mathrm{~nm}$ and specific surface area as high as $80.1 \mathrm{~m}^{-2} \mathrm{~g}^{-1}$. To form the sensor electrode, the produced $\mathrm{SnO}_{2}$ nanosheets are dispersed in ethanol and deposited on oxidised Si substrate with $\mathrm{Cr} / \mathrm{Au}$ electrode arrays and heated at $400{ }^{\circ} \mathrm{C}$ for $2 \mathrm{~h}$. The electrode was then heated at $300{ }^{\circ} \mathrm{C}$ for a week to improve its stability. The sensing measurements were taken at temperatures between 150 and $300{ }^{\circ} \mathrm{C}$, while the relative humidity was around $40 \%$. The hierarchical porous 
nanosheets-based sensor exhibits a high response value of about 71, based on the resistance ratio, for a wide range of ethanol concentrations (5-5000 ppm). It was also found that the response of the sensor improved by decreasing the $\mathrm{SnO}_{2}$ nanosheets, i.e. by increasing the GO content in the initial charge. The idea of using graphene sacrificial scaffolds could be used to synthesise other 2D materials nanostructures.

Yu et al. [221] tried to use advantages of noble metals, graphene, and metal oxide in one composite; they developed $\mathrm{ZnO}$ doped $\mathrm{SnO}_{2}$ nanowires and applied them over $\mathrm{Au}-\mathrm{rGO}$ surface to sense alcohols and ketones by cataluminescence (CTL). The substrates of Au-graphene for both GO and rGO are prepared through similar methods where GO (or rGO) is refluxed in the presence of chloroauric acid and sodium citrate, and after turning the colour of the solution from black to purple, it is washed and dried at $80{ }^{\circ} \mathrm{C}$. The substrate is coated with tungsten coil, and atmospheric pressure chemical vapour deposition (APCVD) was used to deposit $\mathrm{SnO}_{2}-\mathrm{ZnO}$ nanowires on it. By measuring the luminescent emission of electromagnetic radiation, which is produced during the catalytic oxidation reaction of gas molecules on the surface of solid catalyst, they were able to achieve a detection limit of $11 \mathrm{ppm}$ for ethanol at $260{ }^{\circ} \mathrm{C}$. It was reported that higher temperatures $\left(>260^{\circ} \mathrm{C}\right)$ offer a stronger CTL response, but signal to noise ratio was decreased. The sensor also responded to ethanol when $\mathrm{Au}$ was removed $\left(\mathrm{rGO}-\mathrm{SnO}_{2}-\mathrm{ZnO}\right.$ ) and without $\mathrm{ZnO}$ (solo $\mathrm{SnO}_{2}-\mathrm{Au}-\mathrm{rGO}$ ), but the intensity of the response was much higher in a composite made of all of them together. The sensor was responding to different types of alcohols and ketones, but not other organic solvents; the highest response was to ethanol and methanol, respectively.

Heterostructures of semiconductor 2D TMD with MO as another semiconductor showed enhanced sensing capability for alcohol detection, particularly when a $p-n$ junction can be formed. Both MO and 2D TMD would have the same Fermi energy level at the interface, which results in a staggered band offset and a built-in internal electric field. When using the heterogamous structure in a sensor, the electron generated from the adsorption reaction can easily move across the interface and transfer to the conductive band. One example for ethanol detection used sensor based on $n$-type semiconductor $\alpha-\mathrm{Fe}_{2} \mathrm{O}_{3}$ hollow microspheres on $\mathrm{MoS}_{2}$ nanosheets prepared by layer by layer self-assembly method [213]. Alpha-iron oxide and $\mathrm{MoS}_{2}$ were prepared separately using hydrothermal method followed by heat treatment. The electrode was then fabricated by casting five layers of $\mathrm{MoS}_{2}$ and $\alpha-\mathrm{Fe}_{2} \mathrm{O}_{3}$ on the substrate of a printed circuit board with interdigital electrodes. Before casting the $\alpha-\mathrm{Fe}_{2} \mathrm{O}_{3} / \mathrm{MoS}_{2}$, two layers of poly-(diallyldimethylammonium chloride) and poly-(sodium 4-styrenesulphonate) PDDA/PSS were deposited as precursor layers for substrate charge enhancement. The developed sensor was able to detect ethanol at concentrations as low as $1 \mathrm{ppm}$ with high response. The response time was as short as $6 \mathrm{~s}$ and recovery time was $5 \mathrm{~s}$, shorter than $\alpha-\mathrm{Fe}_{2} \mathrm{O}_{3}$ or $\mathrm{MoS}_{2}$ devices. The enhancement of the sensing performance of the $\alpha-\mathrm{Fe}_{2} \mathrm{O}_{3} / \mathrm{MoS}_{2}$ was attributed to the increase in the active sites for gas molecules adsorption, such as defects or oxygen vacancies, when $\alpha-\mathrm{Fe}_{2} \mathrm{O}_{3}$ into $\mathrm{MoS}_{2}$ nanosheets.

Yan et al. prepared another 2D TMD-MO $\left(\mathrm{SnO}_{2}-\mathrm{MoS}_{2}\right)$ composite sensor with $p-n$ junction for ethanol detection. The composite was prepared by hydrothermal co-treatment of tin and molybdenum salts [208]. The sensor casted on an aluminium tube attached to gold electrodes, while supplied with a $\mathrm{Ni} / \mathrm{Cr}$ heater inside the tube. The changes in the resistance of the sensor were used to measure the amount of ethanol in its surrounding atmosphere. A response as high as $120\left(R_{\mathrm{a}} / R_{\mathrm{g}}\right)$ was obtained for ethanol at $280{ }^{\circ} \mathrm{C}$ when the heterostructure was used, compared to a response of about $40\left(R_{\mathrm{a}} / R_{\mathrm{g}}\right)$ at an optimum temperature about $350^{\circ} \mathrm{C}$ when $\mathrm{SnO}_{2}$ film was used. The $\mathrm{SnO}_{2}-\mathrm{MoS}_{2}$ composite sensors also showed good selectivity towards ethanol.

$\mathrm{ZnO}$ nanoparticles on $\mathrm{MoS}_{2}$ nanosheets were another composite with $p-n$ heterojunctions that have been tested for ethanol detection. The composite was prepared using two hydrothermal steps to produce 2D flower-like structure consisting of $\mathrm{MoS}_{2}$ nanosheets decorated with $10 \mathrm{~nm}$ particles of $\mathrm{ZnO}$ [209]. Investigating the sensing properties of the nanocomposite at different temperatures showed that the response to ethanol reached a peak of about 42 at about $260{ }^{\circ} \mathrm{C}$. The response at all temperatures was higher than that of $\mathrm{ZnO}$ nanoparticle, nanorods, and flower-like nanostructure, proving the role of the $p-n$ junction on enhancing the performance of the sensor. The electrode showed good response at various concentration of ethanol in the range of 50-1000 ppm, unlike the $\mathrm{ZnO}$ electrode, which was less sensitive at low gas concentration. The $\mathrm{ZnO}-\mathrm{MoS}_{2}$ electrode was more sensitive to ethanol than other tested gases, including methanol and ammonia, which makes the electrode suitable for selective detection. Jha et al. prepared composite of $\mathrm{WO}_{3} / \mathrm{WS}_{2}$ by sonicating a mixture of bulk 
oxides in isopropyl. The sensor fabricated from $\mathrm{WO}_{3} / \mathrm{WS}_{2}$ composites showed more selectivity towards ammonia and a lower response to small alcohols [220]. It should be mentioned here that there are some reports about $\mathrm{WO}_{3}$ changing its conductivity when the bulk particles are sonicated to the nano level, and therefore, the $\mathrm{WO}_{3} / \mathrm{WS}_{2}$ composite may not have enough $p-n$ junctions to facilitate the electron transferee and work as active sites to attract oxygen from alcohol.

Fibre optics are well-known types of optical sensors and biosensors that apply optical fibres as transducers for light which showed a good application in sensor development for environmental, medical, and chemical purposes [254-256]. Studies on 2D materials, such as GO which showed low reflective indexes [257], give the idea that the low refractive index difference between refractive indexes of fibres core and layers of 2D materials could be used to develop an optical sensor, where using a different number of (2D material) layers could affect the sensitivity of the sensor [104]. This finally leads to using various 2D materials in the construction of fibre optics to detect different analytes such as humidity or $\mathrm{NH}_{3}$ [258-260]. Very recently, the application of 2D materials in the development of novel fibre optics for detection of alcohols in near IR region is reported [102, 223]; both sensors [102, 223] responded towards simple alcohols, yet the fluoride-graphene sensor showed a peak for ethanol at higher degrees (angle) comparing to methanol, while it is completely the opposite for the polymer-MoS $\mathrm{M}_{2}$ sensor. The polymer-MoS $\mathrm{S}_{2}$ sensor is actually made of a samarium doped chalcogenide $\left(\mathrm{Se}_{95} \mathrm{Te}_{5} \mathrm{Sm}_{0.25}\right)$ as fibre core which covered with four layers namely a clad (perfluorinated polymer), $\mathrm{Ag}$ (42 nm thick), $\mathrm{MoS}_{2}$ (0.71 nm thick), and polythiophene ( $7 \mathrm{~nm}$ thick) from the core to outside. The detection mechanism is based on measuring the power loss occurred in the SPR sensing region; connected processing system shows this power loss as a sharp peak, and in the presence of alcohols, this peak shows a shift [223].

Laser sources of longer NIR wavelength lead to a better detection limit of the sensor. However, it decreases the sensitivity of the sensor in both mentioned sensors. A U-bent optical fibre sensor made of a polymethylmethacrylate core which is coated with GO and showed a sensory behaviour against solvents from simple alcohols to more complex organic solvents [104]. For coating the surface with GO, the hexamethylenedi-amine functionalised U-bent plastic optical fibre (BPOF) probes are simply dipped in different concentrations of GO solution (GO dispersed in water by sonication) and experience heat treatment for $24 \mathrm{~h}$. Control probe (bare) and GO covered probes were coupled to a halogen light source from one side and a spectrometer from the other side to study the response of the developed sensor. It was suggested that by adding alcohols to the sensing environment, the absorbance of the sensor increased due to alcohols ability to effectively intercalate the GO layers and increasing the RI of the GO layer. This increase in RI around fibre core reduces the RI contrast and thus leads to improved absorbance response; however, alcohol might also react with the functionalisations and removes some of it to affect the RI contrast. The surface structure was scanned with Raman after various heating periods in the incubator, and the most uniform structure was obtained after $24 \mathrm{~h}$ heating. The highest tested coating concentration of GO $\left(100 \mu \mathrm{L} \mathrm{mg}^{-1}\right)$ presented the best sensitivity among all [104].

It has been suggested that few layered black phosphorus (BP) could be used for detecting alcohols like methanol with a limit of detection (LoD) of about 28 ppm [261]. However, black phosphorus, as opposed to phosphorene, is considered more of bulk material and its stability, especially against moisture, is low. Its application for sensing chemicals other than $\mathrm{H}_{2} \mathrm{O}$ seems to be far from implementation, especially for complex matrixes, so it is not discussed in this paper.

The ability of $h$-BN to detect small alcohols is not in question, whether in solo [218] or heterostructure form [262], but if there are more complex organic molecules in the matrix, such as petroleum gases or chloroform, it will be preferentially attracted to them over small alcohols like ethanol [263]. This attraction towards larger organic/bio-organic molecules along with the huge surface of $2 \mathrm{D} h$-BN has even lead to the development of single-molecule detection systems to detect certain analytes like DNA [264]. Surface modification could change this trade and allow $h$-BN to work as a more selective sensor for small alcohols.

Despite available methods that can directly measure ethanol in various matrices such as body fluids or vapours, the lifetime of ethanol in the body is short and its metabolic pathway will rapidly distribute it through the body. Especially when it comes to medical, forensic, or even workplace alcohol consumption tests, some of the ethanol metabolites can be used to measure alcohol intake, indirectly. Ethyl glucuronide (EtG), ethyl sulphate (EtS), fatty acid ethyl esters (FAEEs), and phosphatidylethanol (PEth) are some of the main biomolecules and biomarkers which are currently used in the examination of alcohol drinking 
and in monitoring therapeutic procedures [265-267]. The level of these ethanol metabolites is mostly studied and measured through analysing different body fluids or tissues (hair, nail, meconium, blood, etc.) by various chromatography approaches, mainly GC-MS/MS and LC-MS/MS [5, 265, 266, 268-272]. Due to the complexity and high costs of these techniques, demand for easy to use, cheaper, and portable sensors is slowly rising, and to address this issue, nanosensors could come in use [273-275]. In a very recent study, $\mathrm{ZnO}$ was used in developing an electrochemical immunosensor [274]. Firstly, a thin layer of $\mathrm{Au}(60 \mathrm{~nm}$ thickness) is deposited on a flexible polyethylene terephthalate (PET) substrate through e-beam evaporation. Afterwards, $2 \mathrm{D} \mathrm{ZnO}$ is separately prepared and then sonicated in the presence of $\mathrm{Au}-\mathrm{PET}$ substrate, while the temperature is kept below $50{ }^{\circ} \mathrm{C}$ during sonication. Then, the developed composite is rinsed with water and dried under $\mathrm{N}_{2}$ before the addition of antibody. Finally, EtG antibody is immobilised on the sensor by its electrostatic interactions with $\mathrm{ZnO}$. Added 2D ZnO actually worked as a glue which assists the binding of the antibody to the surface of the sensor without any need for an additional layer to make and maintain this link. The biosensor offers an LoD of $1 \mathrm{ng} \mathrm{mL}^{-1}$ and a linear range up to $100 \mu \mathrm{g} \mathrm{mL}^{-1}$ for ethyl glucuronide. Correspondingly, when it comes to forensic or pharmaceutical studies, working towards developing selective sensors to detect ethanol metabolites could be an interesting field of work and 2D materials for example graphene or metal oxides could offer many benefits from mechanical strength and flexibility to high conductivity and affordability for such sensors.

\section{A Comparison Between Nanosensors}

Other than the examples of chemical sensors and conventional alcohol sensing methods which were discussed in the introduction of this paper, a lot of different nanosensors with various nanomorphologies have been developed for alcohol sensing purposes, including zero-dimensional nanoparticles (0D, such as clusters, spheres, and dots), one-dimensional nanomorphologies (1D, such as tubes, wires, rods, and fibres) and their combinations. Here, some of those alcohol nanosensors are discussed briefly (Table 2) to present a comparison with two-dimensional morphologies in terms of detection limits, sensitivity, and selectivity. The sensing mechanism is similar, regardless of changes in nanomorphology. In many cases, the sensing mechanism is based on the interaction between the reductive gases and the oxygen on the surface of sensors. This oxygen adoption on the surface of the sensor stops free electrons from the conduction band forming a space charge layer and eventually results in a higher resistance. The exposure to reductive gas molecules releases the trapped electrons back to the conduction band and increases carrier concentration which leads to a decrease in the resistances of sensors [276].

Through comparison of several sensors with similar molecular structures that possess different morphologies,

Table 2 Analytical parameters of alcohol nanosensors and biosensors, sorted by LoD and type

\begin{tabular}{|c|c|c|c|c|c|}
\hline Nos. & Analyte detected & Sensing materials & Limit of detection & Sensing matrix & References \\
\hline 1 & Ethanol and NADH & SWCNT-PBCP & $0.1 \mathrm{mmol} \mathrm{L}^{-1}$ & Liquid & [277] \\
\hline 2 & Ethanol and NADH & $A u-A g N P s / P(C y s) / r G O$ & $5 \mathrm{ppm}$ & Liquid & {$[21]$} \\
\hline 3 & Ethanol & PbS QDs/ZnO NRs & $100 \mathrm{ppm}$ & Gas & [278] \\
\hline 4 & Ethanol & ZnO NRs/MWCNTs & $5 \mathrm{ppm}$ & Gas & [279] \\
\hline 5 & Ethanol & $\mathrm{ZnO} / \mathrm{MoS}_{2}$ & $50 \mathrm{ppm}$ & Gas & [209] \\
\hline 6 & Ethanol & $\mathrm{ZnO} / \mathrm{GO}$ & $10 \mathrm{ppm}$ & Gas & [211] \\
\hline 7 & Ethanol & $\alpha-\mathrm{Fe}_{2} \mathrm{O}_{3}$ nanofibres & 100 ppm & Gas & {$[280]$} \\
\hline 8 & Ethanol & $\alpha-\mathrm{Fe}_{2} \mathrm{O}_{3} / \mathrm{MoS}_{2}$ & $1 \mathrm{ppm}$ & Gas & [213] \\
\hline 9 & Ethanol & $\mathrm{Ag} / \mathrm{TiO}_{2}$ nanobelts & $300 \mathrm{ppm}$ & Gas & [281] \\
\hline 10 & $\begin{array}{l}\text { Ethanol, ammonia, methanol, } \\
\text { and acetone }\end{array}$ & $\mathrm{TiO}_{2} / \mathrm{GO}$ & $100 \mathrm{ppm}$ & Gas & [202] \\
\hline 11 & Ethanol & Ni-doped $\mathrm{SnO}_{2}$ & $0.6 \mathrm{nM}$ & Gas & [282] \\
\hline 12 & Ethanol & $\mathrm{SnO}_{2}$ & $5 \mathrm{ppm}$ & Gas & [212] \\
\hline
\end{tabular}

Rows that contain 2D sensors are showed in italic 
one can see 2D-based sensors are working better in terms of detection limits or response times. For example, the LoD of a 2D graphene-based sensor which is based on alcohol dehydrogenases [21] is 20 times better than the LoD of carbon nanotube-based 1D sensor which utilises the same enzyme for sensing ethanol [277]. Another example is $\alpha-\mathrm{Fe}_{2} \mathrm{O}_{3}$ nanofibres prepared by an electrospinning process which showed a LoD of $100 \mathrm{ppm}$ as well as a fast response and recovery of 3 and $5 \mathrm{~s}$, respectively. A 2D-based sensor of $\alpha-\mathrm{Fe}_{2} \mathrm{O}_{3}$ with $\mathrm{MoS}_{2}$ showed a LoD of $1 \mathrm{ppm}$ for ethanol [213], which is 100 times greater than the 1D morphology (nanofibre) of similar chemical composition [280]. A composite made of $\mathrm{PbS}$ QDs and $\mathrm{ZnO}$ NRs developed a porous flower-like nanostructure which was able to sense ethanol gas at room temperature with a detection limit of $100 \mathrm{ppm}$ [278].

Another room temperature ethanol gas sensor was developed from combination of two 1D nanoparticles, i.e. $\mathrm{ZnO}$ nanorods and multi-walled carbon nanotubes (MWCNTs). The linear range of the sensor was reported to be between 5 and $5000 \mathrm{ppm}$, while the response time of the sensor against $50 \mathrm{ppm}$ ethanol was found to be about $7 \mathrm{~s}$ which was almost half of pure $\mathrm{ZnO}$ response (13 s) to the same amount of ethanol [279]. A sensor based on a 2D hybrid that contains $\mathrm{ZnO}$ and graphene was able to achieve a detection limit of $10 \mathrm{ppm}$, which is 10 times better than that of QDs and 5 times better than 1D based sensor [213]. $1 \mathrm{D} \mathrm{TiO}_{2}$ nanobelts and $\mathrm{Ag}-\mathrm{TiO}_{2}$ nanobelts were used to formulate an ethanol sensor; the response time and the sensitivity for different concentrations of ethanol from 5 to $500 \mathrm{ppm}$ were tested, and they were weak below $300 \mathrm{ppm}$ [281]. On the other hand, a sensor developed from 2D $\mathrm{TiO}_{2}$ offers much better sensitivity (100 ppm), yet the 1D sensors seem to work better in terms of selectivity [202]. Choi et al. conducted a systematic study using four different morphologies of $\mathrm{Co}_{3} \mathrm{O}_{4}$ as gas sensors [283]. Almost all of the structures responded selectively towards ethanol, compared to other tested gases (hydrogen and carbon dioxide). A comparison of agglomerated micro-size powders of $\mathrm{Co}_{3} \mathrm{O}_{4}$, its nanosheets, nanorods, and nanocubes showed that nanosheets had the strongest response to ethanol. $\mathrm{Co}_{3} \mathrm{O}_{4}$ nanosheet showed a response of $57.7 R_{\mathrm{g}} / R_{\mathrm{a}}$ towards $100 \mathrm{ppm}$ of ethanol, while nanorods, nanocubes, and micro-powder showed $R_{\mathrm{g}} / R_{\mathrm{a}}$ responses of 25.7, 24.7, and 5.5 , respectively.

\section{Concluding Remarks and Outlook}

The potential applications of ultrathin materials in sensing and biosensing are persuading increasing numbers of scholars to probe deeply into their properties and applications. 2D materials are promising elements of electrochemical and optical sensors. With the outstanding surface to mass ratio and unique physical and chemical properties, 2D materials are able to provide an extensive library of additional candidates for broad applications in developing sensors. In this review, we first discussed the chemical and physical characteristics of stable 2D materials with application in alcohol sensing and looked at some of their synthesis methods. Then, we briefly addressed the fundamentals of the sensors and how 2D materials could benefit the development of sensors and biosensors. Finally, a comprehensive review of selected examples of 2D materials as highly sensitive sensors for industrial, forensic, pharmaceutical, and analytical study of alcohols was presented to the reader.

Graphene is still one of the most widely used 2D materials for general sensory uses, and it also works as a perfect substrate for coupling with other chemicals or biochemicals in order to amplify the selectivity of the sensor, but other 2D materials, as discussed in this paper, are proved to offer better properties such as improved LoD, different working temperature and so forth. One of the main challenges in the way of exploration of 2D materials' properties, function, and applications, other than graphene, is the lack of facile, feasible, and reliable methods for largescale preparation and sealing them. The second field to work on is finding functionalisation methods and developing methods to anchor selective receptors directly on the surface of 2D materials, which is still the matter in question even for well-established reduced graphene oxide layers. Also, as proved, a combination of two different 2D materials leads to optimised properties and searching to find other possible combinations for various uses could be another field of study for the future. Using GO-based solid-state electrolyte films to replace conventional liquid acids was an example of how 2D materials could work towards evolving old technologies. Promising applications of MOFs in sensing alcohols could be merged with the benefits of 2D morphologies, to achieve characteristics such as larger surface area to achieve lower detection limits. Deeper investigations on the 2D sensors' selectivity, 
multiplexity, durability, and reusability can help better understanding of their nature and help scholars to focus more on composites which may offer better application for industrial developments. Large surface of thin materials improves the interactions between sensor and matrix, yet in some of the discussed sensors, their functional groups and sensing mechanisms play a more important role than their thickness to sense alcohols. Doping metal oxide nanosensors with other metals can drastically improve their sensing characteristics in terms of selectivity and sensitivity as it can be seen for $\mathrm{SnO}_{2}$ in Table 2. One of the main things that we understand from analysis of the literature is that real samples, especially biological samples, such as blood, are not well studied yet and most of the real samples were artificial, laboratory-made samples like a mixture of gases in a certain range; so working towards developing an alcohol sensor to work in relatively lower temperatures with application in bio-analytical studies could be an interesting field of study for 2D sensors. We hope this review will guide future developments that can enhance new sensory technologies which not only respond to industrial demands, but also protect our environment, health, and safety.

Open Access This article is licensed under a Creative Commons Attribution 4.0 International License, which permits use, sharing, adaptation, distribution and reproduction in any medium or format, as long as you give appropriate credit to the original author(s) and the source, provide a link to the Creative Commons licence, and indicate if changes were made. The images or other third party material in this article are included in the article's Creative Commons licence, unless indicated otherwise in a credit line to the material. If material is not included in the article's Creative Commons licence and your intended use is not permitted by statutory regulation or exceeds the permitted use, you will need to obtain permission directly from the copyright holder. To view a copy of this licence, visit http://creativecommons.org/licenses/by/4.0/.

\section{References}

1. M.A. Hamburg, Advancing regulatory science. Science 331(6020), 987 (2011). https://doi.org/10.1126/science.12044 32

2. J. Sultana, M.S. Islam, K. Ahmed, A. Dinovitser, B.W.H. Ng, D. Abbott, Terahertz detection of alcohol using a photonic crystal fiber sensor. Appl. Opt. 57(10), 2426-2433 (2018). https://doi.org/10.1364/AO.57.002426

3. U.A. Kirgöz, D. Odaci, S. Timur, A. Merkoçi, S. Alegret, N. Beşün, A. Telefoncu, A biosensor based on graphite epoxy composite electrode for aspartame and ethanol detection. Anal. Chim. Acta 570(2), 165-169 (2006). https://doi. org/10.1016/j.aca.2006.04.010

4. A.M. Azevedo, D.M.F. Prazeres, J.M.S. Cabral, L.P. Fonseca, Ethanol biosensors based on alcohol oxidase. Biosens. Bioelectron. 21(2), 235-247 (2005). https://doi.org/10.1016/j. bios.2004.09.030

5. R. Paul, L. Tsanaclis, C. Murray, R. Boroujerdi, L. Facer, A.J.A. Corbin, Ethyl glucuronide as a long-term alcohol biomarker in fingernail and hair. Matrix comparison and evaluation of gender bias. Alcohol Alcohol. 54(4), 402-407 (2019). https://doi.org/10.1093/alcalc/agz015

6. R.P. Pohanish, Sittig's Handbook of Toxic and Hazardous Chemicals and Carcinogens (William Andrew, Norwich, 2008)

7. K. Triyana, A. Sembiring, A. Rianjanu, S.N. Hidayat, R. Riowirawan et al., Chitosan-based quartz crystal microbalance for alcohol sensing. Electronics 7(9), 181 (2018). https://doi. org/10.3390/electronics7090181

8. W.R. de Araujo, T.M.G. Cardoso, R.G. da Rocha, M.H.P. Santana, R.A.A. Muñoz et al., Portable analytical platforms for forensic chemistry: a review. Anal. Chim. Acta 1034, 1-21 (2018). https://doi.org/10.1016/j.aca.2018.06.014

9. V. García-Cañas, C. Simó, M. Herrero, E. Ibáñez, A. Cifuentes, Present and future challenges in food analysis: foodomics. Anal. Chem. 84(23), 10150-10159 (2012). https ://doi.org/10.1021/ac301680q

10. B.B. Dzantiev, N.A. Byzova, A.E. Urusov, A.V. Zherdev, Immunochromatographic methods in food analysis. Trends Anal. Chem. 55, 81-93 (2014). https://doi.org/10.1016/j. trac.2013.11.007

11. A.W. Martinez, S.T. Phillips, G.M. Whitesides, E. Carrilho, Diagnostics for the developing world: microfluidic paperbased analytical devices. Anal. Chem. 82(1), 3-10 (2010). https://doi.org/10.1021/ac9013989

12. A. Escarpa, Lights and shadows on food microfluidics. Lab Chip 14(17), 3213-3224 (2014). https://doi.org/10.1039/ c4lc00172a

13. E.M.A. Ali, H.G.M. Edwards, The detection of flunitrazepam in beverages using portable raman spectroscopy. Drug Test. Anal. 9(2), 256-259 (2017). https://doi.org/10.1002/dta.1969

14. W.W. Yu, I.M. White, Inkjet-printed paper-based SERS dipsticks and swabs for trace chemical detection. Analyst 138(4), 1020-1025 (2013). https://doi.org/10.1039/c2an36116g

15. T. Mostowtt, B. McCord, Surface enhanced raman spectroscopy (SERS) as a method for the toxicological analysis of synthetic cannabinoids. Talanta 164, 396-402 (2017). https ://doi.org/10.1016/j.talanta.2016.11.002

16. M.M. Ayad, N. Salahuddin, I.M. Minisy, Detection of some volatile organic compounds with chitosan-coated quartz crystal microbalance. Des. Monomers Polym. 17(8), 795-802 (2014). https://doi.org/10.1080/15685551.2014.918019

17. R.-J. Hwang, J. Beltran, C. Rogers, J. Barlow, G. Razatos, Measurement of uncertainty for blood alcohol concentration by headspace gas chromatography. Can. Soc. Forensic 
Sci. J. 50(3), 114-124 (2017). https://doi.org/10.1080/00085 030.2017.1312069

18. A. Pérez-Ponce, S. Garrigues, M. de la Guardia, Vapour generation-fourier transform infrared direct determination of ethanol in alcoholic beverages. Analyst 121(7), 923-928 (1996). https://doi.org/10.1039/AN9962100923

19. Y. Jung, J. Kim, O. Awofeso, H. Kim, F. Regnier, E. Bae, Smartphone-based colorimetric analysis for detection of saliva alcohol concentration. Appl. Opt. 54(31), 9183-9189 (2015). https://doi.org/10.1364/AO.54.009183

20. J.T.S. Allan, H.L. Geoffrey, E.B. Easton, The effect of the gas diffusion layer on the performance of fuel cell catalyst layers in ethanol sensors. Sens. Actuators B 254, 120-132 (2018). https://doi.org/10.1016/j.snb.2017.07.056

21. G.A. Tiğg, Highly sensitive amperometric biosensor for determination of NADH and ethanol based on $\mathrm{Au}-\mathrm{Ag}$ nanoparticles/poly(L-cysteine)/reduced graphene oxide nanocomposite. Talanta 175, 382-389 (2017). https://doi.org/10.1016/j.talan ta.2017.07.073

22. S. Cinti, M. Basso, D. Moscone, F. Arduini, A paper-based nanomodified electrochemical biosensor for ethanol detection in beers. Anal. Chim. Acta 960, 123-130 (2017). https://doi. org/10.1016/j.aca.2017.01.010

23. B. Kuswandi, T. Irmawati, M. Hidayat, M.J.S. Ahmad, A simple visual ethanol biosensor based on alcohol oxidase immobilized onto polyaniline film for halal verification of fermented beverage samples. Sensors 14(2), 2135-2149 (2014). https://doi.org/10.3390/s140202135

24. Z. Zhu, C.-T. Kao, R.-J. Wu, A highly sensitive ethanol sensor based on $\mathrm{Ag} @ \mathrm{TiO}_{2}$ nanoparticles at room temperature. Appl. Surf. Sci. 320, 348-355 (2014). https://doi.org/10.1016/j. apsusc.2014.09.108

25. X.J. Li, S.J. Chen, C.Y. Feng, Characterization of silicon nanoporous pillar array as room-temperature capacitive ethanol gas sensor. Sens. Actuators B 123(1), 461-465 (2007). https://doi.org/10.1016/j.snb.2006.09.021

26. W. Muangrat, W. Wongwiriyapan, S. Morimoto, Y. Hashimoto, Graphene nanosheet-grafted double-walled carbon nanotube hybrid nanostructures by two-step chemical vapor deposition and their application for ethanol detection. Sci. Rep. 9(1), 7871 (2019). https://doi.org/10.1038/s4159 8-019-44315-y

27. R. Bajpai, A. Motayed, A.V. Davydov, V.P. Oleshko, G.S. Aluri et al., UV-assisted alcohol sensing using $\mathrm{SnO}_{2}$ functionalized gan nanowire devices. Sens. Actuators B 171-172, 499-507 (2012). https://doi.org/10.1016/j. snb.2012.05.018

28. J. Wei, X. Li, Y. Han, J. Xu, H. Jin et al., Highly improved ethanol gas-sensing performance of mesoporous nickel oxides nanowires with the stannum donor doping. Nanotechnology 29(24), 245501 (2018). https://doi.org/10.1088/13616528/aab9d8

29. V. Pentyala, P. Davydovskaya, M. Ade, R. Pohle, G.J.S. Urban, A.B. Chemical, Metal-organic frameworks for alcohol gas sensor. Sens. Actuators B 222, 904-909 (2016). https ://doi.org/10.1016/j.snb.2015.09.014
30. W. Vandezande, K.P. Janssen, F. Delport, R. Ameloot, D.E. De Vos, J. Lammertyn, M. Roeffaers, Parts per million detection of alcohol vapors via metal organic framework functionalized surface plasmon resonance sensors. Anal. Chem. 89(8), 4480-4487 (2017). https://doi.org/10.1021/acs.analc hem.6b04510

31. A.G. Cavinato, D.M. Mayes, Z. Ge, J.B. Callis, Noninvasive method for monitoring ethanol in fermentation processes using fiber-optic near-infrared spectroscopy. Anal. Chem. 62(18), 1977-1982 (1990). https://doi.org/10.1021/ac002 $17 \mathrm{a} 015$

32. M. Parthibavarman, S. Sangeetha, B. Renganathan, R. BoopathiRaja, High-performance fiber optic gas sensor-based $\mathrm{Co}_{3} \mathrm{O}_{4}$ /mwcnt composite by a novel microwave technique. J. Iran. Chem. Soc. 16(11), 2463-2472 (2019). https://doi. org/10.1007/s13738-019-01717-z

33. M. Mitsushio, T. Masunaga, T. Yoshidome, M. Higo, Alcohol selectivity and measurement of ethanol concentrations in liquors using teflon ${ }^{\circledR}$ af 2400 -coated gold-deposited surface plasmon resonance-based glass rod sensor. Prog. Org. Coat. 91, 33-38 (2016). https://doi.org/10.1016/j.porgcoat.2015.11.014

34. M. Akamatsu, T. Mori, K. Okamoto, H. Komatsu, K. Kumagai et al., Detection of ethanol in alcoholic beverages or vapor phase using fluorescent molecules embedded in a nanofibrous polymer. ACS Appl. Mater. Interfaces 7(11), 6189-6194 (2015). https://doi.org/10.1021/acsami.5b00289

35. Z.H. Zhang, R. Lockwood, J.G.C. Veinot, A. Meldrum, Detection of ethanol and water vapor with silicon quantum dots coupled to an optical fiber. Sens. Actuators B 181, 523528 (2013). https://doi.org/10.1016/j.snb.2013.01.070

36. A.K. Geim, K.S. Novoselov, The rise of graphene. Nat. Mater. 6(3), 183-191 (2007). https://doi.org/10.1038/nmat1849

37. H. Zhang, Ultrathin two-dimensional nanomaterials. ACS Nano 9(10), 9451-9469 (2015). https://doi.org/10.1021/acsna no. 5 b05040

38. X. Huang, C. Tan, Z. Yin, H. Zhang, 25th anniversary article: hybrid nanostructures based on two-dimensional nanomaterials. Adv. Mater. 26(14), 2185-2203 (2014). https://doi. org/10.1002/adma.201304964

39. J. Park, J. Kim, K. Kim, S.-Y. Kim, W.H. Cheong et al., Wearable, wireless gas sensors using highly stretchable and transparent structures of nanowires and graphene. Nanoscale 8(20), 10591-10597 (2016). https://doi. org/10.1039/C6NR01468B

40. S. Kabiri Ameri, R. Ho, H. Jang, L. Tao, Y. Wang et al., Graphene electronic tattoo sensors. ACS Nano 11(8), 7634-7641 (2017). https://doi.org/10.1021/acsnano.7b021 82

41. G. Ko, H.Y. Kim, J. Ahn, Y.M. Park, K.Y. Lee, J. Kim, Graphene-based nitrogen dioxide gas sensors. Curr. Appl. Phys. 10(4), 1002-1004 (2010). https://doi.org/10.1016/j. cap.2009.12.024

42. G. Neri, Thin 2D: the new dimensionality in gas sensing. Chemosensors 5(3), 21 (2017). https://doi.org/10.3390/ chemosensors 5030021 
43. H. Morgan, C.S. Rout, D.J. Late, in Chapter 14-Future Prospects of 2D Materials for Sensing Applications. ed. by M. Hywel, C.S. Rout, D.J. Late (Woodhead Publishing, 2019), pp. 481-482. https://doi.org/10.1016/B978-0-08102577-2.00014-2

44. A. Nisha, P. Maheswari, P.M. Anbarasan, K.B. Rajesh, Z. Jaroszewicz, Sensitivity enhancement of surface plasmon resonance sensor with 2D material covered noble and magnetic material (Ni). Opt. Quantum Electron. 51(1), 19 (2019). https://doi.org/10.1007/s11082-018-1726-3

45. F. Xia, H. Wang, D. Xiao, M. Dubey, A. Ramasubramaniam, Two-dimensional material nanophotonics. Nat. Photon. 8(12), 899-907 (2014). https://doi.org/10.1038/nphoton.2014.271

46. A.D. Franklin, Nanomaterials in transistors: from highperformance to thin-film applications. Science 349(6249), aab2750 (2015). https://doi.org/10.1126/science.aab2750

47. P. Miró, M. Audiffred, T. Heine, An atlas of two-dimensional materials. Chem. Soc. Rev. 43(18), 6537-6554 (2014). https ://doi.org/10.1039/c4cs00102h

48. C. Tan, X. Cao, X.J. Wu, Q. He, J. Yang et al., Recent advances in ultrathin two-dimensional nanomaterials. Chem. Rev. 117(9), 6225-6331 (2017). https://doi.org/10.1021/acs. chemrev.6b00558

49. H. Zeng, X. Cui, An optical spectroscopic study on twodimensional group-vi transition metal dichalcogenides. Chem. Soc. Rev. 44(9), 2629-2642 (2015). https://doi. org/10.1039/c4cs00265b

50. X. Kong, Q. Liu, C. Zhang, Z. Peng, Q. Chen, Elemental two-dimensional nanosheets beyond graphene. Chem. Soc. Rev. 46(8), 2127-2157 (2017). https://doi.org/10.1039/c6cs0 $0937 \mathrm{a}$

51. Y. Guo, K. Xu, C. Wu, J. Zhao, Y. Xie, Surface chemicalmodification for engineering the intrinsic physical properties of inorganic two-dimensional nanomaterials. Chem. Soc. Rev. 44(3), 637-646 (2015). https://doi.org/10.1039/c4cs0 $0302 \mathrm{k}$

52. H. Liu, Y. Du, Y. Deng, P.D. Ye, Semiconducting black phosphorus: synthesis, transport properties and electronic applications. Chem. Soc. Rev. 44(9), 2732-2743 (2015). https://doi. org/10.1039/c4cs00257a

53. M. Chhowalla, D. Jena, H. Zhang, Two-dimensional semiconductors for transistors. Nat. Rev. Mater. 1(11), 16052 (2016). https://doi.org/10.1038/natrevmats.2016.52

54. B. Anasori, M.R. Lukatskaya, Y. Gogotsi, 2D metal carbides and nitrides (MXenes) for energy storage. Nat. Rev. Mater. 2(2), 16098 (2017). https://doi.org/10.1038/natrevmats .2016 .98

55. W. Lei, G. Liu, J. Zhang, M. Liu, Black phosphorus nanostructures: recent advances in hybridization, doping and functionalization. Chem. Soc. Rev. 46(12), 3492-3509 (2017). https://doi.org/10.1039/c7cs00021a

56. M.G. Kochameshki, M. Mahmoudian, A. Marjani, K. Farhadi, M. Enayati, H.S. Mollayousefi, Graphene oxide grafted poly(acrylic acid) synthesized via surface initiated raft as a $\mathrm{pH}$-responsive additive for mixed matrix membrane.
J. Appl. Polym. Sci. 136(12), 47213 (2019). https://doi. org/10.1002/app.47213

57. D. Akinwande, N. Petrone, J. Hone, Two-dimensional flexible nanoelectronics. Nat. Commun. 5, 5678 (2014). https://doi. org/10.1038/ncomms6678

58. A. Naseri, R. Barati, F. Rasoulzadeh, M. Bahram, Studies on adsorption of some organic dyes from aqueous solution onto graphene nanosheets. Iran. J. Chem. Chem. Eng. (IJCCE) 34(2), 51-60 (2015)

59. P. Kumar, J. Liu, P. Ranjan, Y. Hu, S.S. Yamijala, S.K. Pati, J. Irudayaraj, G.J. Cheng, Alpha lead oxide $(\alpha-\mathrm{PbO})$ : a new 2D material with visible light sensitivity. Small 14(12), 1703346 (2018). https://doi.org/10.1002/smll.201703346

60. S.J. Choi, I.D. Kim, Recent developments in 2D nanomaterials for chemiresistive-type gas sensors. Electron. Mater. Lett. 14(3), 221-260 (2018). https://doi.org/10.1007/s1339 $1-018-0044-\mathrm{z}$

61. M. Akhtar, G. Anderson, R. Zhao, A. Alruqi, J.E. Mroczkowska, G. Sumanasekera, J.B. Jasinski, Recent advances in synthesis, properties, and applications of phosphorene. NPJ 2D Mater. Appl. 1, 5 (2017). https://doi.org/10.1038/s4169 9-017-0007-5

62. L. Meng, Y. Wang, L. Zhang, S. Du, R. Wu et al., Buckled silicene formation on $\operatorname{Ir}(111)$. Nano Lett. 13(2), 685-690 (2013). https://doi.org/10.1021/nl304347w

63. M. Fortin-Deschênes, O. Waller, T.O. Menteş, A. Locatelli, S. Mukherjee et al., Synthesis of antimonene on germanium. Nano Lett. 17(8), 4970-4975 (2017). https://doi.org/10.1021/ acs.nanolett.7b02111

64. M. Servalli, A.D. Schlüter, Synthetic two-dimensional polymers. Ann. Rev. Mater. Res. 47, 361-389 (2017). https://doi. org/10.1146/annurev-matsci-070616-124040

65. S. Majdi, A. Jabbari, H. Heli, H. Yadegari, A.A. MoosaviMovahedi, S. Haghgoo, Electrochemical oxidation and determination of ceftriaxone on a glassy carbon and carbonnanotube-modified glassy carbon electrodes. J. Solid State Electrochem. 13(3), 407-416 (2009). https://doi.org/10.1007/ s10008-008-0567-6

66. N. Sattarahmady, H. Heli, S.E. Moradi, Cobalt hexacyanoferrate/graphene nanocomposite-application for the electrocatalytic oxidation and amperometric determination of captopril. Sens. Actuators B 177, 1098-1106 (2013). https://doi. org/10.1016/j.snb.2012.12.035

67. H.Q. Li, R.L. Liu, D.Y. Zhao, Y.Y. Xia, Electrochemical properties of an ordered mesoporous carbon prepared by direct tri-constituent co-assembly. Carbon 45(13), 2628-2635 (2007). https://doi.org/10.1016/j.carbon.2007.08.005

68. A. Rahi, K. Karimian, H. Heli, Nanostructured materials in electroanalysis of pharmaceuticals. Anal. Biochem. 497, 39-47 (2016). https://doi.org/10.1016/j.ab.2015.12.018

69. J.C. Meyer, A.K. Geim, M.I. Katsnelson, K.S. Novoselov, T.J. Booth, S.J.N. Roth, The structure of suspended graphene sheets. Nature 446(7131), 60-63 (2007). https://doi. org/10.1038/nature05545 
70. K.S. Novoselov, A.K. Geim, S.V. Morozov, D. Jiang, Y. Zhang et al., Electric field in atomically thin carbon films. Science 306(5696), 666-669 (2004). https://doi.org/10.1126/ science. 1102896

71. J. Hass, W.A. De Heer, E.H. Conrad, The growth and morphology of epitaxial multilayer graphene. J. Phys.: Condens. Matter 20, 323202 (2008). https://doi.org/10.1038/natur e05545

72. K.S. Novoselov, A.K. Geim, S.V. Morozov, D. Jiang, M.I. Katsnelson, I.V. Grigorieva, S.V. Dubonos, A.A. Firsov, Two-dimensional gas of massless dirac fermions in graphene. Nature 438(7065), 197-200 (2005). https://doi.org/10.1038/ nature 04233

73. Y. Zhang, Y.W. Tan, H.L. Stormer, P. Kim, Experimental observation of the quantum hall effect and berry's phase in graphene. Nature 438(7065), 201-204 (2005). https://doi. org/10.1038/nature04235

74. R.R. Nair, P. Blake, A.N. Grigorenko, K.S. Novoselov, T.J. Booth et al., Fine structure constant defines visual transparency of graphene. Science 320(5881), 1308 (2008). https:// doi.org/10.1126/science. 1156965

75. A.A. Balandin, S. Ghosh, W. Bao, I. Calizo, D. Teweldebrhan, F. Miao, C.N. Lau, Superior thermal conductivity of single-layer graphene. Nano Lett. 8(3), 902-907 (2008). https ://doi.org/10.1021/n10731872

76. C. Lee, X. Wei, J.W. Kysar, J. Hone, Measurement of the elastic properties and intrinsic strength of monolayer graphene. Science 321(5887), 385-388 (2008). https://doi.org/10.1126/ science. 1157996

77. X. Huang, Z. Yin, S. Wu, X. Qi, Q. He et al., Graphenebased materials: synthesis, characterization, properties, and applications. Small 7(14), 1876-1902 (2011). https://doi. org/10.1002/smll.201002009

78. X. Wang, X. Li, Y. Zhao, Y. Chen, J. Yu, J. Wang, The influence of oxygen functional groups on gas-sensing properties of reduced graphene oxide (rGO) at room temperature. RSC Adv. 6(57), 52339-52346 (2016). https://doi.org/10.1039/ c6ra05659h

79. J. Chang, G. Zhou, E.R. Christensen, R. Heideman, J. Chen, Graphene-based sensors for detection of heavy metals in water: a review chemosensors and chemoreception. Anal. Bioanal. Chem. 406(16), 3957-3975 (2014). https://doi. org/10.1007/s00216-014-7804-x

80. B.C. Brodie, On the atomic weight of graphite. Philos. Trans. R. Soc. Lond. 149, 249-259 (1859). https://doi.org/10.1098/ rstl.1859.0013

81. L. Staudenmaier, Verfahren zur darstellung der graphitsäure. Ber. Dtsch. Chem. Ges. 31(2), 1481-1487 (1898). https://doi. org/10.1002/cber.18980310237

82. D.R. Dreyer, S. Park, C.W. Bielawski, R.S. Ruoff, The chemistry of graphene oxide. Chem. Soc. Rev. 39(1), 228-240 (2010). https://doi.org/10.1039/B917103G

83. W.S. Hummers, R.E. Offeman, Preparation of graphitic oxide. J. Am. Chem. Soc. 80(6), 1339 (1958). https://doi. org/10.1021/ja01539a017
84. A.M. Abdelkader, I.A. Kinloch, R.A.W. Dryfe, High-yield electro-oxidative preparation of graphene oxide. Chem. Commun. 50(61), 8402-8404 (2014). https://doi.org/10.1039/ $\mathrm{C} 4 \mathrm{CC} 03260 \mathrm{H}$

85. S. Stankovich, D.A. Dikin, R.D. Piner, K.A. Kohlhaas, A. Kleinhammes et al., Synthesis of graphene-based nanosheets via chemical reduction of exfoliated graphite oxide. Carbon 45(7), 1558-1565 (2007). https://doi.org/10.1016/j.carbo n.2007.02.034

86. S. Pei, J. Zhao, J. Du, W. Ren, H.M. Cheng, Direct reduction of graphene oxide films into highly conductive and flexible graphene films by hydrohalic acids. Carbon 48(15), 44664474 (2010). https://doi.org/10.1016/j.carbon.2010.08.006

87. J. Zhang, H. Yang, G. Shen, P. Cheng, J. Zhang, S. Guo, Reduction of graphene oxide via 1-ascorbic acid. Chem. Commun. 46(7), 1112-1114 (2010). https://doi.org/10.1039/ B917705A

88. E.C. Salas, Z. Sun, A. Lüttge, J.M. Tour, Reduction of graphene oxide via bacterial respiration. ACS Nano 4(8), 48524856 (2010). https://doi.org/10.1021/nn101081t

89. D. Chen, L. Li, L. Guo, An environment-friendly preparation of reduced graphene oxide nanosheets via amino acid. Nanotechnology 22(32), 325601 (2011). https://doi. org/10.1088/0957-4484/22/32/325601

90. Z.J. Fan, W. Kai, J. Yan, T. Wei, L.J. Zhi et al., Facile synthesis of graphene nanosheets via Fe reduction of exfoliated graphite oxide. ACS Nano 5(1), 191-198 (2011). https://doi. org/10.1021/nn102339t

91. R.S. Dey, S. Hajra, R.K. Sahu, C.R. Raj, M.K. Panigrahi, A rapid room temperature chemical route for the synthesis of graphene: metal-mediated reduction of graphene oxide. Chem. Commun. 48(12), 1787-1789 (2012). https://doi. org/10.1039/c2cc16031e

92. Z. Fan, K. Wang, T. Wei, J. Yan, L. Song, B. Shao, An environmentally friendly and efficient route for the reduction of graphene oxide by aluminum powder. Carbon 48(5), 16861689 (2010). https://doi.org/10.1016/j.carbon.2009.12.063

93. H.A. Becerril, J. Mao, Z. Liu, R.M. Stoltenberg, Z. Bao, Y. Chen, Evaluation of solution-processed reduced graphene oxide films as transparent conductors. ACS Nano 2(3), 463470 (2008). https://doi.org/10.1021/nn700375n

94. S. Nandini, S. Nalini, R. Manjunatha, S. Shanmugam, J.S. Melo, G.S. Suresh, Electrochemical biosensor for the selective determination of hydrogen peroxide based on the Codeposition of palladium, horseradish peroxidase on functionalized-graphene modified graphite electrode as composite. J. Electroanal. Chem. 689, 233-242 (2013). https://doi. org/10.1016/j.jelechem.2012.11.004

95. D. Wu, Y. Li, Y. Zhang, P. Wang, Q. Wei, B. Du, Sensitive electrochemical sensor for simultaneous determination of dopamine, ascorbic acid, and uric acid enhanced by amino-group functionalized mesoporous $\mathrm{Fe}_{3} \mathrm{O}_{4} @$ graphene sheets. Electrochim. Acta 116, 244-249 (2014). https://doi. org/10.1016/j.electacta.2013.11.033

96. M. Cittadini, M. Bersani, F. Perrozzi, L. Ottaviano, W. Wlodarski, A. Martucci, Graphene oxide coupled with 
gold nanoparticles for localized surface plasmon resonance based gas sensor. Carbon 69, 452-459 (2014). https://doi. org/10.1016/j.carbon.2013.12.048

97. X. Li, Z. Zheng, X. Liu, S. Zhao, S. Liu, Nanostructured photoelectrochemical biosensor for highly sensitive detection of organophosphorous pesticides. Biosens. Bioelectron. 64, 1-5 (2015). https://doi.org/10.1016/j.bios.2014.08.006

98. P. Ramesh, B. Jebasingh, A facile synthesis of bis(pththalimidoethyl)-amine functionalized graphene oxide and its dual performance as a supercapacitor electrode and fluorescence sensor. Mater. Chem. Phys. 222, 45-54 (2019). https://doi.org/10.1016/j.matchemphys.2018.09.075

99. Q. Zhang, J. Zhao, W. Liu, Y. Yue, K. Yu, D. Xu, X. Ding, Graphene oxide-based fluorescence sensor for betaxolol hydrochloride detection in plasma. J. Chem. Soc. Pak. 40(3), 519-528 (2018)

100. R. Mitra, A. Saha, Reduced graphene oxide based "turn-on" fluorescence sensor for highly reproducible and sensitive detection of small organic pollutants. ACS Sustain. Chem. Eng. 5(1), 604-615 (2017). https://doi.org/10.1021/acssu schemeng.6b01971

101. S.K. Basiruddin, S.K. Swain, Phenylboronic acid functionalized reduced graphene oxide based fluorescence nano sensor for glucose sensing. Mater. Sci. Eng. C 58, 103-109 (2016). https://doi.org/10.1016/j.msec.2015.07.068

102. A.K. Sharma, A. Dominic, Fluoride fiber-optic SPR sensor with graphene and $\mathrm{NaF}$ layers: analysis of accuracy, sensitivity, and specificity in near infrared. IEEE Sens. J. 18(10), 4053-4058 (2018). https://doi.org/10.1109/JSEN.2018.28181 97

103. R. Majidi, A.R. Karami, Caffeine and nicotine adsorption on perfect, defective and porous graphene sheets. Diam. Relat. Mater. 66, 47-51 (2016). https://doi.org/10.1016/j.diamo nd.2016.03.014

104. M. Divagar, A. Gowri, S. John, V.V.R. Sai, Graphene oxide coated U-bent plastic optical fiber based chemical sensor for organic solvents. Sens. Actuators B 262, 1006-1012 (2018). https://doi.org/10.1016/j.snb.2018.02.059

105. H. Teymourian, A. Salimi, S.J.B. Khezrian, $\mathrm{Fe}_{3} \mathrm{O}_{4}$ magnetic nanoparticles/reduced graphene oxide nanosheets as a novel electrochemical and bioeletrochemical sensing platform. Biosens. Bioelectron. 49, 1-8 (2013). https://doi.org/10.1016/j. bios.2013.04.034

106. Z.-H. Sheng, X.-Q. Zheng, J.-Y. Xu, W.-J. Bao, F.-B. Wang, X.-H.J.B. Xia, Bioelectronics. Electrochemical sensor based on nitrogen doped graphene: simultaneous determination of ascorbic acid, dopamine and uric acid. Sens. Actuators B 34(1), 125-131 (2012). https://doi. org/10.1016/j.bios.2012.01.030

107. R. Antiochia, L.J.S. Gorton, A.B. Chemical, A new osmium-polymer modified screen-printed graphene electrode for fructose detection. Sens. Actuators B 195, 287293 (2014). https://doi.org/10.1016/j.snb.2014.01.050

108. N. Ruecha, R. Rangkupan, N. Rodthongkum, O.J.B. Chailapakul, Novel paper-based cholesterol biosensor using graphene/polyvinylpyrrolidone/polyaniline nanocomposite.
Biosens. Bioelectron. 52, 13-19 (2014). https://doi. org/10.1016/j.bios.2013.08.018

109. Y. Song, Y. Luo, C. Zhu, H. Li, D. Du, Y. Lin, Recent advances in electrochemical biosensors based on graphene two-dimensional nanomaterials. Biosens. Bioelectron. 76, 195-212 (2016). https://doi.org/10.1016/j.bios.2015.07.002

110. H. Hashemzadeh, H. Raissi, Covalent organic framework as smart and high efficient carrier for anticancer drug delivery: a DFT calculations and molecular dynamics simulation study. J. Phys. D-Appl. Phys. 51(34), 345401 (2018). https ://doi.org/10.1088/1361-6463/aad3e8

111. Z.B. Liu, Y.F. Xu, X.Y. Zhang, X.L. Zhang, Y.S. Chen, J.G. Tian, Porphyrin and fullerene covalently functionalized graphene hybrid materials with large nonlinear optical properties. J. Phys. Chem. B 113(29), 9681-9686 (2009). https://doi.org/10.1021/jp9004357

112. L. Feng, L. Wu, J. Wang, J. Ren, D. Miyoshi, N. Sugimoto, X. Qu, Detection of a prognostic indicator in earlystage cancer using functionalized graphene-based peptide sensors. Adv. Mater. 24(1), 125-131 (2012). https://doi. org/10.1002/adma.201103205

113. J. Labuta, J.P. Hill, S. Ishihara, L. Hanyková, K. Ariga, Chiral sensing by nonchiral tetrapyrroles. Acc. Chem. Res. 48(3), 521-529 (2015). https://doi.org/10.1021/acs.accou nts. 5 b00005

114. H. Li, G. Lu, Y. Wang, Z. Yin, C. Cong et al., Mechanical exfoliation and characterization of single- and few-layer nanosheets of $\mathrm{WSe}_{2}, \mathrm{TaS}_{2}$, and $\mathrm{TaSe}_{2}$. Small 9(11), 19741981 (2013). https://doi.org/10.1002/smll.201202919

115. Z. Zeng, Z. Yin, X. Huang, H. Li, Q. He, G. Lu, F. Boey, H. Zhang, Single-layer semiconducting nanosheets: highyield preparation and device fabrication. Angew. Chem. Int. Ed. 50(47), 11093-11097 (2011). https://doi.org/10.1002/ anie. 201106004

116. J.N. Coleman, M. Lotya, A. O’Neill, S.D. Bergin, P.J. King et al., Two-dimensional nanosheets produced by liquid exfoliation of layered materials. Science 331(6017), 568-571 (2011). https://doi.org/10.1126/science.1194975

117. K.K. Liu, W. Zhang, Y.H. Lee, Y.C. Lin, M.T. Chang et al., Growth of large-area and highly crystalline $\mathrm{MoS}_{2}$ thin layers on insulating substrates. Nano Lett. 12(3), 1538-1544 (2012). https://doi.org/10.1021/nl2043612

118. W.T. Koo, J.H. Cha, J.W. Jung, S.J. Choi, J.S. Jang, D.H. Kim, I.D. Kim, Few-layered $\mathrm{WS}_{2}$ nanoplates confined in Co, $\mathrm{N}$-doped hollow carbon nanocages: abundant $\mathrm{WS}_{2}$ edges for highly sensitive gas sensors. Adv. Funct. Mater. 28(36), 1802575 (2018). https://doi.org/10.1002/adfm.201802575

119. S.R. Shakil, S.A. Khan, Sensing properties of gas sensor based on adsorption of $\mathrm{NO}_{2}$ with defect, pristine, $\mathrm{Fe}$ and $\mathrm{Si}-$ $\mathrm{MoS}_{2}$ layer. J. Nano Electron. Phys. 6(4), 04004-1 (2014)

120. J.H. Cha, S.J. Choi, S. Yu, I.D. Kim, $2 \mathrm{D} \mathrm{WS}_{2}$-edge functionalized multi-channel carbon nanofibers: effect of $\mathrm{WS}_{2}$ edge-abundant structure on room temperature $\mathrm{NO}_{2}$ sensing. J. Mater. Chem. A 5(18), 8725-8732 (2017). https://doi. org/10.1039/c6ta11019c 
121. Z. Qin, K. Xu, H. Yue, H. Wang, J. Zhang, C. Ouyang, C. Xie, D. Zeng, Enhanced room-temperature $\mathrm{NH}_{3}$ gas sensing by $2 \mathrm{D} \mathrm{SnS}_{2}$ with sulfur vacancies synthesized by chemical exfoliation. Sens. Actuators B 262, 771-779 (2018). https:// doi.org/10.1016/j.snb.2018.02.060

122. Y. Wang, Z. Sofer, J. Luxa, M. Pumera, Lithium exfoliated vanadium dichalcogenides $\left(\mathrm{VS}_{2}, \mathrm{VSe}_{2}, \mathrm{VTe}_{2}\right)$ exhibit dramatically different properties from their bulk counterparts. Adv. Mater. Interfaces 3(23), 1600433 (2016). https://doi. org/10.1002/admi.201600433

123. J. Wu, Y. Lu, Z. Wu, S. Li, Q. Zhang et al., Two-dimensional molybdenum disulfide $\left(\mathrm{MoS}_{2}\right)$ with gold nanoparticles for biosensing of explosives by optical spectroscopy. Sens. Actuators B 261, 279-287 (2018). https://doi.org/10.1016/j. snb.2018.01.166

124. T.D. Thanh, N.D. Chuong, H.V. Hien, T. Kshetri, L.H. Tuan, N.H. Kim, J.H. Lee, Recent advances in two-dimensional transition metal dichalcogenides-graphene heterostructured materials for electrochemical applications. Prog. Mater. Sci. 96, 51-85 (2018). https://doi.org/10.1016/j.pmats ci.2018.03.007

125. X. Cao, Ultra-sensitive electrochemical DNA biosensor based on signal amplification using gold nanoparticles modified with molybdenum disulfide, graphene and horseradish peroxidase. Microchim. Acta 181(9-10), 1133-1141 (2014). https://doi.org/10.1007/s00604-014-1301-y

126. Y. Chu, B. Cai, Y. Ma, M. Zhao, Z. Ye, J. Huang, Highly sensitive electrochemical detection of circulating tumor DNA based on thin-layer $\mathrm{MoS}_{2}$ /graphene composites. RSC Adv. 6(27), 22673-22678 (2016). https://doi.org/10.1039/c5ra2 $7625 \mathrm{j}$

127. K.J. Huang, Y.J. Liu, H.B. Wang, T. Gan, Y.M. Liu, L.L. Wang, Signal amplification for electrochemical DNA biosensor based on two-dimensional graphene analogue tungsten sulfide-graphene composites and gold nanoparticles. Sens. Actuators B 191, 828-836 (2014). https://doi.org/10.1016/j. snb.2013.10.072

128. J. Zhu, E. Ha, G. Zhao, Y. Zhou, D. Huang et al., Recent advance in MXenes: a promising 2D material for catalysis, sensor and chemical adsorption. Coord. Chem. Rev. 352, 306-327 (2017). https://doi.org/10.1016/j.ccr.2017.09.012

129. M. Naguib, M. Kurtoglu, V. Presser, J. Lu, J. Niu et al., Two-dimensional nanocrystals produced by exfoliation of $\mathrm{Ti}_{3} \mathrm{AlC}_{2}$. Adv. Mater. 23(37), 4248-4253 (2011). https:// doi.org/10.1002/adma.201102306

130. M. Naguib, V.N. Mochalin, M.W. Barsoum, Y.J.A.M. Gogotsi, 25th anniversary article: MXenes: a new family of two-dimensional materials. Adv. Mater. 26(7), 992-1005 (2014). https://doi.org/10.1002/adma.201304138

131. M. Ghidiu, M.R. Lukatskaya, M.-Q. Zhao, Y. Gogotsi, M. Barsoum, Conductive two-dimensional titanium carbide 'clay' with high volumetric capacitance. Nature 516(7529), 78-81 (2014). https://doi.org/10.1038/nature13970

132. M.A. Hope, A.C. Forse, K.J. Griffith, M.R. Lukatskaya, M. Ghidiu, Y. Gogotsi, C. Grey, NMR reveals the surface functionalisation of $\mathrm{Ti}_{3} \mathrm{C}_{2}$ MXene. Phys. Chem. Chem. Phys.
18(7), 5099-5102 (2016). https://doi.org/10.1039/C6CP0 0330C

133. P. Urbankowski, B. Anasori, T. Makaryan, D. Er, S. Kota et al., Synthesis of two-dimensional titanium nitride $\mathrm{Ti}_{4} \mathrm{~N}_{3}$ (MXene). Nanoscale 8(22), 11385-11391 (2016). https:// doi.org/10.1039/C6NR02253G

134. B. Xu, M. Zhu, W. Zhang, X. Zhen, Z. Pei, Q. Xue, C. Zhi, P. Shi, Ultrathin MXene-micropattern-based field-effect transistor for probing neural activity. Adv. Mater. 28(17), 3333-3339 (2016). https://doi.org/10.1002/adma.20150 4657

135. Y. Ma, N. Liu, L. Li, X. Hu, Z. Zou et al., A highly flexible and sensitive piezoresistive sensor based on mxene with greatly changed interlayer distances. Nat. Commun. 8(1), 1207 (2017). https://doi.org/10.1038/s41467-017-01136-9

136. F. Wang, C. Yang, M. Duan, Y. Tang, J.J.B. Zhu, $\mathrm{TiO}_{2}$ nanoparticle modified organ-like $\mathrm{Ti}_{3} \mathrm{C}_{2}$ mxene nanocomposite encapsulating hemoglobin for a mediator-free biosensor with excellent performances. Biosens. Bioelectron. 74, 1022-1028 (2015). https://doi.org/10.1016/j.bios.2015.08.004

137. G.S. Papaefstathiou, T. Friščić, L.R. MacGillivray, Design and construction of a 2D metal organic framework with multiple cavities: a nonregular net with a paracyclophane that codes for multiply fused nodes. J. Am. Chem. Soc. 127(41), 14160-14161 (2005). https://doi.org/10.1021/ja054841n

138. T.N. Tu, M.V. Nguyen, H.L. Nguyen, B. Yuliarto, K.E. Cordova, S. Demir, Designing bipyridine-functionalized zirconium metal-organic frameworks as a platform for clean energy and other emerging applications. Coord. Chem. Rev. 364, 33-50 (2018). https://doi.org/10.1016/j.ccr.2018.03.014

139. W. Zhao, J. Peng, W. Wang, S. Liu, Q. Zhao, W. Huang, Ultrathin two-dimensional metal-organic framework nanosheets for functional electronic devices. Coord. Chem. Rev. 377, 44-63 (2018). https://doi.org/10.1016/j. ccr.2018.08.023

140. H. Wang, Q.-L. Zhu, R. Zou, Q. Xu, Metal-organic frameworks for energy applications. Chem 2(1), 52-80 (2017). https://doi.org/10.1016/j.chempr.2016.12.002

141. C. Sengottaiyan, R. Jayavel, R.G. Shrestha, T. Subramani, S. Maji et al., Indium oxide/carbon nanotube/reduced graphene oxide ternary nanocomposite with enhanced electrochemical supercapacitance. Bull. Chem. Soc. Jpn. 92(3), 521-528 (2018). https://doi.org/10.1246/bcsj.20180338

142. X. Wang, C. Chi, K. Zhang, Y. Qian, K.M. Gupta, Z. Kang, J. Jiang, D. Zhao, Reversed thermo-switchable molecular sieving membranes composed of two-dimensional metalorganic nanosheets for gas separation. Nat. Commun. 8, 14460 (2017). https://doi.org/10.1038/ncomms 14460

143. C. Hermosa, B.R. Horrocks, J.I. Martínez, F. Liscio, J. Gómez-Herrero, F. Zamora, Mechanical and optical properties of ultralarge flakes of a metal-organic framework with molecular thickness. Chem. Sci. 6(4), 2553-2558 (2015). https://doi.org/10.1039/C4SC03115F

144. P. Amo-Ochoa, L. Welte, R. González-Prieto, P.J. Sanz Miguel, C.J. Gómez-García et al., Single layers of a multifunctional laminar $\mathrm{Cu}(\mathrm{i}$, ii) coordination polymer. 
Chem. Commun. 46(19), 3262-3264 (2010). https://doi. org/10.1039/B919647A

145. Y. Ding, Y.-P. Chen, X. Zhang, L. Chen, Z. Dong et al., Controlled intercalation and chemical exfoliation of layered metal-organic frameworks using a chemically labile intercalating agent. J. Am. Chem. Soc. 139(27), 9136-9139 (2017). https://doi.org/10.1021/jacs.7b04829

146. J. Huang, Y. Li, R.-K. Huang, C.-T. He, L. Gong et al., Electrochemical exfoliation of pillared-layer metal-organic framework to boost the oxygen evolution reaction. Angew. Chem. Int. Ed. 130(17), 4722-4726 (2018). https://doi. org/10.1002/ange.201801029

147. L. Cao, Z. Lin, F. Peng, W. Wang, R. Huang et al., Self-supporting metal-organic layers as single-site solid catalysts. Angew. Chem. Int. Ed. 55(16), 4962-4966 (2016). https:// doi.org/10.1002/anie.201512054

148. R. Dong, Z. Zheng, D.C. Tranca, J. Zhang, N. Chandrasekhar et al., Immobilizing molecular metal dithiolenediamine complexes on 2D metal-organic frameworks for electrocatalytic $\mathrm{H}_{2}$ production. Chemistry 23(10), 22552260 (2017). https://doi.org/10.1002/chem.201605337

149. A. Pustovarenko, M.G. Goesten, S. Sachdeva, M. Shan, Z. Amghouz et al., Nanosheets of nonlayered aluminum metal-organic frameworks through a surfactant-assisted method. Adv. Mater. 30(26), 1707234 (2018). https://doi. org/10.1002/adma.201707234

150. M. Zhao, Y. Wang, Q. Ma, Y. Huang, X. Zhang et al., Ultrathin 2D metal-organic framework nanosheets. Adv. Mater. 27(45), 7372-7378 (2015). https://doi.org/10.1002/ adma.201503648

151. J. Duan, S. Chen, C. Zhao, Ultrathin metal-organic framework array for efficient electrocatalytic water splitting. Nat. Commun. 8, 15341 (2017). https://doi.org/10.1038/ncomm s15341

152. S. He, Y. Chen, Z. Zhang, B. Ni, W. He, X. Wang, Competitive coordination strategy for the synthesis of hierarchicalpore metal-organic framework nanostructures. Chem. Sci. 7(12), 7101-7105 (2016). https://doi.org/10.1039/C6SC0 $2272 \mathrm{C}$

153. I. Stassen, N. Burtch, A. Talin, P. Falcaro, M. Allendorf, R. Ameloot, An updated roadmap for the integration of metalorganic frameworks with electronic devices and chemical sensors. Chem. Soc. Rev. 46(11), 3185-3241 (2017). https ://doi.org/10.1039/C7CS00122C

154. L. Liu, Y. Zhou, S. Liu, M. Xu, The applications of metal-organic frameworks in electrochemical sensors. ChemElectroChem 5(1), 6-19 (2018). https://doi. org/10.1002/celc.201700931

155. M.G. Campbell, D. Sheberla, S.F. Liu, T.M. Swager, M. Dincă, $\mathrm{Cu}_{3}$ (hexaiminotriphenylene) ${ }_{2}$ : an electrically conductive 2D metal-organic framework for chemiresistive sensing. Angew. Chem. Int. Ed. 54(14), 4349-4352 (2015). https://doi.org/10.1002/anie.201411854

156. R. Boroujerdi, Ce(iii)—porphyrin sandwich complex $\mathrm{Ce}_{2}(\mathrm{tpp})_{3}$ : a rod-like nanoparticle as a fluorescence turnoff probe for detection of $\mathrm{Hg}$ (ii) and $\mathrm{Cu}$ (ii). J. Fluoresc.
26(3), 781-790 (2016). https://doi.org/10.1007/s 1089 5-015-1761-4

157. W.P. Lustig, S. Mukherjee, N.D. Rudd, A.V. Desai, J. Li, S.K. Ghosh, Metal-organic frameworks: functional luminescent and photonic materials for sensing applications. Chem. Soc. Rev. 46(11), 3242-3285 (2017). https://doi.org/10.1039/ C6CS00930A

158. X.-J. Liu, Y.-H. Zhang, Z. Chang, A.-L. Li, D. Tian et al., A water-stable metal-organic framework with a double-helical structure for fluorescent sensing. Inorg. Chem. 55(15), 73267328 (2016). https://doi.org/10.1021/acs.inorgchem.6b00935

159. M. Zhang, G. Feng, Z. Song, Y.-P. Zhou, H.-Y. Chao et al., Two-dimensional metal-organic framework with wide channels and responsive turn-on fluorescence for the chemical sensing of volatile organic compounds. J. Am. Chem. Soc. 136(20), 7241-7244 (2014). https://doi.org/10.1021/ja502 $643 \mathrm{p}$

160. Z.-Q. Li, L.-G. Qiu, W. Wang, T. Xu, Y. Wu, X. Jiang, Fabrication of nanosheets of a fluorescent metal-organic framework $\left[\mathrm{Zn}(\mathrm{bdc})\left(\mathrm{H}_{2} \mathrm{O}\right)\right] \mathrm{n}$ ( $\mathrm{bdc}=1$,4-benzenedicarboxylate): ultrasonic synthesis and sensing of ethylamine. Inorg. Chem. Commun. 11(11), 1375-1377 (2008). https://doi. org/10.1016/j.inoche.2008.09.010

161. P.R. Solanki, A. Kaushik, V.V. Agrawal, B.D. Malhotra, Nanostructured metal oxide-based biosensors. NPG Asia Mater. 3, 17 (2011). https://doi.org/10.1038/asiamat.2010.137

162. K. Shavanova, Y. Bakakina, I. Burkova, I. Shtepliuk, R. Viter et al., Application of 2D non-graphene materials and 2D oxide nanostructures for biosensing technology. Sensors 16(2), 223 (2016). https://doi.org/10.3390/s16020223

163. Y. Shu, J. Xu, J. Chen, Q. Xu, X. Xiao, D. Jin, H. Pang, $X$. Hu, Ultrasensitive electrochemical detection of $\mathrm{H}_{2} \mathrm{O}_{2}$ in living cells based on ultrathin $\mathrm{MnO}_{2}$ nanosheets. Sens. Actuators B 252, 72-78 (2017). https://doi.org/10.1016/j. snb.2017.05.124

164. M.R. Alenezi, A.S. Alshammari, T.H. Alzanki, P. Jarowski, S.J. Henley, S.R.P. Silva, ZnO nanodisk based uv detectors with printed electrodes. Langmuir 30(13), 3913-3921 (2014). https://doi.org/10.1021/la500143w

165. A.P. Dral, J.E. Elshof, 2D metal oxide nanoflakes for sensing applications: review and perspective. Sens. Actuators B 272, 369-392 (2018). https://doi.org/10.1016/j.snb.2018.05.157

166. D. Chen, X. Hou, H. Wen, Y. Wang, H. Wang et al., The enhanced alcohol-sensing response of ultrathin $\mathrm{WO}_{3}$ nanoplates. Nanotechnology 21(3), 035501 (2010). https://doi. org/10.1088/0957-4484/21/3/035501

167. Z. Jing, J. Zhan, Fabrication and gas-sensing properties of porous $\mathrm{ZnO}$ nanoplates. Adv. Mater. 20(23), 4547-4551 (2008). https://doi.org/10.1002/adma.200800243

168. Y.J. Chen, L. Nie, X.Y. Xue, Y.G. Wang, T.H. Wang, Linear ethanol sensing of $\mathrm{SnO}_{2}$ nanorods with extremely high sensitivity. Appl. Phys. Lett. 88(8), 083105 (2006). https://doi. org/10.1063/1.2166695

169. X.Y. Xue, Y.J. Chen, Y.G. Liu, S.L. Shi, Y.G. Wang, T.H. Wang, Synthesis and ethanol sensing properties of 
indium-doped tin oxide nanowires. Appl. Phys. Lett. 88(20), 201907 (2006). https://doi.org/10.1063/1.2203941

170. Q. Wan, Q.H. Li, Y.J. Chen, T.H. Wang, X.L. He, J.P. Li, C.L. Lin, Fabrication and ethanol sensing characteristics of $\mathrm{ZnO}$ nanowire gas sensors. Appl. Phys. Lett. 84(18), 3654-3656 (2004). https://doi.org/10.1063/1.1738932

171. X.Y. Xue, Y.J. Chen, Y.G. Wang, T.H. Wang, Synthesis and ethanol sensing properties of $\mathrm{ZnSnO}_{3}$ nanowires. Appl. Phys. Lett. 86(23), 1-3 (2005). https://doi.org/10.1063/1.1944204

172. X.Y. Xue, Y.J. Chen, Q.H. Li, C. Wang, Y.G. Wang, T.H. Wang, Electronic transport characteristics through individual $\mathrm{ZnSnO}_{3}$ nanowires. Appl. Phys. Lett. 88(18), 182102 (2006). https://doi.org/10.1063/1.2199612

173. H. Zeng, C. Zhi, Z. Zhang, X. Wei, X. Wang et al., "White graphenes": boron nitride nanoribbons via boron nitride nanotube unwrapping. Nano Lett. 10(12), 5049-5055 (2010). https://doi.org/10.1021/nl103251m

174. K. Zhang, Y. Feng, F. Wang, Z. Yang, J. Wang, Two dimensional hexagonal boron nitride (2D-hBN): synthesis, properties and applications. J. Mater. Chem. C 5(46), 11992-12022 (2017). https://doi.org/10.1039/c7tc04300g

175. D. Pacile, J. Meyer, Ç. Girit, A. Zettl, The two-dimensional phase of boron nitride: few-atomic-layer sheets and suspended membranes. Appl. Phys. Lett. 92(13), 133107 (2008). https://doi.org/10.1063/1.2903702

176. Y. Lin, J.W.J.N. Connell, Advances in 2D boron nitride nanostructures: nanosheets, nanoribbons, nanomeshes, and hybrids with graphene. Nanoscale 4(22), 6908-6939 (2012). https://doi.org/10.1039/c2nr32201c

177. A. Pakdel, C. Zhi, Y. Bando, D. Golberg, Low-dimensional boron nitride nanomaterials. Mater. Today 15(6), 256-265 (2012). https://doi.org/10.1016/S1369-7021(12)70116-5

178. A. Pakdel, Y. Bando, D. Golberg, Nano boron nitride flatland. Chem. Soc. Rev. 43(3), 934-959 (2014). https://doi. org/10.1039/c3cs60260e

179. A. Pakdel, X. Wang, C. Zhi, Y. Bando, K. Watanabe et al., Facile synthesis of vertically aligned hexagonal boron nitride nanosheets hybridized with graphitic domains. J. Mater. Chem. 22(11), 4818-4824 (2012). https://doi.org/10.1039/ c2jm15109j

180. T. Ouyang, Y. Chen, Y. Xie, K. Yang, Z. Bao, J.J.N. Zhong, Thermal transport in hexagonal boron nitride nanoribbons. Nanotechnology 21(24), 245701 (2010). https://doi. org/10.1088/0957-4484/21/24/245701

181. J. Wang, F. Ma, M. Sun, Graphene, hexagonal boron nitride, and their heterostructures: properties and applications. RSC Adv. 7(27), 16801-16822 (2017). https://doi.org/10.1039/ c7ra00260b

182. R. Gao, L. Yin, C. Wang, Y. Qi, N. Lun et al., High-yield synthesis of boron nitride nanosheets with strong ultraviolet cathodoluminescence emission. J. Phys. Chem. C 113(34), 15160-15165 (2009). https://doi.org/10.1021/jp904246j

183. K. Watanabe, T. Taniguchi, H. Kanda, Direct-bandgap properties and evidence for ultraviolet lasing of hexagonal boron nitride single crystal. Nat. Mater. 3(6), 404 (2004). https://doi.org/10.1038/nmat1134

184. V. Barone, J. Peralta, Magnetic boron nitride nanoribbons with tunable electronic properties. Nano Lett. 8(8), 22102214 (2008). https://doi.org/10.1021/n1080745j

185. K. Novoselov, D. Jiang, F. Schedin, T. Booth, V. Khotkevich, S. Morozov, A. Geim, Two-dimensional atomic crystals. PNAS 102(30), 10451-10453 (2005). https://doi. org/10.1073/pnas.0502848102

186. L. Jiao, L. Zhang, X. Wang, G. Diankov, H. Dai, Narrow graphene nanoribbons from carbon nanotubes. Nature 458(7240), 877 (2009). https://doi.org/10.1038/nature07919

187. S. Zhang, G. Lian, H. Si, J. Wang, X. Zhang et al., Ultrathin BN nanosheets with zigzag edge: one-step chemical synthesis, applications in wastewater treatment and preparation of highly thermal-conductive $\mathrm{BN}$ - polymer composites. J. Mater. Chem. A 1(16), 5105-5112 (2013). https://doi. org/10.1039/c3ta01597a

188. W.-Q. Han, H.-G. Yu, Z. Liu, Convert graphene sheets to boron nitride and boron nitride-carbon sheets via a carbonsubstitution reaction. Appl. Phys. Lett. 98(20), 203112 (2011). https://doi.org/10.1063/1.3593492

189. F. Müller, K. Stöwe, H. Sachdev, Symmetry versus commensurability: epitaxial growth of hexagonal boron nitride on $\mathrm{Pt}(111)$ from b-trichloroborazine $(\mathrm{CLBNH})_{3}$. Chem. Mater. 17(13), 3464-3467 (2005). https://doi.org/10.1021/cm048 $629 \mathrm{e}$

190. C. Zhi, Y. Bando, C. Tang, H. Kuwahara, D. Golberg, Largescale fabrication of boron nitride nanosheets and their utilization in polymeric composites with improved thermal and mechanical properties. Adv. Mater. 21(28), 2889-2893 (2009). https://doi.org/10.1002/adma.200900323

191. M.L. Yola, N. Atar, A novel detection approach for serotonin by graphene quantum dots/two-dimensional (2D) hexagonal boron nitride nanosheets with molecularly imprinted polymer. Appl. Surf. Sci. 458, 648-655 (2018). https://doi. org/10.1016/j.apsusc.2018.07.142

192. M. Sajjad, P. Feng, Study the gas sensing properties of boron nitride nanosheets. Mater. Res. Bull. 49, 35-38 (2014). https ://doi.org/10.1016/j.materresbull.2013.08.019

193. R.-M. Kong, X.-B. Zhang, L.-L. Zhang, X.-Y. Jin, S.-Y. Huan, G.-L. Shen, R.-Q. Yu, An ultrasensitive electrochemical "turn-on" label-free biosensor for $\mathrm{Hg}^{2+}$ with aunp-functionalized reporter DNA as a signal amplifier. Chem. Commun. 37, 5633-5635 (2009). https://doi.org/10.1039/B911163H

194. Y.-H. Sun, R.-M. Kong, D.-Q. Lu, X.-B. Zhang, H.-M. Meng, W. Tan, G.-L. Shen, R.-Q. Yu, A nanoscale DNA-Au dendrimer as a signal amplifier for the universal design of functional DNA-based sers biosensors. Chem. Commun. 47(13), 3840-3842 (2011). https://doi.org/10.1039/C0CC05133K

195. A.R. Fakhari, A. Sahragard, H. Ahmar, Development of an electrochemical sensor based on reduced graphene oxide modified screen-printed carbon electrode for the determination of buprenorphine. Electroanalysis 26(11), 2474-2483 (2014). https://doi.org/10.1002/elan.201400196 
196. A. Navaee, A. Salimi, H. Teymourian, Graphene nanosheets modified glassy carbon electrode for simultaneous detection of heroine, morphine and noscapine. Biosens. Bioelectron. 31(1), 205-211 (2012). https://doi.org/10.1016/j. bios.2011.10.018

197. X. Xu, J. Zhou, Y. Xin, G. Lubineau, Q. Ma, L. Jiang, Alcohol recognition by flexible, transparent and highly sensitive graphene-based thin-film sensors. Sci. Rep. 7(1), 4317 (2017). https://doi.org/10.1038/s41598-017-04636-2

198. G.J. Thangamani, K. Deshmukh, K. Chidambaram, M.B. Ahamed, K.K. Sadasivuni et al., Influence of $\mathrm{CuO}$ nanoparticles and graphene nanoplatelets on the sensing behaviour of poly(vinyl alcohol) nanocomposites for the detection of ethanol and propanol vapors. J. Mater. Sci.: Mater. Electron. 29(6), 5186-5205 (2018). https://doi.org/10.1007/s1085 4-017-8484-Z

199. A. Lipatov, A. Varezhnikov, P. Wilson, V. Sysoev, A. Kolmakov, A. Sinitskii, Highly selective gas sensor arrays based on thermally reduced graphene oxide. Nanoscale 5(12), 54265434 (2013). https://doi.org/10.1039/c3nr00747b

200. C.A. Zito, T.M. Perfecto, C.S. Fonseca, D.P. Volanti, Effective reduced graphene oxide sheets/hierarchical flower-like $\mathrm{NiO}$ composites for methanol sensing under high humidity. New J. Chem. 42(11), 8638-8645 (2018). https://doi. org/10.1039/c8nj01061g

201. J. Tan, M. Dun, L. Li, J. Zhao, W. Tan, Z. Lin, X.J.S. Huang, Synthesis of hollow and hollowed-out $\mathrm{Co}_{3} \mathrm{O}_{4}$ microspheres assembled by porous ultrathin nanosheets for ethanol gas sensors: responding and recovering in one second. Sens. Actuators B 249, 44-52 (2017). https://doi.org/10.1016/j. snb.2017.04.063

202. E. Lee, D. Lee, J. Yoon, Y. Yin, Y. Lee, S. Uprety, Y. Yoon, D.-J.J.S. Kim, Enhanced gas-sensing performance of GO/ $\mathrm{TiO}_{2}$ composite by photocatalysis. Sensors 18(10), 3334 (2018). https://doi.org/10.3390/s18103334

203. Z. Yin, Z. Sun, J. Wu, R. Liu, S. Zhang, Y. Qian, Y. Min, Facile synthesis of hexagonal single-crystalline $\mathrm{ZnCo}_{2} \mathrm{O}_{4}$ nanosheet arrays assembled by mesoporous nanosheets as electrodes for high-performance electrochemical capacitors and gas sensors. Appl. Surf. Sci. 457, 1103-1109 (2018). https://doi.org/10.1016/j.apsusc.2018.06.297

204. Y. Liu, Y. Jiao, Z. Zhang, F. Qu, A. Umar, X. Wu, Hierarchical $\mathrm{SnO}_{2}$ nanostructures made of intermingled ultrathin nanosheets for environmental remediation, smart gas sensor, and supercapacitor applications. ACS Appl. Mater. Interfaces 6(3), 2174-2184 (2014). https://doi.org/10.1021/ am405301v

205. L. Liu, P. Song, Q. Wei, X. Zhong, Z. Yang, Q. Wang, Synthesis of porous $\mathrm{SnO}_{2}$ hexagon nanosheets loaded with au nanoparticles for high performance gas sensors. Mater. Lett. 201, 211-215 (2017). https://doi.org/10.1016/j.matle t.2017.05.024

206. C. Zhang, Z.L. Hou, B.X. Zhang, H.M. Fang, S. Bi, High sensitivity self-recovery ethanol sensor based on polyporous graphene oxide/melamine composites. Carbon 137, 467-474 (2018). https://doi.org/10.1016/j.carbon.2018.05.055
207. P.X. Zhao, Y. Tang, J. Mao, Y.X. Chen, H. Song et al., Onedimensional $\mathrm{MoS}_{2}$-decorated $\mathrm{TiO}_{2}$ nanotube gas sensors for efficient alcohol sensing. J. Alloys Compd. 674, 252-258 (2016). https://doi.org/10.1016/j.jallcom.2016.03.029

208. H. Yan, P. Song, S. Zhang, Z. Yang, Q.J.R.A. Wang, Dispersed $\mathrm{SnO}_{2}$ nanoparticles on $\mathrm{MoS}_{2}$ nanosheets for superior gas-sensing performances to ethanol. RSC Adv. 5(97), 79593-79599 (2015). https://doi.org/10.1039/C5RA15019A

209. H. Yan, P. Song, S. Zhang, Z. Yang, Q. Wang, Facile synthesis, characterization and gas sensing performance of Zno nanoparticles-coated $\mathrm{MoS}_{2}$ nanosheets. J. Alloys Compd. 662, 118-125 (2016). https://doi.org/10.1016/j.jallc om.2015.12.066

210. G. Jiang, M. Goledzinowski, F.J.E. Comeau, H. Zarrin et al., Free-standing functionalized graphene oxide solid electrolytes in electrochemical gas sensors. Adv. Funct. Mater. 26(11), 1729-1736 (2016). https://doi.org/10.1002/ adfm.201504604

211. S. Liang, J. Zhu, J. Ding, H. Bi, P. Yao, Q. Han, X. Wang, Deposition of cocoon-like $\mathrm{ZnO}$ on graphene sheets for improving gas-sensing properties to ethanol. Appl. Surf. Sci. 357, 1593-1600 (2015). https://doi.org/10.1016/j.apsus c. 2015.10 .033

212. C. Zhao, H. Gong, W. Lan, R. Ramachandran, H. Xu, S. Liu, F.J.S. Wang, A.B. Chemical, Facile synthesis of $\mathrm{SnO}_{2}$ hierarchical porous nanosheets from graphene oxide sacrificial scaffolds for high-performance gas sensors. Sens. Actuators B 258, 492-500 (2018). https://doi.org/10.1016/j. snb.2017.11.167

213. D. Zhang, X. Fan, A. Yang, X. Zong, Hierarchical assembly of urchin-like alpha-iron oxide hollow microspheres and molybdenum disulphide nanosheets for ethanol gas sensing. J. Colloid Interface Sci. 523, 217-225 (2018). https://doi. org/10.1016/j.jcis.2018.03.109

214. L. Li, C. Zhang, R. Zhang, X. Gao, S. He et al., 2D ultrathin $\mathrm{Co}_{3} \mathrm{O}_{4}$ nanosheet array deposited on 3D carbon foam for enhanced ethanol gas sensing application. Sens. Actuators B 244, 664-672 (2017). https://doi.org/10.1016/j. snb.2017.01.056

215. S.J. Kim, H.-J. Koh, C.E. Ren, O. Kwon, K. Maleski et al., Metallic $\mathrm{Ti}_{3} \mathrm{C}_{2} \mathrm{~T}_{\mathrm{x}}$ MXene gas sensors with ultrahigh signalto-noise ratio. ACS Nano 12(2), 986-993 (2018). https://doi. org/10.1021/acsnano.7b07460

216. C. Yuejiao, Y. Ling, L. Qing, W. Yan, L. Qiuhong, W. Taihong, An evolution from 3D face-centered-cubic $\mathrm{ZnSnO}_{3}$ nanocubes to $2 \mathrm{D}$ orthorhombic $\mathrm{ZnSnO}_{3}$ nanosheets with excellent gas sensing performance. Nanotechnology 23(41), 415501 (2012). https://doi.org/10.1088/09574484/23/41/415501

217. E. Lee, A. VahidMohammadi, B.C. Prorok, Y.S. Yoon, M. Beidaghi, D.-J. Kim, Room temperature gas sensing of two-dimensional titanium carbide (MXene). ACS Appl. Mater. Interfaces 9(42), 37184-37190 (2017). https://doi. org/10.1021/acsami.7b11055

218. L. Lin, T. Liu, Y. Zhang, R. Sun, W. Zeng, Z. Wang, Synthesis of boron nitride nanosheets with a few atomic layers and their 
gas-sensing performance. Ceram. Int. 42(1, Part A), 971-975 (2016). https://doi.org/10.1016/j.ceramint.2015.08.109

219. B.P. Mathew, H.J. Yang, J. Kim, J.B. Lee, Y.T. Kim et al., An annulative synthetic strategy for building triphenylene frameworks by multiple $\mathrm{C}-\mathrm{H}$ bond activations. Angew. Chem. Int. Ed. 56(18), 5007-5011 (2017). https://doi.org/10.1002/ anie. 201700405

220. R.K. Jha, M. Wan, C. Jacob, P.K. Guha, Enhanced gas sensing properties of liquid-processed semiconducting tungsten chalcogenide ( $\mathrm{WX}_{\mathrm{i}}, \mathrm{x}=\mathrm{O}$ and $\mathrm{S}$ ) based hybrid nanomaterials. IEEE Sens. J. 18(9), 3494-3501 (2018). https://doi. org/10.1109/JSEN.2018.2810811

221. L. Yu, H. Song, Y. Tang, L. Zhang, Y. Lv, Controllable deposition of $\mathrm{ZnO}$-doped $\mathrm{SnO}_{2}$ nanowires on $\mathrm{Au} / \mathrm{graphene}$ and their application in cataluminescence sensing for alcohols and ketones. Sens. Actuators B 203, 726-735 (2014). https ://doi.org/10.1016/j.snb.2014.06.015

222. Z. Li, A.A. Haidry, Y. Liu, L. Sun, L. Xie et al., Strongly coupled $\mathrm{Ag} / \mathrm{TiO}_{2}$ heterojunction: from one-step facile synthesis to effective and stable ethanol sensing performances. J. Mater. Sci.: Mater. Electron. 29(22), 19219-19227 (2018). https://doi.org/10.1007/s10854-018-0048-3

223. A.K. Sharma, B. Kaur, Chalcogenide fiber-optic SPR chemical sensor with $\mathrm{MoS}_{2}$ monolayer, polymer clad, and polythiophene layer in NIR using selective ray launching. Opt. Fiber Technol. 43, 163-168 (2018). https://doi.org/10.1016/j.yofte .2018 .05 .003

224. H.-K. Jeong, Y.P. Lee, M.H. Jin, E.S. Kim, J.J. Bae, Y. Lee, Thermal stability of graphite oxide. Chem. Phys. Lett. 470(4-6), 255-258 (2009). https://doi.org/10.1016/j.cplet t.2009.01.050

225. B. Xu, S. Yue, Z. Sui, X. Zhang, S. Hou, G. Cao, Y.J.E. Yang, E. Science, What is the choice for supercapacitors: Graphene or graphene oxide? Energy Environ. Sci. 4(8), 2826-2830 (2011). https://doi.org/10.1039/c1ee01198g

226. M.S. Peresin, Y. Habibi, J.O. Zoppe, J.J. Pawlak, O.J.J.B. Rojas, Nanofiber composites of polyvinyl alcohol and cellulose nanocrystals: manufacture and characterization. Biomacromolecules 11(3), 674-681 (2010). https://doi.org/10.1021/ bm901254n

227. S. Tanpichai, F. Quero, M. Nogi, H. Yano, R.J. Young, T. Lindström, W.W. Sampson, S.J.J.B. Eichhorn, Effective young's modulus of bacterial and microfibrillated cellulose fibrils in fibrous networks. Biomacromolecules 13(5), 1340-1349 (2012). https://doi.org/10.1021/bm300042t

228. U. Lad, G.M. Kale, R. Bryaskova, Glucose oxidase encapsulated polyvinyl alcohol-silica hybrid films for an electrochemical glucose sensing electrode. Anal. Chem. 85(13), 6349-6355 (2013). https://doi.org/10.1021/ac400719h

229. R. Rahmanian, S.A. Mozaffari, Electrochemical fabrication of $\mathrm{ZnO}$-polyvinyl alcohol nanostructured hybrid film for application to urea biosensor. Sens. Actuators B 207, 772-781 (2015). https://doi.org/10.1016/j.snb.2014.10.129

230. N. Sanaeifar, M. Rabiee, M. Abdolrahim, M. Tahriri, D. Vashaee, L. Tayebi, A novel electrochemical biosensor based on $\mathrm{Fe}_{3} \mathrm{O}_{4}$ nanoparticles-polyvinyl alcohol composite for sensitive detection of glucose. Anal. Biochem. 519, 19-26 (2017). https://doi.org/10.1016/j.ab.2016.12.006

231. S.H. Baek, J. Roh, C.Y. Park, M.W. Kim, R. Shi, S.K. Kailasa, T.J. Park, Cu-nanoflower decorated gold nanoparticles-graphene oxide nanofiber as electrochemical biosensor for glucose detection. Mater. Sci. Eng. C 107, 110273 (2020). https://doi.org/10.1016/j.msec.2019.110273

232. S. Ampuero, J.O. Bosset, The electronic nose applied to dairy products: a review. Sens. Actuators B 94(1), 1-12 (2003). https://doi.org/10.1016/S0925-4005(03)00321-6

233. C.D. Natale, A. Macagnano, A. D’Amico, F. Davide, Electronic-nose modelling and data analysis using a self-organizing map. Meas. Sci. Technol. 8(11), 1236-1243 (1997). https://doi.org/10.1088/0957-0233/8/11/004

234. T. Kavinkumar, D. Sastikumar, S. Manivannan, Effect of functional groups on dielectric, optical gas sensing properties of graphene oxide and reduced graphene oxide at room temperature. RSC Adv. 5(14), 10816-10825 (2015). https ://doi.org/10.1039/c4ra12766h

235. J.-S. Kim, H.-W. Yoo, H.O. Choi, H.-T. Jung, Tunable volatile organic compounds sensor by using thiolated ligand conjugation on $\mathrm{MoS}_{2}$. Nano Lett. 14(10), 5941-5947 (2014). https://doi.org/10.1021/nl502906a

236. R. Zou, G. He, K. Xu, Q. Liu, Z. Zhang, J. Hu, ZnO nanorods on reduced graphene sheets with excellent field emission, gas sensor and photocatalytic properties. J. Mater. Chem. A 1(29), 8445-8452 (2013). https://doi. org/10.1039/C3TA11490B

237. X. Yu, G. Zhang, H. Cao, X. An, Y. Wang, Z. Shu, X. An, F. Hua, ZnO@ZnS hollow dumbbells-graphene composites as high-performance photocatalysts and alcohol sensors. New J. Chem. 36(12), 2593-2598 (2012). https://doi. org/10.1039/C2NJ40770A

238. N.D. Khoang, D.D. Trung, N. Van Duy, N.D. Hoa, N. Van Hieu, Design of $\mathrm{SnO}_{2} / \mathrm{ZnO}$ hierarchical nanostructures for enhanced ethanol gas-sensing performance. Sens. Actuators B 174, 594-601 (2012). https://doi.org/10.1016/j. snb.2012.07.118

239. S. Wei, S. Wang, Y. Zhang, M. Zhou, Different morphologies of $\mathrm{ZnO}$ and their ethanol sensing property. Sens. Actuators B 192, 480-487 (2014). https://doi.org/10.1016/j. snb.2013.11.034

240. A. Rothschild, H.L. Tuller, Gas sensors: new materials and processing approaches. J. Electroceram. 17(2), 1005-1012 (2006). https://doi.org/10.1007/s10832-006-6737-y

241. Y. Tian, J. Li, H. Xiong, J. Dai, Controlled synthesis of ZnO hollow microspheres via precursor-template method and its gas sensing property. Appl. Surf. Sci. 258(22), 8431-8438 (2012). https://doi.org/10.1016/j.apsusc.2011.12.090

242. D.R. Miller, S.A. Akbar, P.A. Morris, Nanoscale metal oxide-based heterojunctions for gas sensing: a review. Sens. Actuators B 204, 250-272 (2014). https://doi.org/10.1016/j. snb.2014.07.074

243. H. Men, P. Gao, B. Zhou, Y. Chen, C. Zhu et al., Fast synthesis of ultra-thin $\mathrm{ZnSnO}_{3}$ nanorods with high ethanol sensing 
properties. Chem. Commun. 46(40), 7581-7583 (2010). https ://doi.org/10.1039/c0cc02222e

244. P. Song, Q. Wang, Z. Yang, Biomorphic synthesis of $\mathrm{ZnSnO}_{3}$ hollow fibers for gas sensing application. Sens. Actuators B 156(2), 983-989 (2011). https://doi.org/10.1016/j. snb.2011.03.017

245. Y. Cao, D. Jia, J. Zhou, Y. Sun, Simple solid-state chemical synthesis of $\mathrm{ZnSnO}_{3}$ nanocubes and their application as gas sensors. Eur. J. Inorg. Chem. 2009(27), 4105-4109 (2009). https://doi.org/10.1002/ejic.200900146

246. Y. Zeng, T. Zhang, H. Fan, G. Lu, M. Kang, Synthesis and gas-sensing properties of $\mathrm{ZnSnO}_{3}$ cubic nanocages and nanoskeletons. Sens. Actuators B 143(1), 449-453 (2009). https://doi.org/10.1016/j.snb.2009.07.021

247. J. Cao, Y. Xu, L. Sui, X. Zhang, S. Gao et al., Highly selective low-temperature triethylamine sensor based on $\mathrm{Ag} / \mathrm{Cr}_{2} \mathrm{O}_{3}$ mesoporous microspheres. Sens. Actuators B 220, 910-918 (2015). https://doi.org/10.1016/j.snb.2015.06.023

248. F. Bao, Z. Zhang, X. Liu, X. Zhao, One-step synthesis of hierarchical $\mathrm{ZnCo}_{2} \mathrm{O}_{4} @ \mathrm{ZnCo}_{2} \mathrm{O}_{4}$ core-shell nanosheet arrays on nickel foam for electrochemical capacitors. RSC Adv. 4(72), 38073-38077 (2014). https://doi.org/10.1039/C4RA06289B

249. H. Chen, G. Jiang, W. Yu, D. Liu, Y. Liu, L. Li, Q. Huang, Z. Tong, Electrospun carbon nanofibers coated with urchin-like $\mathrm{ZnCo}_{2} \mathrm{O}_{4}$ nanosheets as a flexible electrode material. J. Mater. Chem. A 4(16), 5958-5964 (2016). https://doi.org/10.1039/ C6TA01880G

250. Z. Sun, X. Lu, A solid-state reaction route to anchoring $\mathrm{Ni}(\mathrm{OH})_{2}$ nanoparticles on reduced graphene oxide sheets for supercapacitors. Ind. Eng. Chem. Res. 51(30), 9973-9979 (2012). https://doi.org/10.1021/ie202706h

251. P. Zhang, J. Wang, X. Lv, H. Zhang, X. Sun, Facile synthesis of Cr-decorated hexagonal $\mathrm{Co}_{3} \mathrm{O}_{4}$ nanosheets for ultrasensitive ethanol detection. Nanotechnology 26(27), 275501 (2015). https://doi.org/10.1088/0957-4484/26/27/275501

252. J.-W. Yoon, J.-K. Choi, J.-H. Lee, Design of a highly sensitive and selective $\mathrm{C}_{2} \mathrm{H}_{5} \mathrm{OH}$ sensor using p-type $\mathrm{Co}_{3} \mathrm{O}_{4}$ nanofibers. Sens. Actuators B 161(1), 570-577 (2012). https://doi. org/10.1016/j.snb.2011.11.002

253. X. Liu, J. Zhang, L. Wang, T. Yang, X. Guo, S. Wu, S. Wang, 3D hierarchically porous $\mathrm{ZnO}$ structures and their functionalization by Au nanoparticles for gas sensors. J. Mater. Chem. 21(2), 349-356 (2011). https://doi.org/10.1039/C0JM01800G

254. B. Chocarro-Ruiz, A. Fernández-Gavela, S. Herranz, L.M. Lechuga, Nanophotonic label-free biosensors for environmental monitoring. Curr. Opin. Biotechnol. 45, 175-183 (2017). https://doi.org/10.1016/j.copbio.2017.03.016

255. I. Arghir, F. Delport, D. Spasic, J. Lammertyn, Smart design of fiber optic surfaces for improved plasmonic biosensing. New Biotechnol. 32(5), 473-484 (2015). https:// doi.org/10.1016/j.nbt.2015.03.012

256. Y.-N. Zhang, H. Peng, X. Qian, Y. Zhang, G. An, Y. Zhao, Recent advancements in optical fiber hydrogen sensors. Sens. Actuators B 244, 393-416 (2017). https://doi. org/10.1016/j.snb.2017.01.004
257. H. Yang, H. Hu, Y. Wang, T. Yu, Rapid and non-destructive identification of graphene oxide thickness using white light contrast spectroscopy. Carbon 52, 528-534 (2013). https:// doi.org/10.1016/j.carbon.2012.10.005

258. B.C. Yao, Y. Wu, A.Q. Zhang, Y.J. Rao, Z.G. Wang et al., Graphene enhanced evanescent field in microfiber multimode interferometer for highly sensitive gas sensing. Opt. Express 22(23), 28154-28162 (2014). https://doi. org/10.1364/OE.22.028154

259. N.M.Y. Zhang, K. Li, P.P. Shum, X. Yu, S. Zeng et al., Hybrid graphene/gold plasmonic fiber-optic biosensor. Adv. Mater. Technol. 2(2), 1600185 (2017). https://doi. org/10.1002/admt.201600185

260. Y. Luo, C. Chen, K. Xia, S. Peng, H. Guan et al., Tungsten disulfide $\left(\mathrm{WS}_{2}\right)$ based all-fiber-optic humidity sensor. Opt. Express 24(8), 8956-8966 (2016). https://doi.org/10.1364/ OE.24.008956

261. C.C. Mayorga-Martinez, Z. Sofer, M. Pumera, Layered black phosphorus as a selective vapor sensor. Angew. Chem. Int. Ed. 54(48), 14317-14320 (2015). https://doi. org/10.1002/anie.201505015

262. G. Liu, S.L. Rumyantsev, C. Jiang, M.S. Shur, A.A. Balandin, Selective gas sensing with h-BN capped $\mathrm{MoS}_{2}$ heterostructure thin-film transistors. IEEE Electron Device Lett. 36(11), 1202-1204 (2015). https://doi.org/10.1109/ LED.2015.2481388

263. J.G. Thangamani, K. Deshmukh, K.K. Sadasivuni, D. Ponnamma, S. Goutham et al., White graphene reinforced polypyrrole and poly(vinyl alcohol) blend nanocomposites as chemiresistive sensors for room temperature detection of liquid petroleum gases. Microchim. Acta 184(10), 39773987 (2017). https://doi.org/10.1007/s00604-017-2402-1

264. S. Liu, B. Lu, Q. Zhao, J. Li, T. Gao et al., Boron nitride nanopores: highly sensitive DNA single-molecule detectors. Adv. Mater. 25(33), 4549-4554 (2013). https://doi. org/10.1002/adma.201301336

265. O. Beck, N.K. Modén, S. Seferaj, G. Lenk, A. Helander, Study of measurement of the alcohol biomarker phosphatidylethanol (PEth) in dried blood spot (DBS) samples and application of a volumetric DBS device. Clin. Chim. Acta 479, 38-42 (2018). https://doi.org/10.1016/j. cca.2018.01.008

266. R. Nanau, M.J.B. Neuman, Biomolecules and biomarkers used in diagnosis of alcohol drinking and in monitoring therapeutic interventions. Biomaterials 5(3), 1339-1385 (2015). https://doi.org/10.3390/biom5031339

267. O. Niemelä, Biomarker-based approaches for assessing alcohol use disorders. Int. J. Environ. Res. Public Health 13(2), 166 (2016). https://doi.org/10.3390/ijerph13020166

268. C. Dumitrascu, R. Paul, R. Kingston, R. Williams, Influence of alcohol containing and alcohol free cosmetics on faee concentrations in hair. A performance evaluation of ethyl palmitate as sole marker, versus the sum of four faees. Forensic Sci. Int. 283, 29-34 (2018). https://doi.org/10.1016/j.forsc iint.2017.12.002 
269. L. Morini, E. Marchei, L. Tarani, M. Trivelli, G. Rapisardi et al., Testing ethylglucuronide in maternal hair and nails for the assessment of fetal exposure to alcohol: comparison with meconium testing. Ther. Drug Monitor. 35(3), 402-407 (2013). https://doi.org/10.1097/FTD.0b013e318283f719

270. R.G. Lande, B. Marin, A comparison of two alcohol biomarkers in clinical practice: ethyl glucuronide versus ethyl sulfate. J. Addict. Dis. 32(3), 288-292 (2013). https://doi. org/10.1080/10550887.2013.824332

271. S.H. Stewart, D.G. Koch, D.M. Burgess, I.R. Willner, A. Reuben, Sensitivity and specificity of urinary ethyl glucuronide and ethyl sulfate in liver disease patients. Alcohol. Clin. Exp. Res. 37(1), 150-155 (2013). https://doi.org/10.11 11/j.1530-0277.2012.01855.x

272. M. Hastedt, S. Herre, F. Pragst, M. Rothe, S.J.A. Hartwig, Workplace alcohol testing program by combined use of ethyl glucuronide and fatty acid ethyl esters in hair. Alcohol Alcohol. 47(2), 127-132 (2011). https://doi.org/10.1093/alcalc/ agr 148

273. F. Alam, A.H. Jalal, R. Sinha, Y. Umasankar, S. Bhansali, N. Pala, $\mathrm{ZnO}$ nanoflakes-based mediator free flexible biosensors for the selective detection of ethylglucuronide (EtG) and lactate. In: Proceedings of SPIE-The International Society for Optical Engineering. 10639 (2018)

274. F. Alam, A.H. Jalal, N. Pala, Selective detection of alcohol through ethyl-glucuronide (EtG) immunosensor based on 2D zinc oxide nanostructures. IEEE Sens. J. 19(11), 3984-3992 (2019). https://doi.org/10.1109/JSEN.2019.2898869

275. A.P. Selvam, S. Muthukumar, V. Kamakoti, S. Prasad, A wearable biochemical sensor for monitoring alcohol consumption lifestyle through ethyl glucuronide (EtG) detection in human sweat. Sci. Rep. 6, 23111 (2016). https://doi. org/10.1038/srep23111

276. X. Zhang, W. Lan, J. Xu, Y. Luo, J. Pan et al., ZIF-8 derived hierarchical hollow $\mathrm{ZnO}$ nanocages with quantum dots for sensitive ethanol gas detection. Sens. Actuators B 289, 144152 (2019). https://doi.org/10.1016/j.snb.2019.03.090
277. D.-W. Yang, H.-H. Liu, Poly(brilliant cresyl blue)-carbonnanotube modified electrodes for determination of nadh and fabrication of ethanol dehydrogenase-based biosensor. Biosens. Bioelectron. 25(4), 733-738 (2009). https://doi. org/10.1016/j.bios.2009.08.016

278. D. Zhang, G. Dong, Y. Cao, Y. Zhang, Ethanol gas sensing properties of lead sulfide quantum dots-decorated zinc oxide nanorods prepared by hydrothermal process combining with successive ionic-layer adsorption and reaction method. J. Colloid Interface Sci. 528, 184-191 (2018). https://doi. org/10.1016/j.jcis.2018.05.085

279. D. Zhang, Y.E. Sun, Y. Zhang, Fabrication and characterization of layer-by-layer nano self-assembled $\mathrm{ZnO}$ nanorods/ carbon nanotube film sensor for ethanol gas sensing application at room temperature. J. Mater. Sci.: Mater. Electron. 26(10), 7445-7451 (2015). https://doi.org/10.1007/s1085 4-015-3378-4

280. W. Zheng, Z. Li, H. Zhang, W. Wang, Y. Wang, C. Wang, Electrospinning route for $\alpha-\mathrm{Fe}_{2} \mathrm{O}_{3}$ ceramic nanofibers and their gas sensing properties. Mater. Res. Bull. 44(6), 1432-1436 (2009). https://doi.org/10.1016/j.materresbu 11.2008 .12 .013

281. P. Hu, G. Du, W. Zhou, J. Cui, J. Lin et al., Enhancement of ethanol vapor sensing of $\mathrm{TiO}_{2}$ nanobelts by surface engineering. ACS Appl. Mater. Interfaces 2(11), 3263-3269 (2010). https://doi.org/10.1021/am100707h

282. M.M. Rahman, A. Jamal, S.B. Khan, M. Faisal, Highly sensitive ethanol chemical sensor based on Ni-doped $\mathrm{SnO}_{2}$ nanostructure materials. Biosens. Bioelectron. 28(1), 127-134 (2011). https://doi.org/10.1016/j.bios.2011.07.024

283. K.-I. Choi, H.-R. Kim, K.-M. Kim, D. Liu, G. Cao, J.-H. Lee, $\mathrm{C}_{2} \mathrm{H}_{5} \mathrm{OH}$ sensing characteristics of various $\mathrm{Co}_{3} \mathrm{O}_{4}$ nanostructures prepared by solvothermal reaction. Sens. Actuators B 146(1), 183-189 (2010). https://doi.org/10.1016/j. snb.2010.02.050 